\title{
Theoretical Studies of Substitutionally Doped Single-Walled Nanotubes
}

\author{
Charles See Yeung, Ya Kun Chen, and Yan Alexander Wang \\ Department of Chemistry, University of British Columbia, Vancouver, BC, Canada V6T 1Z1 \\ Correspondence should be addressed to Yan Alexander Wang, yawang@chem.ubc.ca
}

Received 1 September 2010; Accepted 19 November 2010

Academic Editor: Valery Khabashesku

Copyright $\odot 2010$ Charles See Yeung et al. This is an open access article distributed under the Creative Commons Attribution License, which permits unrestricted use, distribution, and reproduction in any medium, provided the original work is properly cited.

The rich chemistry of single-walled carbon nanotubes (SWCNTs) is enhanced by substitutional doping, a process in which a single atom of the nanotube sidewall is replaced by a heteroatom. These so-called heteroatom-substituted SWCNTs (HSWCNTs) exhibit unique chemical and physical properties not observed in their corresponding undoped congeners. Herein, we present theoretical studies of both main group element and transition metal-doped HSWCNTs. Within density functional theory (DFT), we discuss mechanistic details of their proposed synthesis from vacancy-defected SWCNTs and describe their geometric and electronic properties. Additionally, we propose applications for these nanomaterials in nanosensing, nanoelectronics, and nanocatalysis.

\section{Introduction}

Iijima's pioneering work on carbon nanotubes (CNTs) [1] and single-walled carbon nanotubes (SWCNTs) [2] in the early 1990s sparked a general interest in both fundamental and practical nanotechnology. Over the past 20 years, research efforts have aimed to improve both efficiency and selectivity of nanotube synthesis, as well as understand their chemical reactivity and extraordinary electronic and thermal properties [3-5]. Carbon nanotubes have significant potential for application in molecular electronics [6-15], nanomechanics [16-20], optics [21-24], sensors [6, 25-31], and even catalysis [32].

The molecular structure of SWCNTs can be obtained by rolling up an infinite graphene sheet into a cylinder [3340]. As illustrated in Figure 1, SWCNTs are characterized by a chiral (or circumferential) vector $\mathbf{A B}$, which is a linear combination of two unit lattice vectors $a$ and $b$. In other words,

$$
\mathbf{A B}=m a+n b,
$$

where $m$ and $n$ are integers. The pair of indices $(m, n)$ determines the diameter and chirality of the tube, as well as the basic electronic character. If $n=m$, the nanotube is classified as armchair and is metallic in nature (i.e., having a band gap of $0 \mathrm{eV}$ ). If $n \neq m$ and both $n$ and $m$ are nonzero, the nanotube is chiral. If $n-m=3 p$, where $p$ is a nonzero integer, the nanotube is semimetallic with a band gap on the order of $\mathrm{meV}[34,37]$. If $n-m \neq 3 p$, where $p$ is a nonzero integer, the nanotube is semiconducting with a band gap on the order of $1 \mathrm{eV}$. Figure 1 also highlights the wrapping direction $x$ and translation direction $y$ for armchair SWCNTs.

While carbon nanotubes can be considered a seamless graphene cylinder, the sidewall curvature has a strong influence on electronic structure. Importantly, this leads to a pyramidalization of the $\mathrm{C}$ atoms, hence weakening the $\pi$ conjugation of the SWCNT. Each individual C atom exhibits partial $s p^{3}$ hybridization which requires a net rehybridization of $\sigma, \sigma^{*}, \pi$, and $\pi^{*}$ orbitals within the sidewall of the nanotube superstructure. Simplistically, this can be viewed as the partial incorporation of the atomic $s$ orbitals into the atomic $p_{\pi}$ orbitals [41]. Locally, each C atom residing in the cylinder exhibits partial $s p^{3}$ character with slight misalignment of $\pi$ orbitals between adjacent atoms [34-36, 39].

One useful strategy for quantifying curved $\pi$-conjugation in nanotubes is Haddon's $\pi$-orbital axis vector (POAV) 

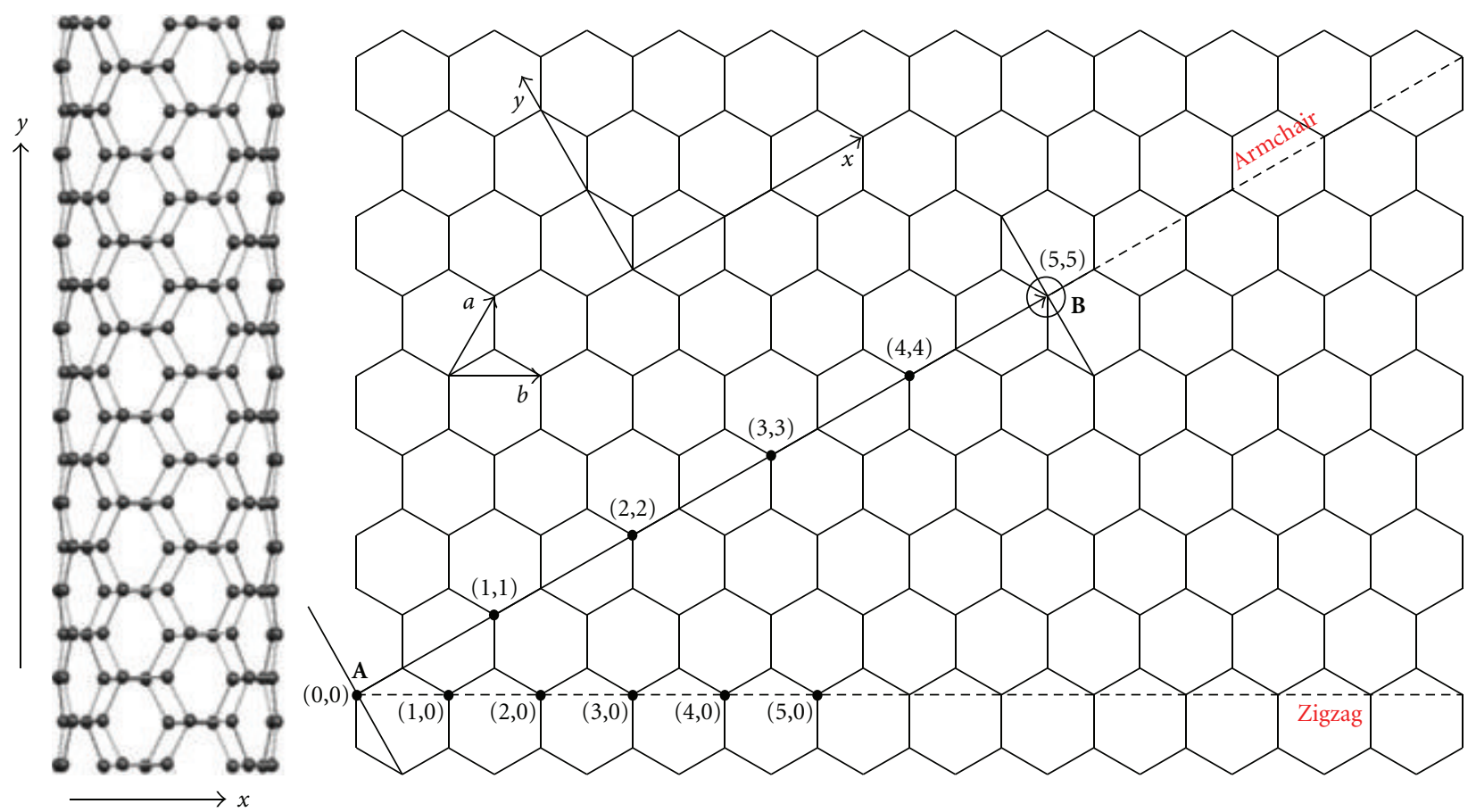

FIGURE 1: A schematic illustrating the wrapping of a graphene sheet to form a SWCNT. The $(5,5)$ SWCNT is shown on the left [35].

method (Figure 2) [41-43]. In this description, the pyramidalization angle $\left(\theta_{p}\right)$ is defined as

$$
\theta_{p}=\theta_{\sigma \pi}-90^{\circ}
$$

where $\theta_{\sigma \pi}$ is the angle between the $\pi$-orbital and the $\sigma$ bond. In ethylene (i.e., $\mathrm{CH}_{2} \mathrm{CH}_{2}$ ), $\theta_{p}=0^{\circ}$ since the $\mathrm{C}=\mathrm{C}$ double bond is planar. The extended carbon framework of graphite exhibits the same geometry as ethylene. In contrast, in methane (i.e., $\left.\mathrm{CH}_{4}\right), \theta_{p}=19.5^{\circ}$ since the $s p^{3}$-hybridized $\mathrm{C}$ atom is pyramidal. The carbon network in diamond exhibits the same geometry as methane. In icosahedral fullerene $\mathrm{C}_{60}, \theta_{p}=11.6^{\circ}$, suggesting some deviation and planarity and, consequently, an increase in strain energy. This third allotrope of carbon exhibits varying degrees of pyramidalization depending on the size of the fullerene. In $(5,5)$ SWCNTs, $\theta_{p}=6.0^{\circ}$, consistent with a more planar superstructure. Carbon nanotubes typically exhibit a slight misalignment of the $\pi$-orbitals in adjacent $C$ atoms depending on tube circumference. Overall, SWCNTs are generally more inert than the corresponding fullerenes of similar diameters $[41,44]$.

While useful, Haddon's POAV analysis treats carbon atoms embedded in supramolecular carbon frameworks as independent entities [46, 47]. As a consequence, this pyramidalization approach only provides a description of mean reactivity of the vertex atoms but do not consider curvature of the $\mathrm{C}-\mathrm{C}$ bonds themselves as predictive factors for chemical reactivity. As such, $\mathrm{Li}$ et al. introduced the concept of bond curvature $K$, which is characterized by directional curvature $K_{D}$ (corresponding to the arc curvature of $\mathrm{C}-\mathrm{C}$ bonds) and its mean $K_{M}$ (corresponding to arc curvature of the vertex carbon atoms). For any given $C_{a}-$ $C_{b}$ bond with biterminal oblique angle $\theta_{i}$, the acute angle between the nanotube axis and the direction of the bond, $K_{D}$ and $K_{M}$ (for vertex atom $i$ ) are defined as

$$
\begin{gathered}
K_{D}=\frac{1}{2} \sum_{i=a, b}\left(K_{i 1} \sin ^{2} \theta_{i}+K_{i 2} \cos ^{2} \theta_{i}\right), \\
K_{M}=\frac{2}{\pi} \int_{0}^{\pi / 2}\left(K_{i 1} \sin ^{2} \theta_{i}+K_{i 2} \cos ^{2} \theta_{i}\right) d \theta_{i}=\frac{1}{2}\left(K_{i 1}+K_{i 2}\right),
\end{gathered}
$$

where $K_{i 1}$ and $K_{i 2}$ are the principle curvatures of carbon $i$. In spherical fullerenes (e.g., $\mathrm{C}_{60}$ ), $K_{D}$ and $K_{M}$ are given:

$$
K_{D}=K_{M}=\frac{1}{R_{S}},
$$

where $R_{S}$ is the radius of the fullerene. For SWCNTs with radius $R, K_{1}=1 / R, K_{2}=0, \theta_{a}=\theta_{b}=\theta$, and hence, $K_{D}$ and $K_{M}$ are given

$$
\begin{aligned}
& K_{D}=\frac{\sin ^{2} \theta}{R}, \\
& K_{M}=\frac{1}{2 R} .
\end{aligned}
$$

Li's bond curvature analysis is also related to the pyramidalization angle as follows:

$$
\begin{gathered}
K_{D}=2 K_{M} \sin ^{2} \theta=\frac{4 \theta_{p}}{r \sin ^{2} \theta}, \\
K_{M}=\frac{1}{2 R} \approx \frac{2 \theta_{p}}{r},
\end{gathered}
$$




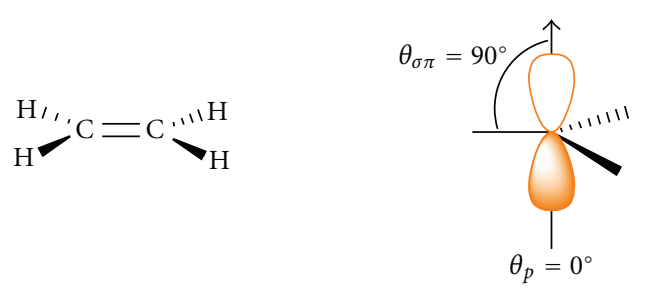

(a) Ethylene

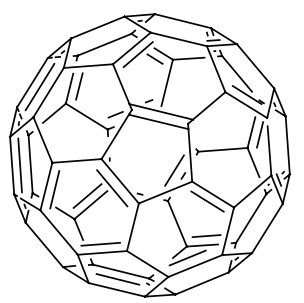

(c) $\mathrm{C}_{60}$
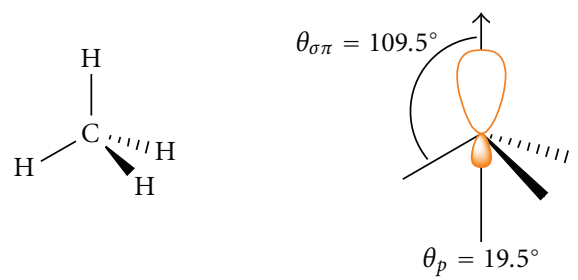

(b) Methane
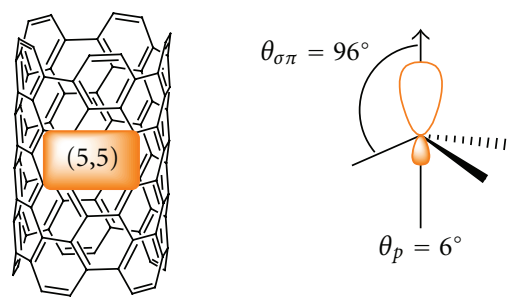

(d) $(5,5)$ SWCNT segment

FIGURE 2: $\pi$-orbital axis vector analysis of curved $\pi$-conjugation in (a) ethylene, (b) methane, (c) $\mathrm{C}_{60}$, and (d) $(5,5)$ SWCNT $[45]$.

where $r$ is the average $\mathrm{C}-\mathrm{C}$ bond length (i.e., 1.42 $\AA$ ). For spherical fullerenes,

$$
K_{M}=K_{D}=\frac{2 \theta_{p}^{s}}{r}
$$

where $\theta_{p}{ }^{s}$ is the pyrimidalization angle for the vertex carbon atoms.

SWCNTs have a very large surface area, and as a consequence, inter-tube interactions are typically quite strong. Attractive forces either of a van der Waals or weak longrange covalent bonding on the order of 0.50 to $0.95 \mathrm{eV}$ per nanometer of tube-to-tube contact have been observed. As a consequence, aggregation of SWCNTs typically leads to the production of hexagonally packed bundles or ropes $[33,37,48,49]$.

Carbon nanotubes are characterized by a very high aspect ratio (i.e., length per width) and extensive levels of electron delocalization $[33,34,50]$. Thus, SWCNTs exhibit strong confinement effects that result in a pronounced onedimensionality and weak interaction between electrons and phonons. These macromolecules are ballistic conductors and exhibit two units of quantum conductance (i.e., $4 e^{2} / h$ ), and the quantum resistance $\left(R_{Q}\right)$ is defined as $[11,33,50-52]$

$$
R_{Q}=\frac{h}{4 e^{2}}=6.5 k \Omega \text {. }
$$

As such, mean free paths on the order of a micron have been suggested [34, 50,53].

Chemical functionalization of carbon nanotubes can easily disrupt the extended conjugation and reduce the electrical conductivity along the axis of the tube. In particular, covalent modification of the sidewalls of carbon nanotubes has been achieved [3] via strategies including tandem fluorination/nucleophilic substitution [54-56], ozonolysis
[57, 58], Diels-Alder cycloaddition [59, 60], osmylation [61], hydroboration [62], dissolving metal reduction (Billups reaction) [63], carbene addition [64], nitrene addition [65], dipolar cycloaddition of azomethine ylides [66], vinyl carbonylation via zwitterionic intermediates $[67,68]$, other electrophilic oxidations [69], radical alkylation [64, 70], perfluoroalkylation [71, 72], and arylation [73]. Current technologies suffer from low reactivity and/or poor selectivity. Additionally, characterization of the functionalized SWCNT products remains a significant challenge.

Substitutional doping of carbon nanotubes is an alternative for electronic tuning [74]. In this case, a single $C$ atom on the sidewall of a SWCNT is substituted with another atom, resulting in the production of a hetero-SWCNT (HSWCNT). Nitrogen- and boron-doping are among the most popular and have both been achieved [75]. Traditionally, N- and B-doped SWCNTs can be prepared via thermal treatment [76], chemical vapor deposition [77], laser ablation [78], and the arc method [79], but generally with poor control of doping position and concentration $[74,75]$. To address these concerns, Srivastava et al. [80] proposed that a free gas-phase neutral $\mathrm{N}$ atom, if brought into close vicinity with a vacancy in the carbon backbone, could induce a selective substitution process to occur. Later, our group proposed the use of NO as a nitrogen source [81] by interaction with the so-called $5-1 \mathrm{DB}$ defects $[82,83]$ (i.e., a single vacancy defect site that contains one five-membered carbocycle and a single $\mathrm{C}$ atom with one dangling bond) that can be induced by ion and electron radiation $[83,84]$.

For substitutional N-doping, calculations have revealed that N-doped SWCNTs display only minimal geometric change in comparison to their undoped SWCNT analogs [85]. By substitution of a $\mathrm{C}$ atom with a $\mathrm{B}$ or $\mathrm{N}$ atom impurity, quasibound states consisting of $p$-orbitals are formed below and above the Fermi energy, respectively [86], 
in analogy to $p$ - and $n$-type semiconductors. This is because boron has one less electron than carbon, while nitrogen has one more electron [75]. In B-doped nanotubes at low amounts of doping, the mean-free path decreases linearly with dopant concentration, according to the Fermi golden rule [87]. Additionally, mean-free path scales linearly with nanotube diameter. At $1.0 \%$ of doping, mean-free paths of $175-275 \mathrm{~nm}$ for B-doped nanotubes with diameters 17$27 \mathrm{~nm}$ have been predicted (cf. 220-250 nm in doped multiwalled nanotubes [88]). The Kubo formula for conductance of a device, $G\left(E, L_{\mathrm{dev}}\right)$, is given:

$$
G\left(E, L_{\mathrm{dev}}\right)=\frac{2 e^{2} n(E) D_{E}\left(\tau_{\mathrm{dev}}\right)}{L_{\mathrm{dev}}},
$$

where $n(E)$ is the density of states per length at energy $E$ and $\tau_{\mathrm{dev}}$ is the time required for the electronic wave to travel distance $L_{\mathrm{dev}}$; hence, $D_{E}\left(\tau_{\mathrm{dev}}\right)$ is the diffusion coefficient [87]. In N-doped nanotubes, for a metallic SWCNT with a diameter of $1 \mathrm{~nm}$, an energy level for the $\mathrm{N}$ atom can be located several hundred $\mathrm{meV}$ below the first van Hove singularity of the $\pi^{*}$-band $[85,89]$. For a semiconducting congener, the nitrogen state lies $150-200 \mathrm{meV}$ below the conduction band [75]. However, electron backscattering can complicate this simple description in some cases $[86,90]$.

The doping of the sidewall of SWCNTs with transition metals, however, remains to be achieved [91-95], despite the fact that the closely related transition metal-doped fullerenes have been synthesized and characterized [96-103]. Pt-, Ir-, Rh-, La-, Sm-, Sc-, and Y-doped fullerenes have been prepared via laser ablation or ionization, typically detected and characterized by mass spectrometry. The mechanism of formation is believed to involve formation of a fullerenetransition metal adsorbate complex, followed by insertion into the carbon framework [104]. Additionally, the synthesis of second- and third-row transition metal-doped fullerenes has been predicted to be attainable via reaction of the corresponding transition metal trichloride (or dichloride) in the presence of chlorine gas $\left(\mathrm{Cl}_{2}\right)$ and buckminsterfullerene $\left(\mathrm{C}_{60}\right)$ [105]. Theoretical studies also provide insight into the electronic properties of transition metal-doped fullerenes [106-109]. In general, the energy gap between the highest occupied molecular orbital (HOMO) and the lowest unoccupied molecular orbital (LUMO) in transition metal-doped fullerenes decreases in comparison to the parent fullerene upon introduction of a transition metal atom into the cage [109], resulting in higher conductivity and reactivity [106], and hence suggests similar effects for nanotubes.

Our work in SWCNTs and their substitutionally doped analogs (i.e., HSWCNTs) is driven from a fundamental interest in the ability of the unique chemical reactivity of these carbon allotropes. In particular, defected [81, 110-112] and doped nanotubes [35, 36, 45, 110, 113, 114] have been the focus of our attention. Since nanomaterials have such great potential for application in biological systems, sensory technology, electronics, and catalysis, their fundamental chemistry warrant further investigation.

It is worthwhile at this point to discuss the toxicology of SWCNTs at the nanolevel [115-120]. It is commonly held that the entry of nanosized particles into biological systems is dangerous due to the ability of these molecules to persist indefinitely [121] because they do not typically undergo metabolism by macrophages. In reality, intertube interactions and bundle formation depends strongly on particle size, surface charge, and surface area. Consequently, agglomeration of nanoparticles and their diffusion through physiological environments are not easy to predict. In fact, recent efforts have shown that SWCNTs functionalized on the surface with carbonyl $(\mathrm{C}=\mathrm{O})$, carboxyl $(\mathrm{COOH})$, and hydroxyl $(\mathrm{OH})$ groups exhibit higher levels of cytotoxicity and can induce cell death either after contact with cell membranes or following internalization [122]. Functionalization with ammonium cations, however, can lead to enhanced clearance rates [123]. The main mode of toxicity in organisms on a macroscale is believed to be oxidative stress induced by the generation of reactive oxygen species (ROSs) $[116,117,124-126]$. The mechanism of action involves lightinduced formation of electron-hole pairs and generation of unpaired electrons that can oxidize molecular oxygen $\left(\mathrm{O}_{2}\right)$ to superoxide $\left(\mathrm{O}_{2}{ }^{-}\right)$. Other electron-active groups can also contribute to the production of superoxide due to defects or surface coatings [116, 117]. Although nature has evolved enzymes (e.g., superoxide dismutase, glutathione [127]) to counteract the effect of ROSs, accumulation over extended periods of time can force cells to respond by more drastic measures [124, 125, 127]. Numerous examples of carbon nanomaterial cytotoxicity have been reported, including work done on human skin fibroblasts [128], macrophages [129, 130], and developing zebrafish embryos [131]. Researchers have also demonstrated that carbon nanotubes can cause interstitial fibrosis [132] and pulmonary toxicity $[121,133]$ in rat lungs and increase plateletderived growth factor (PDGF) messenger RNA (mRNA) levels significantly [132]. Clinically relevant toxicity data remains sparse [117], however, and several recent accounts suggest that low levels of nanosized carbon do not trigger immunological or inflammatory reactions [122] and may persist in mice for up to four months without any observable toxicity [134].

Nanotoxicity aside, nanotubes may find potential uses in therapy. For example, consider the interaction between SWCNTs and nitrogen monoxide (NO). Although nitrogen is one of the most important elements in biological systems, $\mathrm{NO}$ is known as being the toxic culprit for destroying ozone $\left(\mathrm{O}_{3}\right)$, causing cancer, and fostering acid rain. However, it plays a critical role at the interface of neuroscience, physiology, and immunology. Nitrogen monoxide was named "Molecule of the Year" in 1992 after its biosynthesis in mammalian cells, and its physiological relevance was recognized in the late 1980s [136, 137]. In fact, NO acts as a biological signaling molecule in the body and is important for learning and memory [138], blood pressure regulation $[138,139]$, skin homeostasis [140], inflammation [141], and carcinoma metastasis [142]. The biosynthesis of the gaseous free radical NO is achieved via a five-electron oxidation of arginine (Figure 3) [135, 136]. Physiological NO can inhibit metabolic pathways directly by binding to transition metal centers [143], as well as combine with molecular oxygen to give other ROSs including hydroxyl radicals, nitrogen 


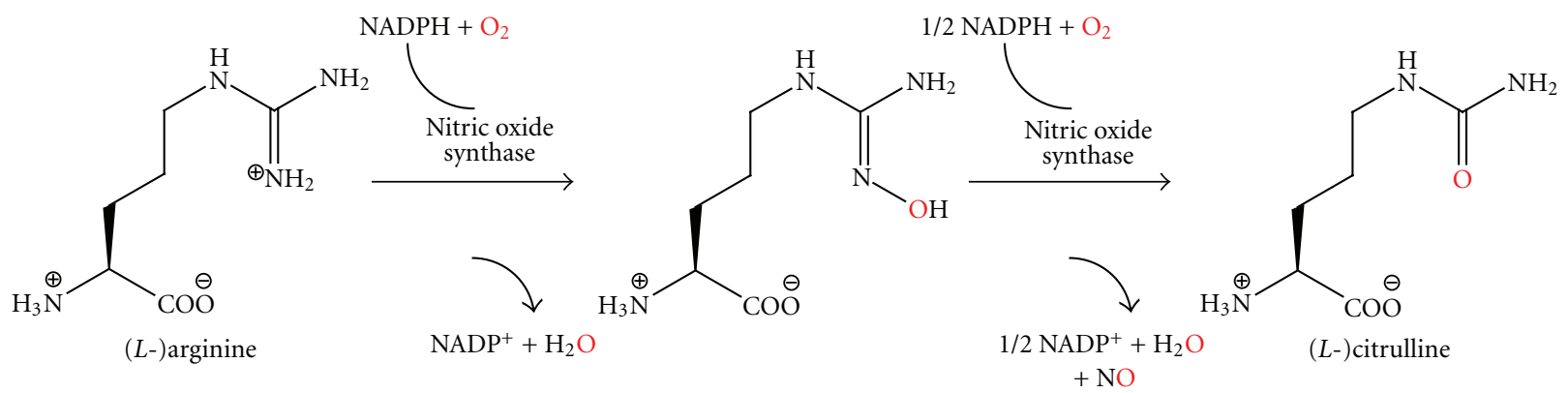

FIgURE 3: Biosynthesis of NO from (L)-arginine [135].

dioxide $\left(\mathrm{N}_{2} \mathrm{O}_{4}\right)$ [137], and peroxynitrite $\left(\mathrm{ONOO}^{-}\right)$[136, $138,143]$. If future nanodevices will be implanted into biological systems, it may interact with the biocycles of NO. Thus, the ability to adsorb NO would be important because it would reduce its concentration, which can be beneficial or dangerous depending on the site of activity. The controlled release of NO has recently attracted attention of researchers for antithrombotic activity [144], for instance. Indeed, chemically designed drugs (Figure 4) [136], zeolites [144, 145], and even Pt nanoparticles [146] may find applicability in NO homeostasis. Carbon nanotubes would represent an alternative strategy for controlling physiological NO.

We envisioned that doping the sidewall of SWCNTs with a transition metal would provide a unique opportunity for interacting with and binding small biologically relevant molecules such as NO. This hypothesis is based on the known ability of metal surfaces and discrete organometallic complexes to coordinate small molecules via the $d$ orbitals of the transition metal. Additionally, we imagined that transition metal-doped SWCNTs would exhibit electronic properties distinct both from the undoped SWCNT and Band N-doped SWCNTs that would enhance its potential for application in nanoelectronics. For example, these nanomaterials may act as sensors by monitoring observed conductance as a function of adsorption of small gas molecules [147, 148]. Designing new nanosensory technology for molecules including carbon monoxide $(\mathrm{CO})$, water $\left(\mathrm{H}_{2} \mathrm{O}\right)$, nitrogen monoxide (NO), ammonia $\left(\mathrm{NH}_{3}\right)$, and hydrogen $\left(\mathrm{H}_{2}\right)$ would be worthwhile [148-154] and would be complementary to Pd nanoparticle/SWCNT hybrids [153], Band N-doped SWCNTs [148], and defected SWCNTs [149]. Additionally, since substitutional doping generates structures bearing electronic similarities to simple transition metal alkyl complexes [114], catalytic applications are also possible.

In this review, we will highlight results from our own studies on the structure and electronic properties of substitutionally doped SWCNTs and their proposed synthesis. In addition, the chemical reactivity of HSWCNTs with small gas molecules will be discussed. The catalytic activity of transition metal-doped SWCNTs will also be described. Our investigative efforts constitute preliminary analyses toward a microscopic understanding of the biological roles of carbonbased nanomaterials and the development and discovery of new functional materials with exciting applications in the real world.

\section{Substitutional Doping of SWCNTs}

2.1. Models and Computational Details. The $(5,5)$ armchair metallic SWCNT and (5,0) zigzag SWCNT were used as models for all computations. Natural bond orbital (NBO) analysis was accomplished with Gaussian NBO Version 3.1 $[155,156]$ to obtain the frontier molecular orbitals (FMOs): the HOMO and the LUMO. Pioneered by Fukui and collaborators [157-161], the FMO analysis offers a powerful (albeit simple) understanding of chemical reactivities. Density of states (DOS) and local DOS (LDOS) studies were performed using PyMOlyze [162]. All other calculations were done with the Gaussian 03 quantum chemical package [163]. The Hessian was evaluated for all optimized structures to verify the nature of the stationary points on the potential energy surface. Both spin-restricted and spin-unrestricted optimizations yielded the same results for all ground-state complexes examined.

To study the substitutional doping of SWCNTs, we proposed that introduction of a single defect could provide a reactive site for atom transfer reagents (e.g., NO, $\mathrm{O}_{3}$ ). A chemical reaction would thus provide a means of selective doping with a noncarbon atom. For our study of defected SWCNTs with NO [81], a $(5,5)$ segment containing two hundred $\mathrm{C}$ atoms and twenty capping $\mathrm{H}$ atoms was chosen $\left(\mathrm{C}_{200} \mathrm{H}_{20}\right)$. A single vacancy was created by removal of a single $\mathrm{C}$ atom, yielding a metastable conformation with three dangling bonds. Geometry optimization was achieved sequentially with the semiempirical MNDO-PM3 method [164], followed by the hybrid Hartree-Fock/density functional theory (DFT) method B3LYP [165-167] with Pople's 6-31G basis set [168-171]. A two-layer ONIOM (our own N-layered integrated molecular orbital and molecular mechanics) model [172] was used for our calculations. The nine-membered ring surrounding the defect was considered the chemically active region and modeled with a $\mathrm{C}_{9} \mathrm{H}_{8}$ fragment as the higher layer treated at the B3LYP/6-31G(d) level of theory. All other $\mathrm{C}$ atoms in the lower layer were treated by the universal force field (UFF) [173]. For our study of defected SWCNTs with $\mathrm{O}_{3}$ [111], a $(5,5)$ segment containing one hundred and twenty $\mathrm{C}$ atoms and twenty capping $\mathrm{H}$ atoms was chosen $\left(\mathrm{C}_{120} \mathrm{H}_{20}\right)$. A single vacancy was created analogously. Geometry optimization was achieved sequentially with the semiempirical AM1 method [174-176], followed by B3LYP [165-167] with Pople's 6-31G basis set 


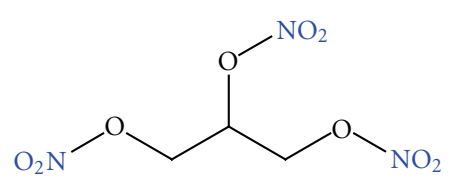

Glyceryl trinitrate (GTN)

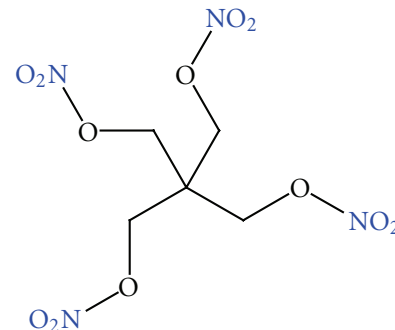

Pentaerythritol tetranitrate (PETN)

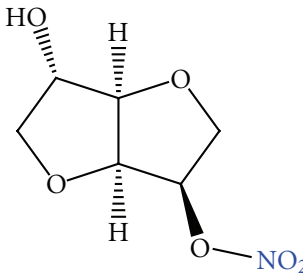

Isosorbide mononitrate (ISMN)

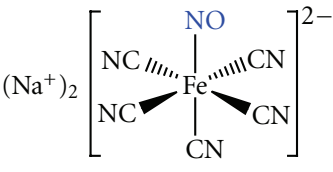

Sodium nitroprusside (SNP)

FIgURE 4: Clinically used NO donor drugs [136].

[168-171]. Although $\mathrm{O}_{3}$ is a multiconfigurational species, DFT is able to accurately describe this system because of the incorporation of the exchange-correlation effects $[61,177,178]$. The static quantum mechanical calculations were confirmed by comparison to an atom-centered density matrix propagation- (ADMP-) [179-181] based $a b$ initio molecular dynamics (AIMD) simulation.

For our study of other main group element-doped and transition metal-doped SWCNTs [110], a $\mathrm{C}_{70} \mathrm{H}_{20}$ fragment terminating with $\mathrm{H}$ atoms was chosen. A single $\mathrm{C}$ atom was removed from the sidewall and replaced with a heteroatom (i.e., $\mathrm{Sn}, \mathrm{Se}, \mathrm{Te}, \mathrm{Ni}, \mathrm{Pd}$ ) to give $\mathrm{C}_{69} \mathrm{H}_{20} \mathrm{Sn}, \mathrm{C}_{69} \mathrm{H}_{20} \mathrm{Se}$, $\mathrm{C}_{69} \mathrm{H}_{20} \mathrm{Te}, \mathrm{C}_{69} \mathrm{H}_{20} \mathrm{Ni}$, and $\mathrm{C}_{69} \mathrm{H}_{20} \mathrm{Pd}$, respectively. DFT calculations were performed using B3LYP [165-167] with the relativistic 18-electron Los Alamos National Laboratory effective core pseudopotential (ECP) of Hay and Wadt (LANL2) [182]. Geometry optimization was achieved sequentially with B3LYP using the smaller LANL2MB basis set, followed by the larger LANL2DZ basis set (Dunning/Huzinaga valence double- $\zeta$ for first row elements and Los Alamos ECP plus double- $\zeta$ for heavier elements) [183]. We considered both exo- and endo-substitutions (vide infra). We also chose $\mathrm{Pt}$ for further investigations $[35,36,110,113,114]$ due to its prevalence in well-defined organometallic complexes [184-187] and heterogeneous catalysis [188-192]. Based on the aforementioned studies, only exo-substitution was considered. For our gas adsorption studies, two such $(5,5)$ models were selected: (1) a $\mathrm{C}_{170}$ fragment with $D_{5 h}$ symmetry and hemispheric caps [35], and (2) a $\mathrm{C}_{70} \mathrm{H}_{20}$ fragment terminating with $\mathrm{H}$ atoms $[113,114]$. Substitution gave $\mathrm{C}_{169} \mathrm{Pt}$ and $\mathrm{C}_{69} \mathrm{H}_{2} \mathrm{Pt}$, respectively. For the $\mathrm{C}_{169} \mathrm{Pt}$, DFT calculations were performed using Becke's exchange (B) [193] and Perdew's correlation functional (PW91) [194, 195] with Hay and Wadt's ECP LANL2 [182] or B3LYP/LANL2MB, followed by LANL2DZ [183]. For $\mathrm{C}_{69} \mathrm{H}_{20} \mathrm{Pt}$, the exchangecorrelation density functional of Perdew, Burke, and Ernzerhof (PBEPBE) [196] was applied using the same basis sets. Model alkylplatinum complex $\mathrm{PtMe}_{3}{ }^{+}$and its $\underline{\mathrm{CO}}$ adsorbates (i.e., where a CO molecule has coordinated to the $\mathrm{Pt}$ atom via the $\mathrm{C}$ atom) were treated similarly.

For our study of catalytic activity of transition metaldoped SWCNTs [45], a $(5,0)$ segment containing thirty C atoms and ten capping $\mathrm{H}$ atoms $\left(\mathrm{C}_{30} \mathrm{H}_{10}\right)$ was chosen. Substitution gave $\mathrm{C}_{29} \mathrm{H}_{10} \mathrm{Pt}$. DFT calculations were performed using B3LYP/LANL2MB, followed by LANL2DZ [183] with Hay and Wadt's relativistic ECP LANL2 [182]. Model systems $\mathrm{PtMe}_{3}{ }^{+}, \mathrm{PtPh}_{3}{ }^{+}, \mathrm{Pt}$-doped phenaline, Pt-doped sumanene, Pt-doped corannulene, and $\mathrm{Pt}$-doped $\mathrm{C}_{24}$ fullerene were treated similarly. Note that there are two distinct structural isomers of Pt-doped $\mathrm{C}_{24}$ fullerene, one in which the $\mathrm{Pt}$ atom substitutes a $\mathrm{C}$ atom at the junction between three pentagons (PPP isomer) and the other in which the Pt atom substitutes a $\mathrm{C}$ atom at the junction between a hexagon and two pentagons (HPP isomer). NMR chemical shifts $(\delta)$ were calculated using the gauge-independent atomic orbital (GIAO) method [197-199]. For the study of catalytic DielsAlder reactions between maleic anhydride and cyclopentadiene, we also compared our hypothetical organoplatinum Lewis acids with traditional Lewis acids (e.g., $\mathrm{AlCl}_{3}, \mathrm{AlMe}_{3}$, $\left.\mathrm{BF}_{3}, \mathrm{BCl}_{3}, \mathrm{BBr}_{3}, \mathrm{SnCl}_{4}, \mathrm{TiCl}_{4}\right)$.

The isoelectronic transition metal-doped single-walled boron nitride nanotube (BNNT) and its undoped analog was also studied for comparison [200]. In fact, our calculations demonstrate that atomic Pt can interact with either pristine or Stone-Wales-defective $(5,5)$ BNNTs to give Pt-doped BNNTs. A truncated $(5,5)$ BNNT containing forty-five B and $\mathrm{N}$ atoms and twenty capping $\mathrm{H}$ atoms was chosen as the model $\left(\mathrm{B}_{45} \mathrm{~N}_{45} \mathrm{H}_{20}\right)$. DFT calculations were performed using B3LYP/LANL2MB, followed by LANL2DZ [183] with Hay and Wadt's relativistic ECP LANL2 [182].

2.2. Defected SWCNT Rods. A single vacancy along the backbone of a $(5,5)$ SWCNT rod $\mathrm{C}_{200} \mathrm{H}_{20}$ can be formed via removal of a single $\mathrm{C}$ atom that can be induced by external radiation $[83,84]$. In our model system, this yields a defected SWCNT with molecular formula $\mathrm{C}_{199} \mathrm{H}_{20}$ that undergoes a structural rearrangement to yield a structure containing one five-membered carbocycle and a single $\mathrm{C}$ atom with one dangling bond (i.e., the 5-1DB defect). The single $\mathrm{C}$ atom that protrudes to the exterior of the sidewall surface of the SWCNT is referred to as the active carbon atom (C1). Nine $\mathrm{C}$ atoms surrounding the active carbon atom constitute the entire 5-1DB defect (Figure 5). The hexagonal lattice of all other $\mathrm{C}$ atoms in the nanotube sidewall remains relatively unaffected. Because the active carbon atom remains outside the SWCNT superstructure, enhanced chemical reactivity with incoming molecular or atomic species should be possible due to coordinative unsaturation, as well as a smaller 


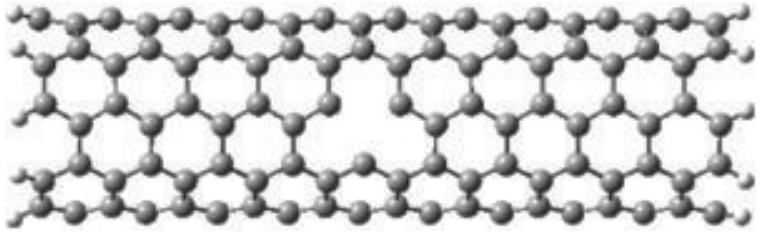

(a) Single vacancy by removal of $\mathrm{C}$ atom

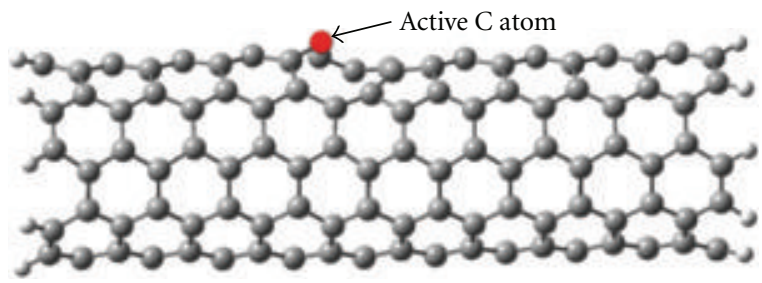

(c) Side view of the 5-1DB defect

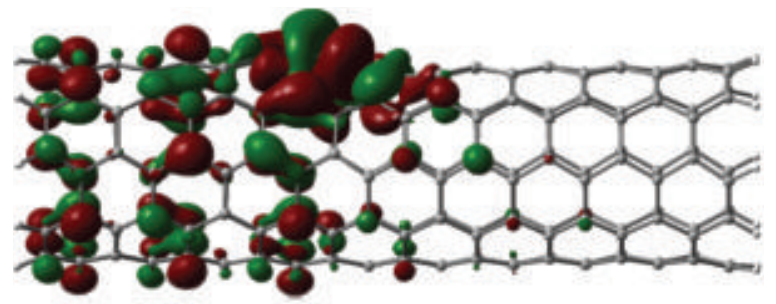

(e) LUMO of $\mathrm{C}_{199} \mathrm{H}_{20}(-3.37 \mathrm{eV})$

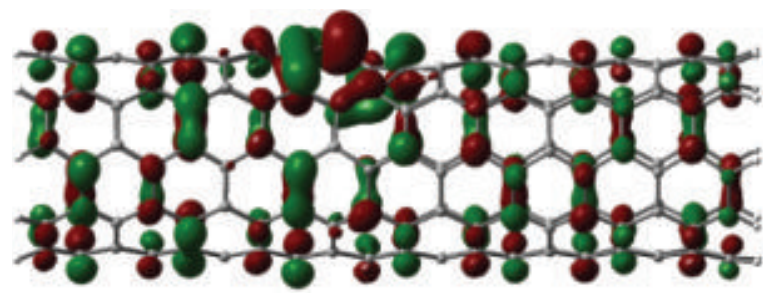

(g) $\mathrm{HOMO}$ of $\mathrm{C}_{199} \mathrm{H}_{20}(-4.21 \mathrm{eV})$

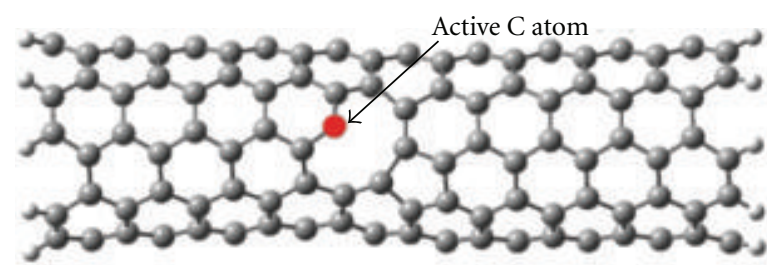

(b) Top view of the 5-1DB defect
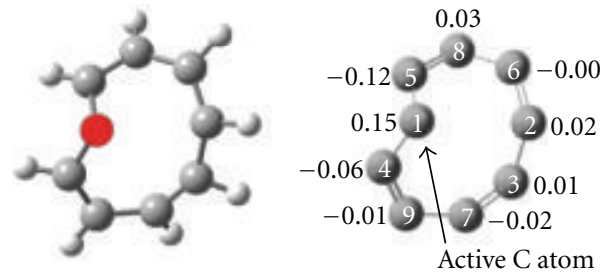

(d) Partial charges of active region $\left(\mathrm{C}_{9} \mathrm{H}_{8}\right)$

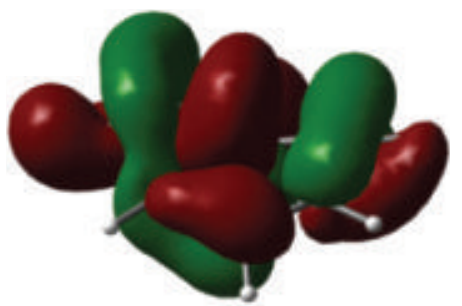

(f) $\mathrm{LUMO}$ of $\mathrm{C}_{9} \mathrm{H}_{8}(-2.78 \mathrm{eV})$

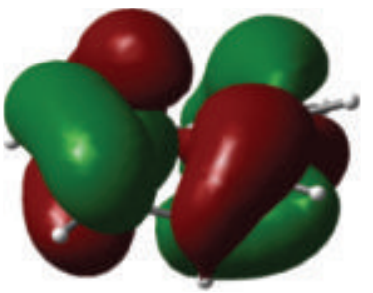

(h) $\mathrm{HOMO}$ of $\mathrm{C}_{9} \mathrm{H}_{8}(-4.79 \mathrm{eV})$

FIgURE 5: Optimized geometry and FMOs of a 5-1DB defected SWCNT and higher-layer model $\mathrm{C}_{9} \mathrm{H}_{8}$. Orbital energies are in parentheses [81]. Legend: dark grey $=$ carbon, light grey $=$ hydrogen .

steric hindrance. Single-point calculations revealed that the HOMO-LUMO gap decreased from 1.38 to $0.84 \mathrm{eV}$ upon the introduction of the defect, suggesting a destabilization of the HOMO and stabilization of the LUMO by formation of the 5-1DB defect. The HOMO contains a large contribution from the lonepair of electrons on the active carbon atom and the $\pi$-bonds of the other atoms within the ninemembered ring highlighted in Figure 5(d). Using a truncated $\mathrm{C}_{9} \mathrm{H}_{8}$ fragment with fixed geometry, FMO analysis revealed that this smaller model can be used to represent most of the chemical properties of the defect. Introduction of the vacancy defect also resulted in several small changes in the DOS (Figure 6).

2.3. Substitutional N-Doping of SWCNTs via Chemical Reaction of Defected SWCNTs with NO. Since the 5-1DB defect possesses an active $\mathrm{C}$ atom, we were intrigued about the possibility of performing chemical reactions between defected SWCNTs and reactive small molecules [81]. In particular, nitrogen monoxide caught our attention due to its biological relevance (vide supra). NBO analysis of the defected SWCNT revealed that the active carbon atom contains an $s p^{2.01}$-orbital with 1.51 electrons and a $p$-orbital with 0.51 electrons. The overall charge on $\mathrm{C} 1$ is 0.149 . Free $\mathrm{NO}$, on the other hand, exhibits polarization, where the $\mathrm{O}$ atom bears a charge of -0.181 .

Our ONIOM model predicts an electrostatic interaction between the defected SWCNT and NO (Figure 7). First, the $\mathrm{O}$-end of the nitrogen monoxide molecule attacks the active carbon atom $\mathrm{C} 1$, producing a heterocycle INT1 containing an $\mathrm{N}-\mathrm{O}$ bond. This is the rate-limiting step of the $\mathrm{N}$ doping process and requires only a mere $8.6 \mathrm{kcal} / \mathrm{mol}$. This type of reaction results from the interaction of a singlyoccupied molecular orbital of $\mathrm{NO}$ and the HOMO of the SWCNT. Subsequently, the $\mathrm{N}$ atom undergoes insertion into the $\mathrm{C} 2-\mathrm{C} 3$ bond to expand the pentagon via a threemembered-ring transition state to liberate INT2. C1-N bond formation occurs with concomitant cleavage of the 


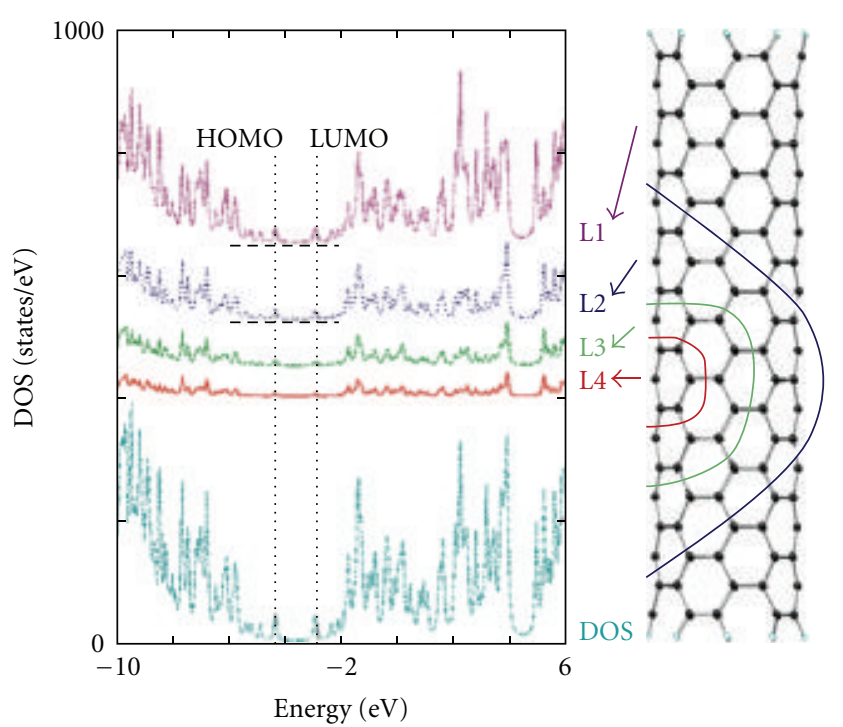

(a) DOS of $\mathrm{C}_{200} \mathrm{H}_{20}$

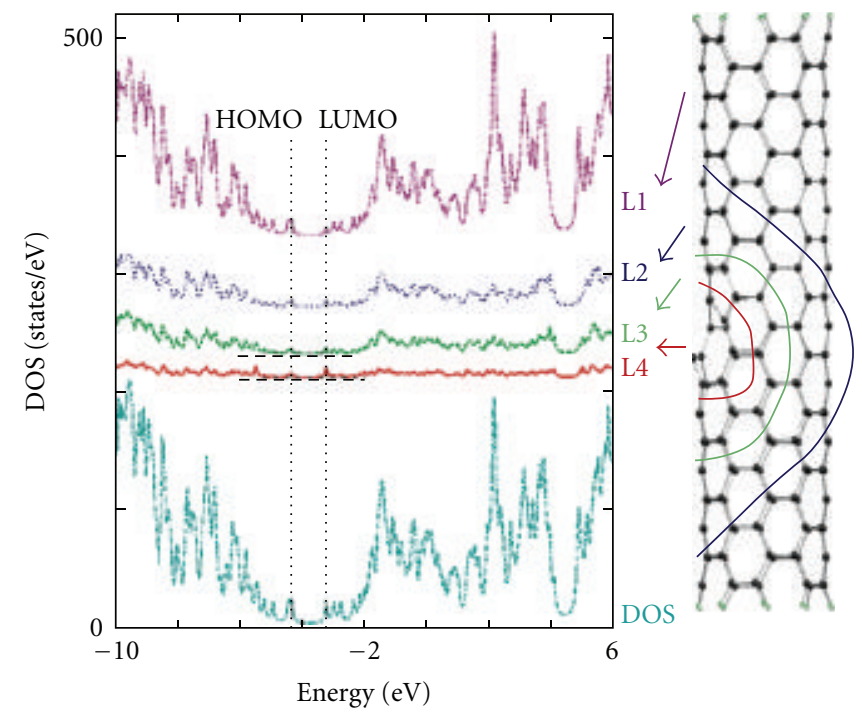

(b) DOS of $\mathrm{C}_{199} \mathrm{H}_{20}$

Figure 6: Optimized geometries, DOS, and LDOS of (a) $\mathrm{C}_{200} \mathrm{H}_{20}\left(\varepsilon_{\mathrm{HOMO}}=-4.35 \mathrm{eV}\right.$, $\left.\varepsilon_{\mathrm{LUMO}}=-2.97 \mathrm{eV}\right)$ and $(\mathrm{b}) \mathrm{C}_{199} \mathrm{H}_{20}\left(\varepsilon_{\mathrm{HOMO}}=\right.$ $\left.-4.21 \mathrm{eV}, \varepsilon_{\mathrm{LUMO}}=-3.37 \mathrm{eV}\right) . \mathrm{L} 1-\mathrm{L} 4$ are the LDOS for the specified layer of atoms [81].

$\mathrm{C} 1-\mathrm{O}$ bond to give INT3. The $\mathrm{N}$-oxide radical $\left(\mathrm{C}_{199} \mathrm{H}_{20} \mathrm{NO}\right)$ that results is formally an $\mathrm{N}$-doped SWCNT that has undergone pyramidalizing oxygenation, where the $\mathrm{N}$ atom has filled the single vacancy where a carbon atom was removed.

In the presence of another equivalent of NO, the SWCNT can react a second time. The optimized geometry of INT3 reveals an $\mathrm{N}-\mathrm{O}$ bond length of $1.41 \AA$ with a partial charge of -0.574 residing on the $\mathrm{O}$ atom. The second molecule of $\mathrm{NO}$ interacts simultaneously with $\mathrm{C} 1$ and $\mathrm{O} 1$ through the $\mathrm{N}$ atom and via a four-membered-ring concerted, asynchronous transition state liberates one molecule of nitrogen dioxide $\left(\mathrm{NO}_{2}\right)$ and the $\mathrm{N}$-doped SWCNT product $\left(\mathrm{C}_{199} \mathrm{H}_{20} \mathrm{~N}\right)$. This product is $78.3 \mathrm{kcal} / \mathrm{mol}$ more stable than the reactants and suggests that the net reaction of $\mathrm{NO}$ with $\mathrm{C}_{199} \mathrm{H}_{20}$ is thermodynamically feasible. Formally, $\mathrm{NO}$ acts as a reducing agent by breaking the weak $\mathrm{N}-\mathrm{O}$ bond of INT3 .

In comparison to the perfect and pristine SWCNT rod $\left(\mathrm{C}_{200} \mathrm{H}_{20}\right)$, the N-doped HSWCNT exhibits a decreased HOMO-LUMO gap of $0.74 \mathrm{eV}$ (cf. $1.38 \mathrm{eV}$ for the undoped SWCNT and $0.84 \mathrm{eV}$ for the defected SWCNT). Geometrically, the $\mathrm{N}$ atom is situated slightly above the nanotube circumference (Figure 8 ). The $\mathrm{N}$ atom bears a charge of -0.325 , whereas the neighboring $\mathrm{C}$ atoms display charges of approximately 0.20 .

\subsection{Substitutional O-Doping of SWCNTs via Chemical Reac-} tion of Defected SWCNTs with $\mathrm{O}_{3}$. Having established an understanding of N-doping in defected SWCNTs, we turned our attention to the chemical reaction of vacancy defects with $\mathrm{O}_{3}$ [111]. $\mathrm{O}_{3}$ is a strong oxidizing agent that is capable of cleaving the $\mathrm{C}=\mathrm{C}$ double bonds of alkenes to generate two $\mathrm{C}=\mathrm{O}$ bonds via the Criegee mechanism [201, 202]. In this reaction, $\mathrm{O}_{3}$ undergoes a [3+2] cycloaddition with the olefin, generating a five-membered ozonide. This intermediate rearranges to form a second ozonide takes place via the intermediacy of a carbonyl and carbonyl oxide. Since nanotube sidewalls consist of extended $\pi$-frameworks of $\mathrm{C}$ atoms, ozonization is presumably possible. Using a shorter $\mathrm{C}_{120} \mathrm{H}_{20}$ segment of a $(5,5)$ armchair SWCNT and repeating the geometry optimization following removal of a single $\mathrm{C}$ atom gave a 5-1DB defect with similar geometry to our $\mathrm{C}_{199} \mathrm{H}_{20}$ system (vide supra). $\mathrm{C} 1$ was confirmed as the active carbon atom, bearing a positive charge of 0.10 .

We considered ozonization of all $\mathrm{C}-\mathrm{C}$ bonds exhibiting partial $\mathrm{C}=\mathrm{C}$ double bond character within the backbone of the defect. Of all the possibilities explored, the reaction manifold that is most possible involves direct interaction between $\mathrm{O}_{3}$ and the active carbon atom (Figure 9). A weak interaction between $\mathrm{O}_{3}$ and the SWCNT takes place first to form the physisorbed INT. Based on NBO analysis, 0.19 electrons have transferred from the SWCNT to $\mathrm{O}_{3} \cdot \mathrm{O}_{3}$ and $\mathrm{C} 1$ then undergo a one-step oxygenation and loss of singlet dioxygen to liberate Product. The transition state (TS) involves a tightly bound four-membered ring in which bond between $\mathrm{C} 1$ and $\mathrm{O} 1$ gets shorter and is essentially barrierless from the starting materials $(-0.3 \mathrm{kcal} / \mathrm{mol})$. Product is formally a substitutionally O-doped SWCNT. The overall process is extremely exothermic $(-88.7 \mathrm{kcal} / \mathrm{mol})$. Additionally, relaxation of singlet $\mathrm{O}_{2}$ to triplet $\mathrm{O}_{2}$ results in further stabilization $(-117.7 \mathrm{kcal} / \mathrm{mol})$. AIMD simulations were conducted in which the $\mathrm{O}_{3}$ molecule was placed above the center of the nine-membered ring of the 5-1DB defect. At $300 \mathrm{~K}$, our calculations confirm the spontaneous reaction between $\mathrm{O}_{3}$ and $\mathrm{C} 1$ in less than $50 \mathrm{fs}$.

Careful examination of Product reveals that the bonding between $\mathrm{C} 1$ and $\mathrm{O} 1$ is very strong, exhibiting a bond length of 1.21 $\AA$ (cf. 1.20 $\AA$ for a $\mathrm{C}=\mathrm{O}$ double bond [203]). Thus, the structure of this product may be more accurately described as oxidation of $\mathrm{C} 1$ to a carbonyl functional group with minimal 


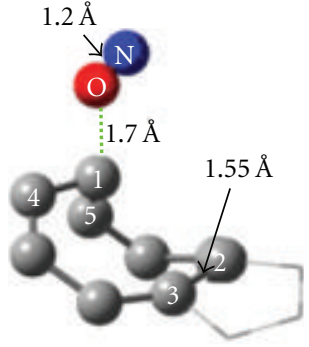

(a) TS1 $(\Delta E=8.6)$

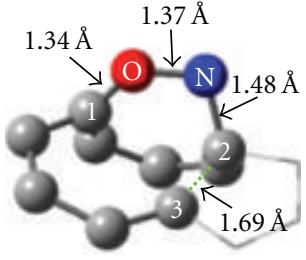

(b) INT1 $(\Delta E=-19.1)$

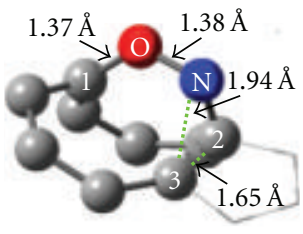

(c) $\operatorname{TS} 2(\Delta E=-6.9)$

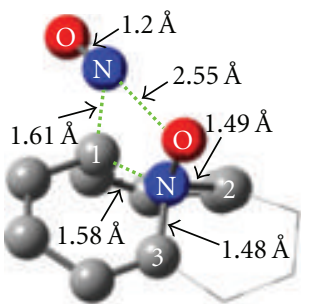

(g) $\operatorname{TS} 4(\Delta E=3.7)$

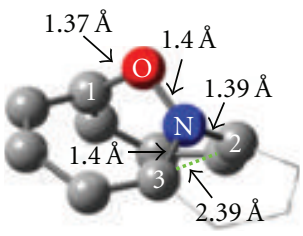

(d) $\operatorname{INT2}(\Delta E=-92.4)$

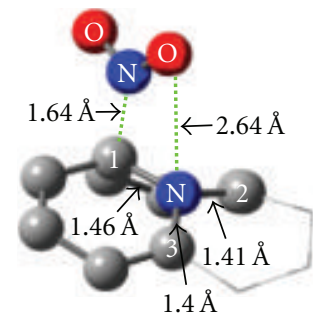

(h) Product $(\Delta E=-78.3)$

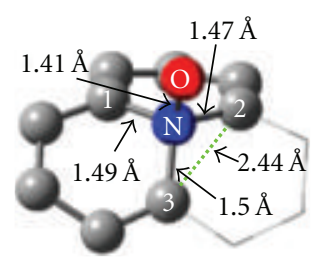

(f) $\operatorname{INT3}(\Delta E=-90)$
TS2

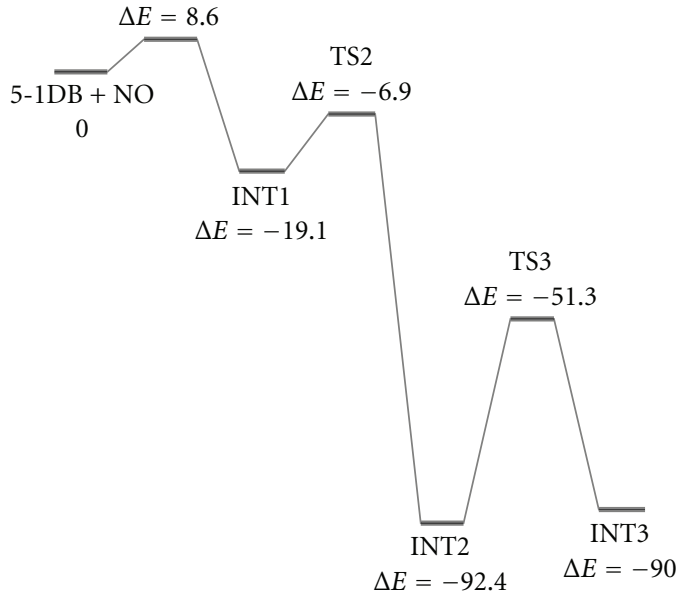

(i) Reaction profile of $\mathrm{NO}$ with the 5-1DB defect

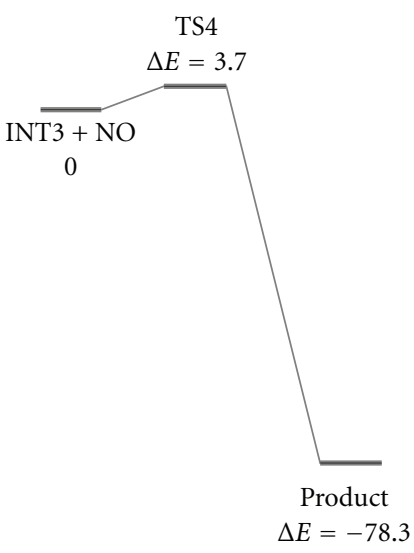

(j) Reaction with second $\mathrm{NO}$

FIGURE 7: Optimized geometries (with distances in $\AA$ ) and energy profiles (with energies in kcal/mol) for the reaction of the defected SWCNT with NO [81]. Legend: dark grey = carbon, navy blue = nitrogen, red $=$ oxygen.

structural rearrangement of the defect itself. The bond length between $\mathrm{C} 1$ and $\mathrm{C} 5$ does not significantly shorten, nor does a strong interaction exist between $\mathrm{C} 5$ and $\mathrm{O} 1$.

2.5. Other Main Group Element-Doped SWCNTs. Based on these investigations, substitutional doping appears to be favored, where the dopant atom is situated to the exterior of the nanotube superstructure. To confirm this assessment, we used a truncated $(5,5)$ SWCNT capped with $\mathrm{H}$ atoms (i.e., $\mathrm{C}_{70} \mathrm{H}_{20}$ ) and substituted a single $\mathrm{C}$ atom in the middle of the segment with a heteroatom (i.e., Sn, Se, and $\mathrm{Te})$. We performed geometry optimization by considering both the possibility of external doping and internal doping (Figure 10) [110]. Our calculations are consistent with the proposal that exo-substitution is more energetically favored than the corresponding endo-HSWCNTs. Significant structural rearrangement is required for end-doping, and a larger buildup of positive charge is observed for the dopant atom (Table 1). FMO analysis revealed that electron density is largely localized at the dopant atoms themselves in the case of endo-substitution but is delocalized along the backbone of the nanotube in exo-substitution (Figure 11).

2.6. Transition Metal-Doped SWCNTs. Using the same approach as described above, we substituted a single $\mathrm{C}$ atom in the middle of a truncated $(5,5)$ SWCNT model capped with $\mathrm{H}$ atoms (i.e., $\mathrm{C}_{70} \mathrm{H}_{20}$ ) and obtained geometries of both endo- and exo-substitution for both $\mathrm{Ni}$ and Pd substitutions. In agreement with our studies on main group element-doped SWCNTs, exo-substitution is more energetically favored and 


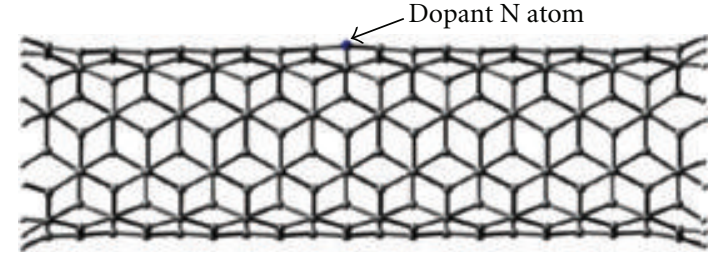

(a) Side view of $\mathrm{C}_{199} \mathrm{H}_{20} \mathrm{~N}$

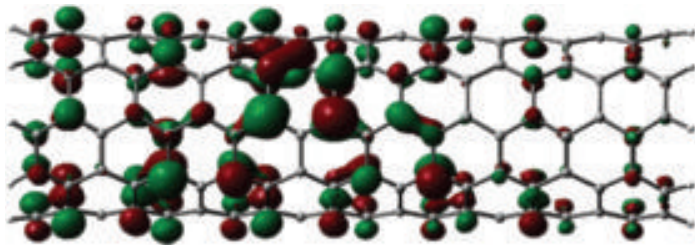

(c) $\operatorname{HOMO}(-3.81 \mathrm{eV})$

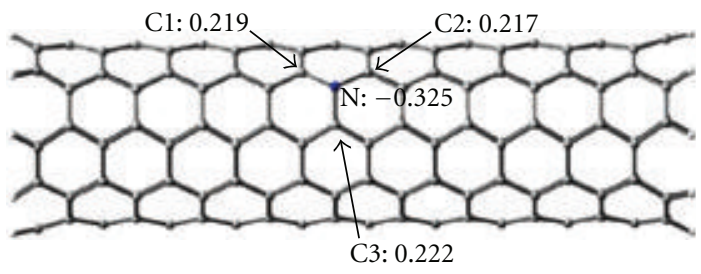

(b) Top view of $\mathrm{C}_{199} \mathrm{H}_{20} \mathrm{~N}$

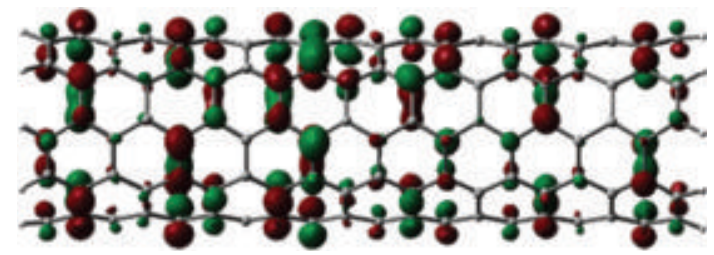

(d) $\operatorname{LUMO}(-3.07 \mathrm{eV})$

FIgURE 8: Optimized geometry and FMOs of $\mathrm{C}_{199} \mathrm{H}_{20} \mathrm{~N}$. Orbital energies are in parentheses [81].

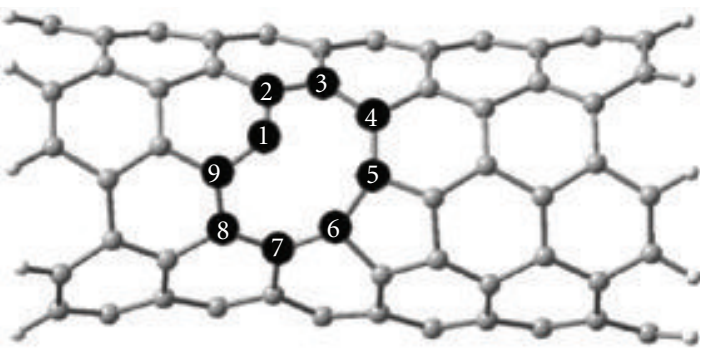

(a) Top view of the 5-1DB defect
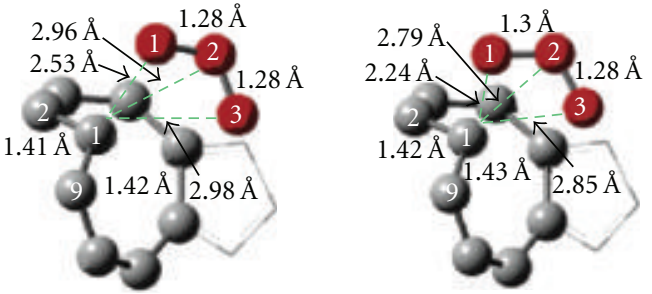

(c) TS $(\Delta E=-0.3)$
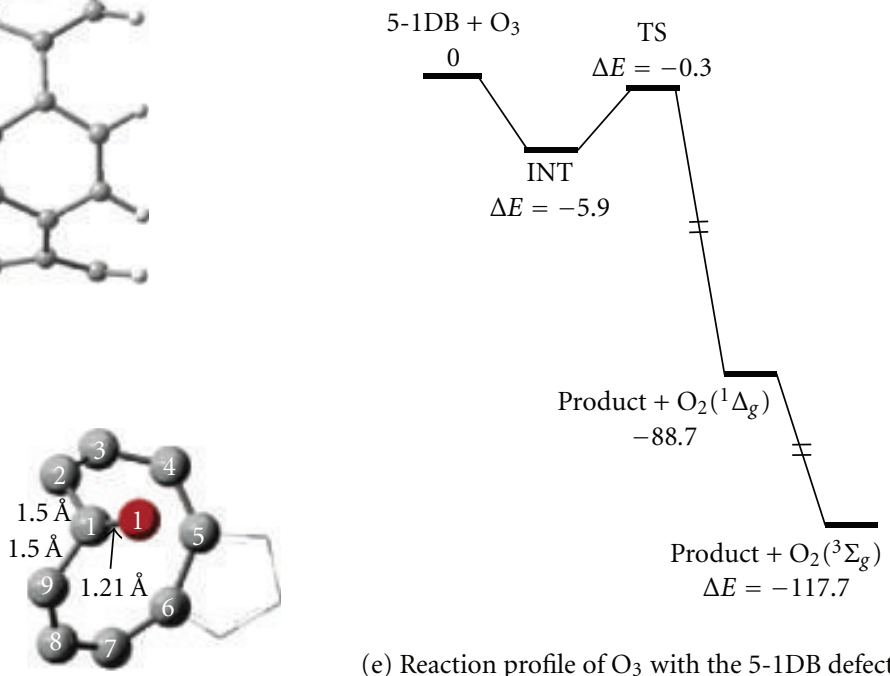

(e) Reaction profile of $\mathrm{O}_{3}$ with the $5-1 \mathrm{DB}$ defect

(d) Product $(\Delta E=-88.7)$

FIGURE 9: Optimized geometries (with distances in $\AA$ ) and energy profiles (with energies in kcal/mol) for the reaction of the defected SWCNT with $\mathrm{O}_{3}[111]$. Legend: dark grey $=$ carbon, light grey $=$ hydrogen, red = oxygen .

TABLE 1: Binding energy and geometric data for main group element-doped SWCNTs [110].

\begin{tabular}{lcccc}
\hline Dopant atom $(\mathrm{X})$ & Adsorption mode & $\mathrm{E}_{\text {elec }}{ }^{\mathrm{a}}$ & $d(\mathrm{X}-\mathrm{C})^{\mathrm{b}}$ & $\mathrm{q}(\mathrm{X})^{\mathrm{c}}$ \\
\hline \multirow{2}{*}{$\mathrm{Sn}$} & Exo & 0.0 & $2.184,2.145,2.145$ & 0.643 \\
& Endo & 4.287 & $2.112,2.111,2.111$ & 0.501 \\
\hline \multirow{2}{*}{ Se } & Exo & 0.0 & $2.121,2.032,2.032$ & 0.797 \\
& Endo & 3.768 & $2.083,1.988,1.988$ & 0.578 \\
\hline \multirow{2}{*}{ Te } & Exo & 0.0 & $2.268,2.163,2.163$ & 0.987 \\
& Endo & 4.828 & $3.013,2.260,2.260$ & 0.496 \\
\hline
\end{tabular}

${ }^{a}$ Relative electronic energy of stabilization (in $\mathrm{eV}$ ).

${ }^{b}$ Bond length (in $\AA$ ) between $\mathrm{X}$ atom and adjacent $\mathrm{C}$ atoms.

'Partial charge on X. 


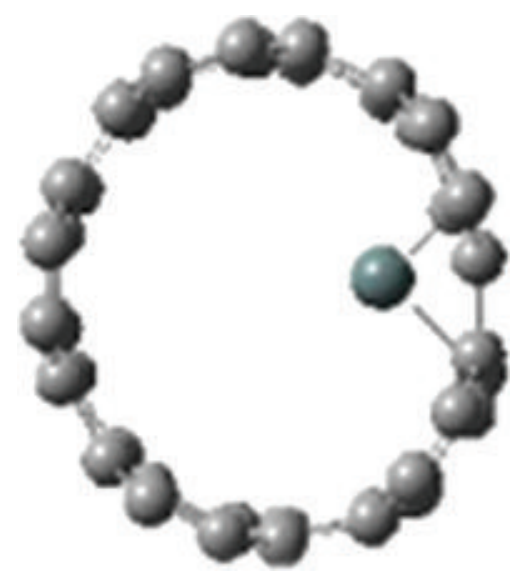

(a) Endo-substitutional doping

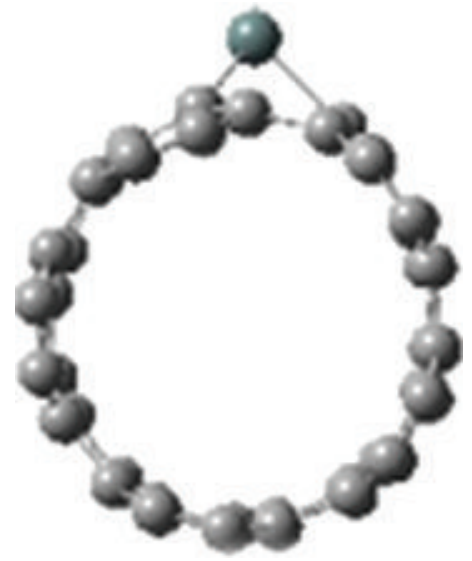

(b) Exo-substitutional doping

FIgURE 10: Two geometries of substitutional doping, namely (a) endo- and (b) exo-substitution. [110].

TABLE 2: Binding energy and geometric data for transition metal-doped SWCNTs [110].

\begin{tabular}{lcccc}
\hline Dopant atom $(X)$ & Adsorption mode & $\mathrm{E}_{\text {elec }}{ }^{\mathrm{a}}$ & $\mathrm{d}(\mathrm{X}-\mathrm{C})^{\mathrm{b}}$ & $\mathrm{q}(\mathrm{X})^{\mathrm{c}}$ \\
\hline \multirow{2}{*}{$\mathrm{Ni}$} & Exo & 0.0 & $1.905,1.851,1.851$ & 0.310 \\
& Endo & 1.633 & $1.791,1.847,1.847$ & -0.004 \\
\hline \multirow{2}{*}{$\mathrm{Pd}$} & Exo & 0.0 & $2.066,2.009,2.009$ & 0.195 \\
& Endo & 2.552 & $1.937,2.022,2.022$ & -0.104 \\
\hline
\end{tabular}

${ }^{a}$ Relative electronic energy of stabilization (in $\mathrm{eV}$ ).

${ }^{\mathrm{b}}$ Bond length (in $\AA$ ) between $\mathrm{X}$ atom and adjacent $\mathrm{C}$ atoms.

${ }^{c}$ Partial charge on $\mathrm{X}$.

induces a smaller structural rearrangement of the atoms of the nanotube sidewall (Table 2) [110]. Interestingly, localization of positive charge is insignificant in endo-substitution. In contrast to main group element-doped SWCNTs, these transition metal-doped congeners exhibit localization of electron density as evaluated by analysis of their FMOs (Figure 12).

2.7. Pt-Doped SWCNT Rods with Fullerene Caps. We were interested in substitutional doping of SWCNTs with a transition metal, particularly with Pt because of its potential application as nanosensors and nanocatalysts. By constructing a $(5,5)$ SWCNT rod capped with fullerene hemispheres $\left(\mathrm{C}_{170}\right.$, Figure 13(a)), we noted that three different types of atom substitution were possible: (1) cap-end-doping to generate $\mathrm{C}_{169} \mathrm{Pt}(\mathrm{ce})$ (Figure 13(b)), (2) cap-doping to generate $\mathrm{C}_{169} \mathrm{Pt}(\mathrm{c})$ (Figure 13(c)), and (3) wall-doping to generate $\mathrm{C}_{169} \mathrm{Pt}(\mathrm{w})$ (Figure 13(d)) [35, 36]. Geometry optimization reveals that the Pt atom typically prefers to protrude to the exterior of the nanotube sidewall, adopting a conformation in which the three adjacent $\mathrm{C}$ atoms are situated in a tripodlike fashion. This may be a result of the larger size of the $\mathrm{Pt}$ atom and is consistent to the conclusions of Sections 2.5 and 2.6.

At the BPW91/6-31G level of theory, $\mathrm{C}_{169} \mathrm{Pt}(\mathrm{ce})$ is the most stable of the three isomers. The energies of $\mathrm{C}_{169} \mathrm{Pt}(\mathrm{c})$ and $\mathrm{C}_{169} \mathrm{Pt}(\mathrm{w})$ are 0.8 and $17.9 \mathrm{kcal} / \mathrm{mol}$, respectively, above that of $\mathrm{C}_{169} \mathrm{Pt}(\mathrm{ce})$. In all calculations, the singlet electronic state was found to be lower in energy than the triplet. Hence, the Pt-doped nanorods exhibit a singlet ground state. Because of the extended $\pi$-framework of the sidewalls, however, the triplet excited state is also accessible.

Figure 13(b) shows the optimized geometry, DOS, and LDOS of $\mathrm{C}_{169} \mathrm{Pt}(\mathrm{ce})$. The bond length between the $\mathrm{Pt}$ and $\mathrm{C}$ atoms at the cap end is $2.01 \AA$ (cf. $1.73 \AA$ for an isolated PtC molecule [114]). A careful analysis of the geometry of this Pt-doped nanorod reveals that the pentagonal and hexagonal structure is significantly distorted as a result of Pt-doping $[35,36]$. Evidently, $\mathrm{C}_{169} \mathrm{Pt}(\mathrm{c})$ is very similar geometrically to $\mathrm{C}_{169} \mathrm{Pt}(\mathrm{ce})$ (Figure 13(c)). The bond distance between $\mathrm{Pt}$ and the $\mathrm{C}$ atom of the cap pentagon is $1.97 \AA$, while the distances to the remaining two $\mathrm{C}$ atoms are $2.00 \AA$. We suspect that the low energy of $\mathrm{C}_{169} \mathrm{Pt}(\mathrm{ce})$ is a result of geometric relaxation of cap strain via the doping process.

The presence of Pt $5 d$ atomic orbitals has a clear impact on the electronic structure of the nanorod in comparison to the undoped nanorod as evaluated by the DOS calculations. In $\mathrm{C}_{169} \mathrm{Pt}(\mathrm{ce}), \mathrm{L} 1$ displays sharp peaks in the LDOS at the cap that are not present in the model $\mathrm{C}_{170}$ segment (Figure 13(a)). This suggests that weak $p_{\pi}-d_{\pi}$ interactions between the $\mathrm{Pt}$ atom and adjacent $\mathrm{C}$ atoms are taking place. The LDOS of the sidewall remains relatively unchanged. Interestingly, a similar electronic structure is observed for $\mathrm{C}_{169} \mathrm{Pt}(\mathrm{c})$ (Figure 13(c)). 
Endo-substitution

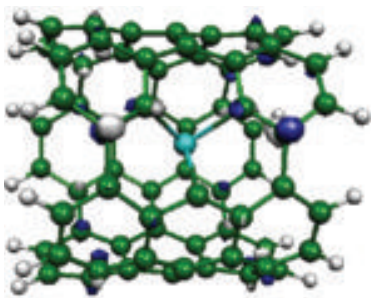

HOMO

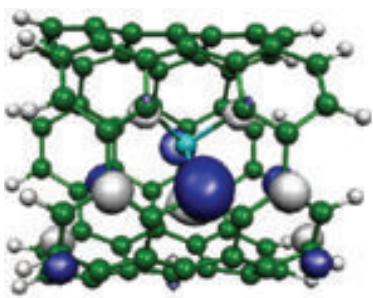

LUMO

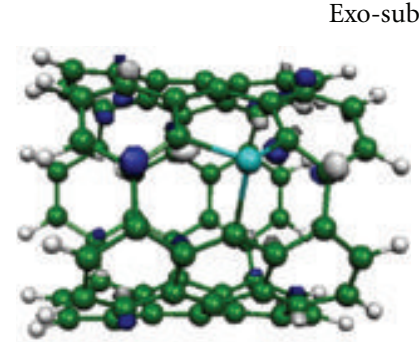

$\mathrm{HOMO}$
Exo-substitution

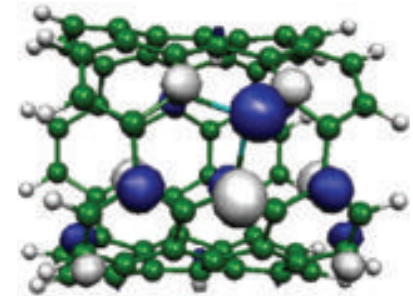

LUMO

(a) $(5,5) \mathrm{Sn}$-doped SWCNT

Endo-substitution

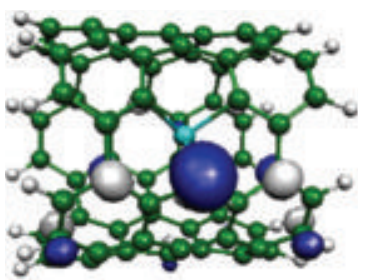

HOMO

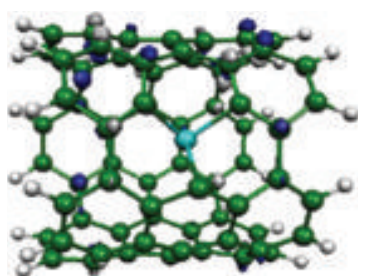

LUMO

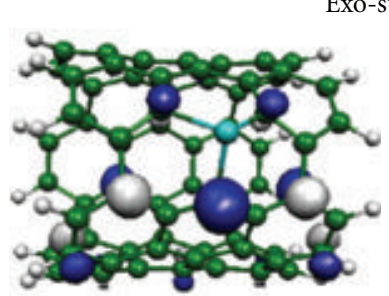

HOMO

Exo-substitution

(b) $(5,5)$ Se-doped SWCNT

Endo-substitution

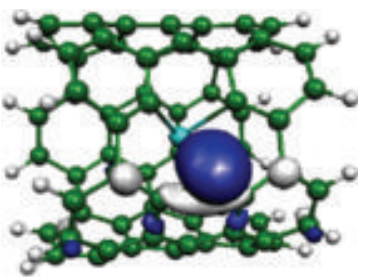

$\mathrm{HOMO}$

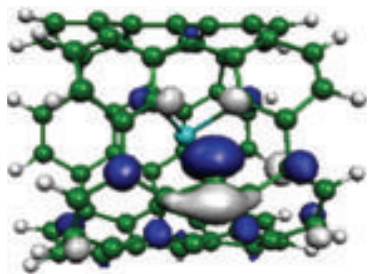

LUMO

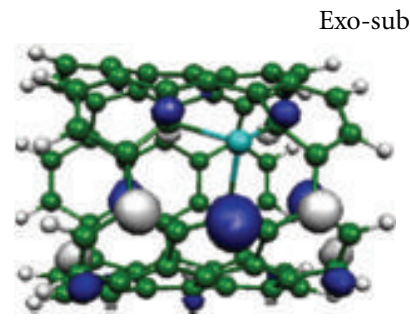

$\mathrm{HOMO}$

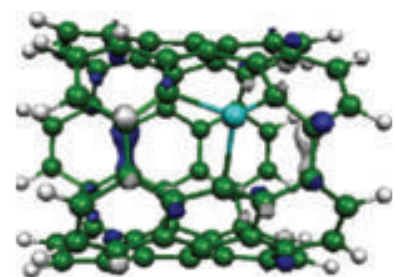

LUMO

(c) $(5,5) \mathrm{Te}$-doped SWCNT

FIgure 11: FMOs of Sn-, Se-, and Te-doped SWCNTs [110].

In the case of the wall-doped $\mathrm{C}_{169} \mathrm{Pt}(\mathrm{w})$, both the geometric and electronic structures differ from the cap Ptdoped SWCNTs. While the LDOS at the cap resembles that of the undoped $\mathrm{C}_{170}$ model, significant changes in the LDOS at the nanotube sidewall can be observed (Figure 13(d)). Particularly, the sharp peaks that result from the Pt doping are now present in L5 instead of at L1.

Molecular orbital analysis confirms our assessment of these hypothetical Pt-doped nanorods with DOS (Figure 14). Indeed, localization of electron density can be seen primarily, where the substitution of the $\mathrm{C}$ atom with the $\mathrm{Pt}$ atom has taken place. The HOMO-LUMO gaps of $\mathrm{C}_{169} \mathrm{Pt}(\mathrm{ce})$, $\mathrm{C}_{169} \mathrm{Pt}(\mathrm{c})$, and $\mathrm{C}_{169} \mathrm{Pt}(\mathrm{w})$ are $0.30,0.23$, and $0.20 \mathrm{eV}$, respectively.

2.8. Pt-Doped SWCNT Rods with Hydrogen Caps. Using a shorter $\mathrm{C}_{69} \mathrm{H}_{20} \mathrm{Pt}$ model derived from a truncated $(5,5)$ SWCNT capped with $\mathrm{H}$ atoms (i.e., $\mathrm{C}_{70} \mathrm{H}_{20}$ ) (Figure 15), we were able to obtain a geometry that is consistent with the wall-doped fullerene-capped $\mathrm{C}_{169} \mathrm{Pt}(\mathrm{w})$ nanorod (see Figure 13(d)) [114]. The $\mathrm{Pt}-\mathrm{C}$ distances are 1.94, 1.94, and $2.01 \AA$ in this case, with the Pt atom situated in the middle of a tripodal structure. A positive charge of 0.83 is present on the Pt center. Surprisingly, the HOMO-LUMO gap increased to $0.74 \mathrm{eV}$ (cf. $0.20 \mathrm{eV}$ for $\mathrm{C}_{169} \mathrm{Pt}(\mathrm{w})$ ). Nonetheless, a clear analogy between the molecular orbitals (MOs) of our $\mathrm{C}_{69} \mathrm{H}_{20} \mathrm{Pt}$ model and the wall-doped $\mathrm{C}_{169} \mathrm{Pt}(\mathrm{w})$ can be observed (Figure 16). This result suggests that using $\mathrm{H}$ atoms to cap the truncated nanotube instead of fullerene hemispheres still allows us to capture most of the chemical properties of the Pt-doped SWCNT.

2.9. Pt-Doped BNNT Rods with Hydrogen Caps. Having acquired preliminary understanding of the geometric and electronic structures of Pt-doped SWCNTs, we turned our attention to the isoelectronic Pt-doped boron-nitride nanotube (BNNT) [200]. Although the B-N couple is isoelectronic with the $\mathrm{C}-\mathrm{C}$ bond, the difference in electronegativity between the $\mathrm{B}$ and $\mathrm{N}$ atoms leads to the formation of dipoles. $B$ has an empty $p$ orbital and is a coordinatively unsaturated trigonal plane, while $\mathrm{N}$ has a full octet. In planar structures, this implies that $\mathrm{B}$ acts as electron acceptors, while $\mathrm{N}$ acts as electron donors. These electronic differences have chemical implications. For example, although molecular borazine $\left(\mathrm{B}_{3} \mathrm{~N}_{3} \mathrm{H}_{6}\right)$ is isoelectronic and isostructural to benzene and possesses aromaticity, it is susceptible to addition reactions 


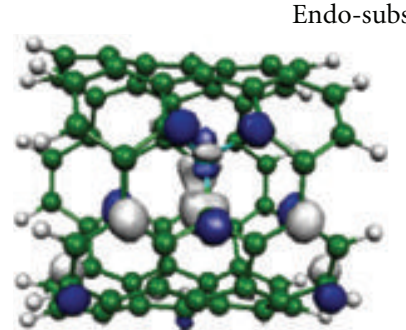

HOMO

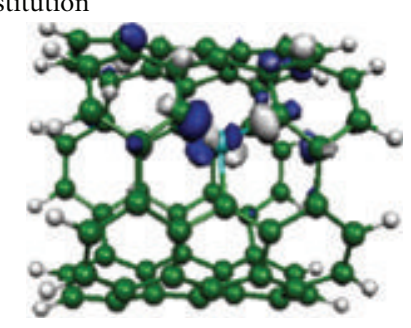

LUMO

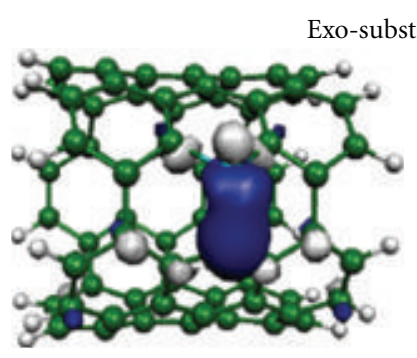

HOMO

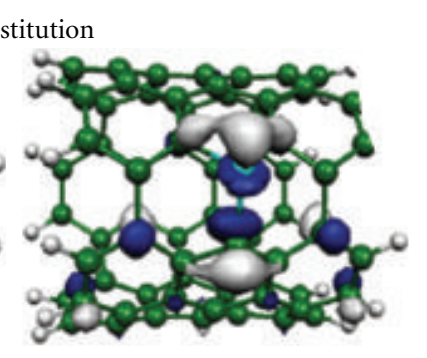

LUMO

(a) $(5,5)$ Ni-doped SWCNT

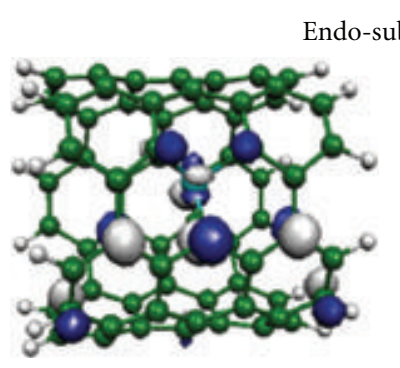

HOMO

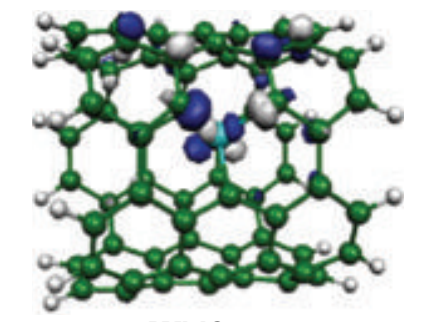

LUMO

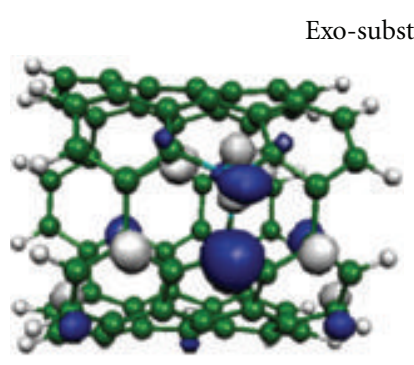

HOMO

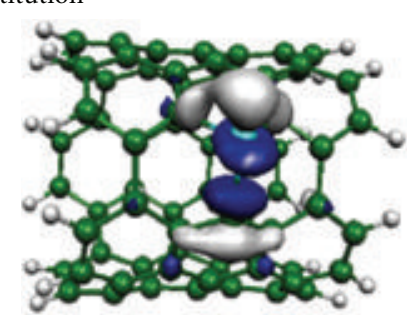

LUMO

(b) $(5,5)$ Pd-doped SWCNT

Figure 12: FMOs of Ni- and Pd-doped SWCNTs [110].

and to both nucleophilic and electrophilic attacks. Hexagonal boron nitride $(\mathrm{hBN})$, the $\mathrm{BN}$ analog of graphite, exhibits extraordinary mechanical hardness and chemical inertness, while carbon graphite is used as a lubricant. BNNTs and SWCNTs also differ in several key regards. Zigzag BNNTs exhibit a nonzero dipole moment because of alternating layers of $\mathrm{B}$ and $\mathrm{N}$ atoms. Their band gaps and electronic structures around the Fermi level are generally invariant to changes in nanotube diameter and chirality due to localized ionic $\mathrm{B}-\mathrm{N}$ bonds. BNNTs are incombustible at high temperatures and retain the chemical inertness of hBN $[200,204]$. As such, BNNTs can be readily applied in nanoelectronics with minimal purification.

Boron-nitride nanotubes exhibit natural defects that can be induced from mechanical fractures $[205,206]$. Among all possible defects, Stone-Wales (SW) defects are of particular interest [207]. Defects consisting of a pentagonalheptagonal-heptagonal-pentagonal structure are found to be more stable than their corresponding quadrilateraloctagonal-octagonal-quadrilateral structure, even though, in the former case, homoatomic $\mathrm{B}-\mathrm{B}$ and $\mathrm{N}-\mathrm{N}$ bonds are present [206].

We initiated our studies by building a truncated $(5,5)$ BNNT model capped with twenty $\mathrm{H}$ atoms $\left(\mathrm{B}_{45} \mathrm{~N}_{45} \mathrm{H}_{20}\right)$ (Figure 17). Pristine BNNT contains two nonequivalent $\mathrm{B}-\mathrm{N}$ bonds: (1) vertical $\mathrm{B}-\mathrm{N}$ bonds perpendicular to the longitudinal direction of the tube (with length $1.453 \AA$ ) and (2) slant B-N bonds (with length $1.455 \AA$ ). Consequently, there are two distinct Stone-Wales defective BNNT resulting from either a slant $\mathrm{B}-\mathrm{N}$ bond rotation (SW1) or a vertical $\mathrm{B}-\mathrm{N}$ bond rotation (SW2). The formation of pentagons and heptagons results in electronic destabilization in comparison to the perfect hexagonal lattice of $\mathrm{B}$ and $\mathrm{N}$ atoms in pristine BNNTs. The HOMO of the pristine BNNT segment is composed largely of delocalized $p_{\pi}$ orbitals on the $\mathrm{N}$ atoms, while the LUMO consists of the unoccupied $p_{\pi^{*}}$ orbitals of the $\mathrm{B}$ atoms. The HOMO-LUMO gap is $6.02 \mathrm{eV}$, rendering the BNNT a good insulator. By introduction of the StoneWales defects, electron density localization at the $\mathrm{B}-\mathrm{B}$ and $\mathrm{N}-\mathrm{N}$ bonds results in a decrease of the HOMO-LUMO gap (4.98 and $5.19 \mathrm{eV}$ for SW1 and SW2, resp.).

While both pristine and SW-defective BNNTs can physisorb Pt atoms, substitutional doping may also be possible. Substitution of either a single $\mathrm{N}$ or $\mathrm{B}$ atom gives two different structures with molecular formula $\mathrm{B}_{45} \mathrm{~N}_{44} \mathrm{H}_{20} \mathrm{Pt}$ and $\mathrm{B}_{44} \mathrm{~N}_{45} \mathrm{H}_{20} \mathrm{Pt}$ that must be considered independently (Figure 18). Both products have doublet ground states. The product resulting from $\mathrm{N}$-substitution (i.e., $\mathrm{B}_{45} \mathrm{~N}_{44} \mathrm{H}_{20} \mathrm{Pt}$ ) exhibits a slight positive charge buildup on the Pt atom. Additionally, the $\alpha$-spin HOMO is comprised of Pt $5 d 6 s$ and $6 p$ orbitals and has an energy of $-3.67 \mathrm{eV}$, making the Ptdoped BNNT a good electron donor. In contrast, the $\alpha$-spin LUMO is raised to $-1.74 \mathrm{eV}$ and displays lower reactivity toward nucleophiles. The $\beta$-spin HOMO is electronically similar to that of pristine BNNT, while the $\beta$-spin is more similar to the $\alpha$-spin LUMO of this Pt-doped BNNT (i.e., $\mathrm{B}_{44} \mathrm{~N}_{45} \mathrm{H}_{20} \mathrm{Pt}$ ). The band gap is $1.9 \mathrm{eV}$ and renders these nanomaterials semiconducting.

The product resulting from B-substitution (i.e., $\mathrm{B}_{45} \mathrm{~N}_{44} \mathrm{H}_{20} \mathrm{Pt}$ ) exhibits net donation of 1.15 electrons from Pt to the extended backbone of the nanotube. Spin density is also delocalized on its three surrounding $\mathrm{N}$ atoms. The $\alpha$-spin HOMO now consists primarily of Pt $5 d$ orbitals, while the $\alpha$-spin LUMO is made of Pt $5 d$ orbitals and $\mathrm{N} p_{\pi}$ 


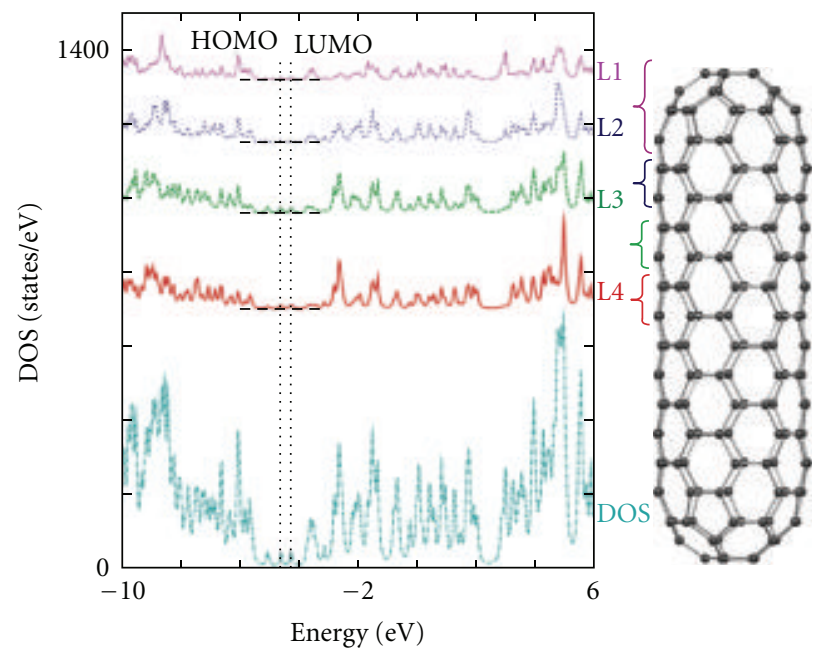

(a) DOS of $\mathrm{C}_{170}$

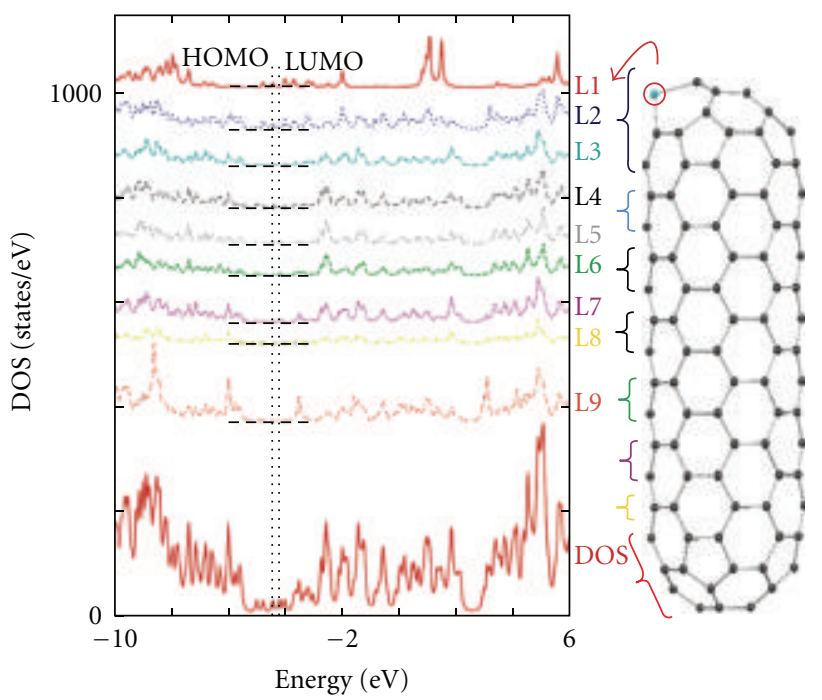

(c) DOS of $\mathrm{C}_{169} \mathrm{Pt}(\mathrm{c})$

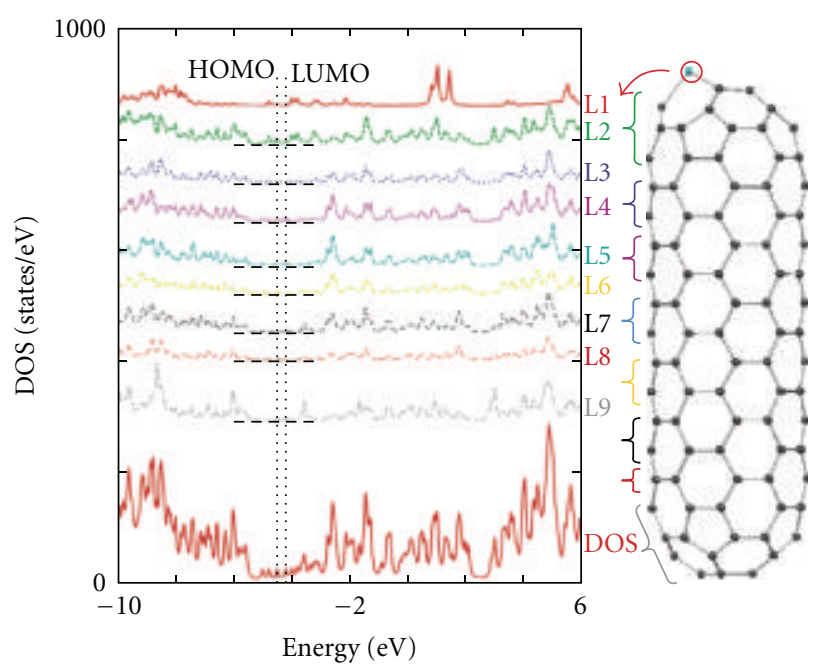

(b) DOS of $\mathrm{C}_{169} \mathrm{Pt}(\mathrm{ce})$

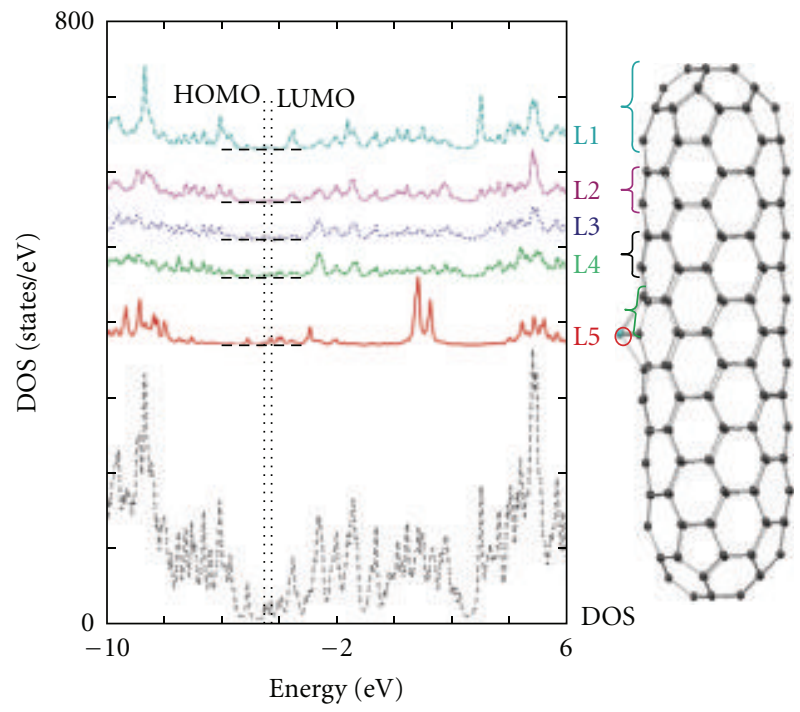

(d) $\mathrm{DOS}$ of $\mathrm{C}_{169} \mathrm{Pt}(\mathrm{w})$

FIgURE 13: Optimized geometries, DOS, and LDOS of (a) $\mathrm{C}_{170}$ with $D_{5 h}$ symmetry $\left(\varepsilon_{\mathrm{HOMO}}=-4.61 \mathrm{eV}, \varepsilon_{\mathrm{LUMO}}=-4.26 \mathrm{eV}\right),(\mathrm{b}) \mathrm{C}_{169} \mathrm{Pt}(\mathrm{ce})$ with $C_{s}$ symmetry $\left(\varepsilon_{\mathrm{HOMO}}=-4.51 \mathrm{eV}, \varepsilon_{\mathrm{LUMO}}=-4.21 \mathrm{eV}\right),(\mathrm{c}) \mathrm{C}_{169} \mathrm{Pt}(\mathrm{c})$ with $C_{s}$ symmetry $\left(\varepsilon_{\mathrm{HOMO}}=-4.48 \mathrm{eV}, \varepsilon_{\mathrm{LUMO}}=-4.25 \mathrm{eV}\right)$, and (d) $\mathrm{C}_{169} \mathrm{Pt}(\mathrm{w})$ with $C_{s}$ symmetry $\left(\varepsilon_{\mathrm{HOMO}}=-4.46 \mathrm{eV}, \varepsilon_{\mathrm{LUMO}}=-4.26 \mathrm{eV}\right)$. L1 $-\mathrm{L} 9$ are the LDOS for each specified layer of atoms as marked on the diagram $[35,36]$.

orbitals, lowering its energy to $-5.58 \mathrm{eV}$. The $\alpha$-spin LUMO is decreased to $-3.72 \mathrm{eV}$, making the Pt-doped BNNT a good electron acceptor. The $\beta$-spin HOMO is comprised primarily of $\mathrm{N}$ atoms surrounding the substitution site. The $\beta$-spin LUMO is lowered by the participation of Pt $5 d$ orbitals.

Overall, substitution of either the B or N atom of a BNNT results in enhanced nucleophilic attack. We thus predict that electron-rich small molecules, such as $\mathrm{N}_{2}$ or $\mathrm{CO}$, should be able to adsorb strongly on the dopant $\mathrm{Pt}$ atom based on the known physisorption of $\mathrm{H}_{2}$ onto Pt-doped BNNTs [208].

\section{Gas Adsorption onto Metal-Doped SWCNTs}

3.1. Adsorption of Carbon Monoxide. Since discrete organometallic Pt complexes $[184,186]$ and metal surfaces
$[188,189]$ are known to undergo coordination or adsorption of carbon monoxide (CO), we imagined that adsorption of CO onto a Pt-doped SWCNT would also be possible [114]. Although the $\mathrm{C} \equiv \mathrm{O}$ triple bond is polarized slightly toward the $\mathrm{C}$ atom, we considered two possibilities for $\mathrm{CO}$ adsorption; namely, $\mathrm{C}$-end adsorption (giving a $\mathrm{CO}-$ adsorbed HSWCNT) and O-end adsorption (giving an OC-adsorbed HSWCNT) were both considered (Figure 19).

Adsorption of CO onto a Pt-doped SWCNT resulted in the release of $41.23 \mathrm{kcal} / \mathrm{mol}$ for $\mathrm{C}$-end adsorption and $6.98 \mathrm{kcal} / \mathrm{mol}$ for O-end adsorption (Table 3). In coordination chemistry, we describe this type of interaction as a dative bond, in which the lone pair of electrons on the $\mathrm{C}$ atom donates into a metal $d$-orbital, causing a backdonation to the $\pi^{*}$-orbital of the adsorbate. This analysis suggests slight 


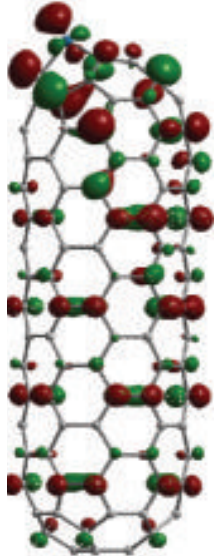

HOMO

$(-4.51 \mathrm{eV})$
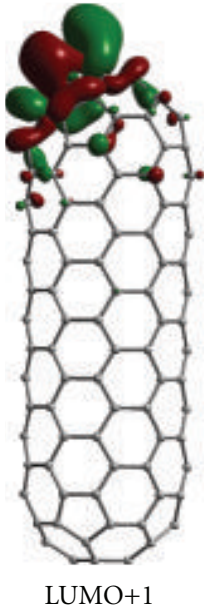

$(-4 \mathrm{eV})$

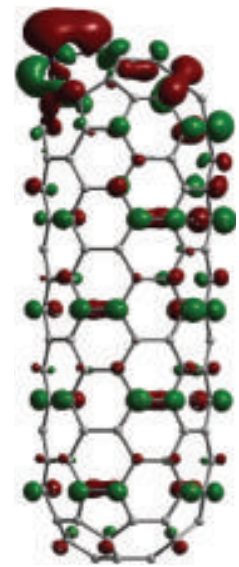

HOMO

$(-4.48 \mathrm{eV})$

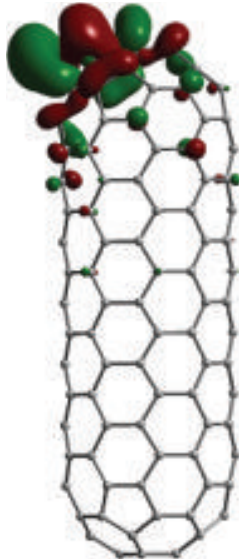

LUMO+1 $(-4.06 \mathrm{eV})$

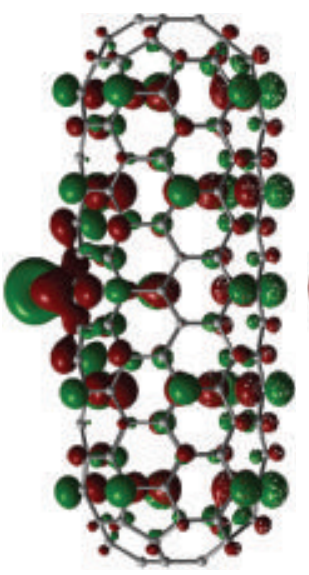

HOMO

$(-4.79 \mathrm{eV})$

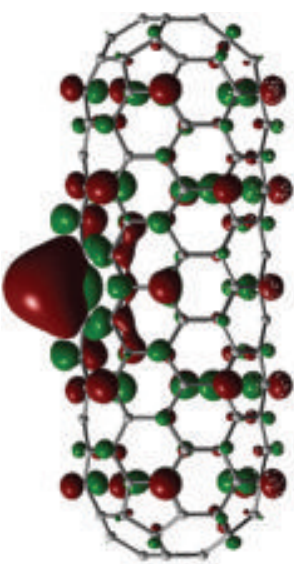

LUMO

$(-4.26 \mathrm{eV})$

(a) $\mathrm{C}_{169} \mathrm{Pt}(\mathrm{ce})$

(b) $\mathrm{C}_{169} \mathrm{Pt}(\mathrm{c})$

(c) $\mathrm{C}_{169} \mathrm{Pt}(\mathrm{w})$

Figure 14: Relevant FMOs for $\mathrm{C}_{169} \mathrm{Pt}(\mathrm{ce}), \mathrm{C}_{169} \mathrm{Pt}(\mathrm{c})$, and $\mathrm{C}_{169} \mathrm{Pt}(\mathrm{w})$. Orbital energies are in parentheses [35, 36].

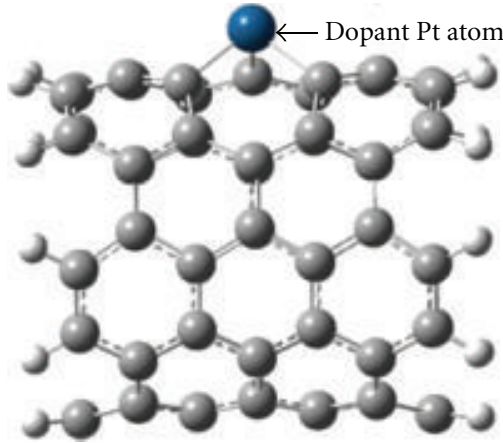

(a) Side view of $\mathrm{C}_{69} \mathrm{H}_{20} \mathrm{Pt}$ perpendicular to the nanotube axis

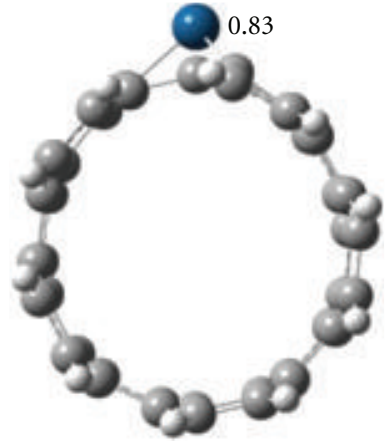

(b) Side view of $\mathrm{C}_{69} \mathrm{H}_{20} \mathrm{Pt}$ parallel to the nanotube axis

FIGURE 15: Optimized geometry of $\mathrm{C}_{69} \mathrm{H}_{20} \mathrm{Pt}$ (a) perpendicular and (b) parallel to the nanotube axis [114]. Legend: dark grey = carbon, light grey $=$ hydrogen, blue $=$ platinum.

lengthening of the $\mathrm{C} \equiv \mathrm{O}$ triple bond. In our system, geometry optimization revealed a slight elongation of the $\mathrm{C} \equiv \mathrm{O}$ triple bond from $1.18 \AA$ in the free gas to $1.19 \AA$ and a net charge of -0.12 on the $\mathrm{CO}$ molecule. In comparison, the $\mathrm{OC}$-adsorbed HSWCNT showed a $\mathrm{C} \equiv \mathrm{O}$ bond length of $1.18 \AA$ and a net charge of -0.02 on the adsorbate. The HOMO-LUMO gap was $0.66 \mathrm{eV}$. Hence, coordination of CO depends strongly on the orientation of the interaction, since adsorption via the $\mathrm{C}$ atom exhibited a more pronounced effect on the electronic structure of the Pt-doped SWCNT than the corresponding O-end adsorption.

It is well known that Pt complexes can host up to six ligands in its coordination sphere. Consequently, we decided to explore the possibility of multiple adsorption. We successfully identified a structure in which two CO molecules have undergone coordination to the Pt center through Cend adsorption (Figure 20). The $(\underline{\mathbf{C O}})_{2}$-adsorbed HSWCNT segment was formed with a further release of energy $(36.83 \mathrm{kcal} / \mathrm{mol}$ per $\mathrm{CO}$ molecule) and displayed almost identical orientation of both adsorbates. In comparison to monoadsorption, the distance between the Pt atom and the $\mathrm{C}$ atom of $\mathrm{CO}$ increased to $2.00 \AA$, while the net charges on the adsorbates decreased to -0.05 per CO molecule [114]. For triple adsorption, we were unable to locate a structure in which three molecules were bound strongly to the Pt atom via C-end adsorption; instead, based on our studies, it appeared that a third additional molecule of CO could interact weakly with the nanotube itself (cf. $3.13 \AA$ between the Pt atom and the $\mathrm{C}$ atom of $\mathrm{CO}$ ) [113]. Structurally, this $(\underline{\mathrm{CO}})_{3}$-adsorbed HSWCNT was similar to the corresponding $(\underline{\mathrm{CO}})_{2}$-adsorbed HSWCNT. The overall process is energetically downhill from the bare Pt-doped SWCNT but uphill from the doubly adsorbed intermediate. Presumably, the steric bulk of the nanotube backbone precludes the possibility of triple adsorption, despite the fact that the Pt atom remains coordinatively unsaturated.

3.2. Comparison with Alkylplatinum Complexes. In light of the ability of a HSWCNT undergoing adsorption with CO [114], we investigated model alkylplatinum complexes 

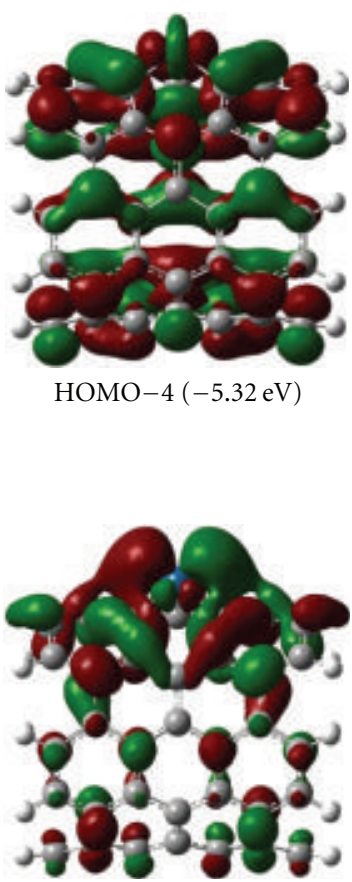

LUMO $(-3.35 \mathrm{eV})$

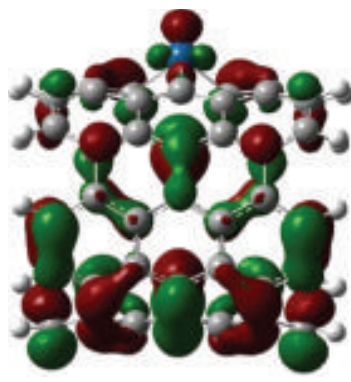

HOMO-2 (-4.89 eV)

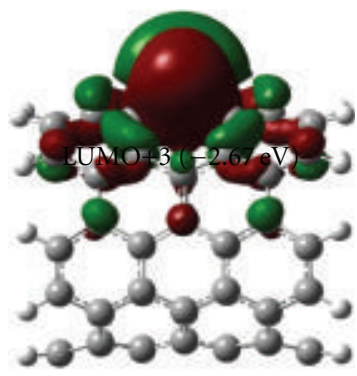

LUMO+1 $(-3.34 \mathrm{eV})$

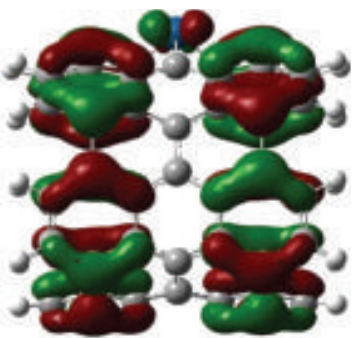

HOMO-1 $(-4.41 \mathrm{eV})$

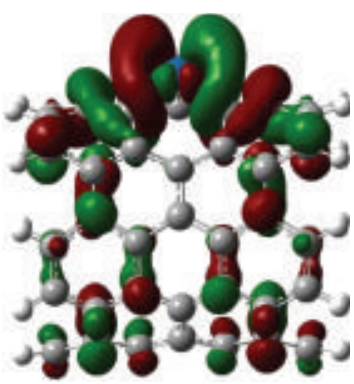

$\mathrm{LUMO}+2(-2.94 \mathrm{eV})$

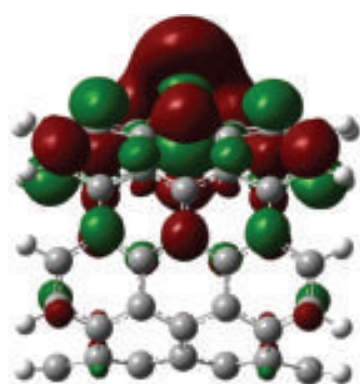

$\operatorname{HOMO}(-4.08 \mathrm{eV})$

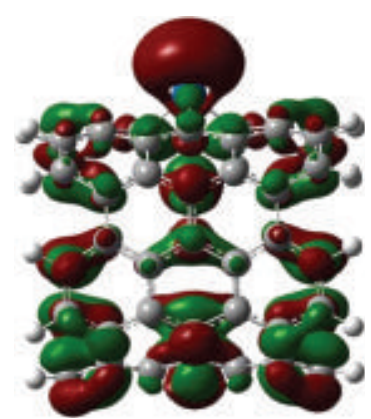

$\mathrm{LUMO}+3(-2.67 \mathrm{eV})$

Figure 16: Relevant MOs for ground-state $\mathrm{C}_{69} \mathrm{H}_{20} \mathrm{Pt}$. Orbital energies are in parentheses [114].

through DFT. We examined all possible trimethylplatinum species of formulae $\mathrm{PtMe}_{3}(\mathrm{CO})_{x}{ }^{n+}$ with $x$ between 0 and 3 and $n$ ranging from -3 to 1 (Figure 21 and Table 4).

Based on the observed geometry and partial charge analysis (with a positive charge of 0.83 on the parent Ptdoped SWCNT), we chose $\mathrm{PtMe}_{3}(\mathrm{CO})_{x}{ }^{+}$for comparison purposes. Interestingly, triple adsorption was possible in this case. The limitation of double adsorption for the nanotube is thus likely a combination of steric and electronic factors. Namely, due to the bulk of the supramolecular framework and a HOMO with decreased electron density in the vicinity of the $\mathrm{Pt}$ atom, adsorption of a third molecule of $\mathrm{CO}$ onto a $(\underline{\mathrm{CO}})_{2}$-adsorbed HSWCNT was not possible (Figure 22).

\subsection{End-On Adsorption of Nitrogen-Based Gases: Nitrogen} Monoxide, Ammonia, and Dinitrogen. Having explored CO adsorption, we considered NO next (Figure 23). Nitrogen monoxide has a doublet ground state, and it is its radical character that dictates its role in biology [136]. Although Pt surfaces are known to interact with NO [188, 209-211], its use as a ligand for transition metal complexes is much less general (although the related $\mathrm{NO}^{+}$and $\mathrm{NO}^{-}$find widespread usage). Since the NO adsorbate has an unpaired electron, spin selection rules dictate that the resulting nanotubeadsorbate complex must also have an electronic state of doublet. We will denote the use of singlet ground-state Ptdoped SWCNT as a starting material as doublet-s, while the corresponding reaction of the triplet excited-state Ptdoped SWCNT will be termed doublet- $t$. Quartet states are also possible. In all cases examined, the quartet spin state had higher energy than the doublet states $(-46.97$ and $-56.49 \mathrm{kcal} / \mathrm{mol}$ for doublet- $s$ and doublet- $t$, respectively) [113]. The Pt center now bears a charge of 0.99 , while the $\mathrm{N}$ atom exhibits a charge of -0.21 and the $\mathrm{O}$ atom, -0.18 . The HOMO-LUMO gap increased to $0.84 \mathrm{eV}$. Multiple adsorption was also considered, but geometry optimization revealed that the interaction of two molecules of $\mathrm{NO}$ with the HSWCNT occurred in an unsymmetrical fashion. In this case, one of the $\mathrm{O}$ atoms of the adsorbates clearly points away from the nanotube (Figure 23). Adsorption of three NO molecules was not considered.

Another small molecule we investigated was $\mathrm{NH}_{3}$, a common stabilizing ligand for a number of Pt complexes [212214 ], including the famous chemotherapy drug cisplatin (i.e., $\left.\left(\mathrm{H}_{3} \mathrm{~N}\right)_{2} \mathrm{PtCl}_{2}\right)$. Heterogeneous $\mathrm{Pt}$ surfaces have also been shown to interact with this gas in the industrial oxidation of $\mathrm{NH}_{3}$ to $\mathrm{NO}$ in the first step of nitric acid production [215]. Unlike CO and NO, however, there is no low-lying $\pi^{*}$ orbital for backbonding to occur. Our optimized geometry of an $\mathrm{NH}_{3}$-adsorbed HSWCNT revealed that the adsorption energy was $-31.79 \mathrm{kcal} / \mathrm{mol}$ and the HOMO-LUMO gap was $0.73 \mathrm{eV}$. The coordination of ammonia, however, appears to be weaker since the distance from $\mathrm{Pt}$ to $\mathrm{N}$ was $2.25 \AA$ (Figure 20). A partial charge analysis revealed that a negative charge of -1.13 resided on the $\mathrm{N}$ atom, while positive charges of 0.44 were present on each of the $\mathrm{H}$ atoms in $\mathrm{NH}_{3}$ and a net charge of 0.19 . Overall, this implies that a net $\sigma$-donation appears to be occurring from the adsorbate to the SWCNT. Biadsorption of $\mathrm{NH}_{3}$ onto the Pt atom of this HSWCNT was possible with an energy change of $-57.10 \mathrm{kcal} / \mathrm{mol}$ 


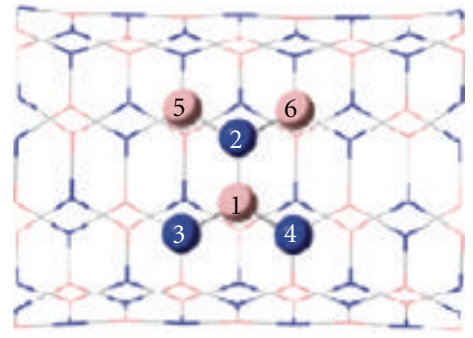

(a) Pristine $(5,5)$ BNNT

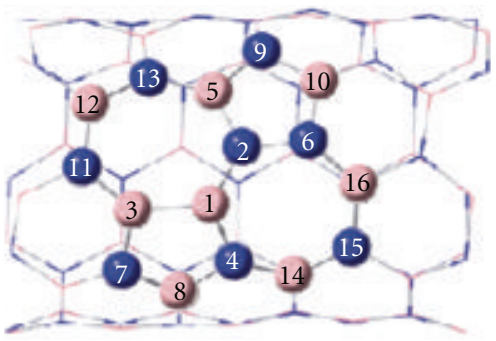

(d) Type-1 Stone-Wales (SW1)

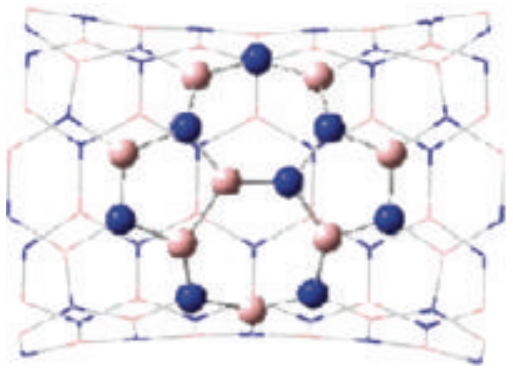

(g) Type-2 Stone-Wales (SW2)

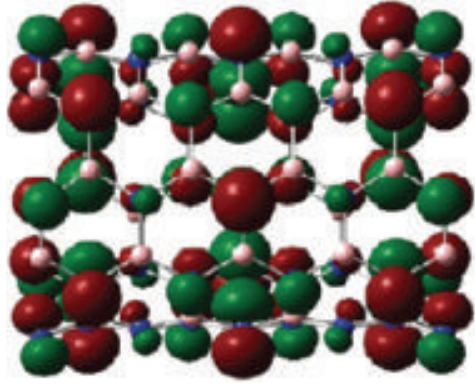

(b) $\mathrm{HOMO}(-6.64 \mathrm{eV})$

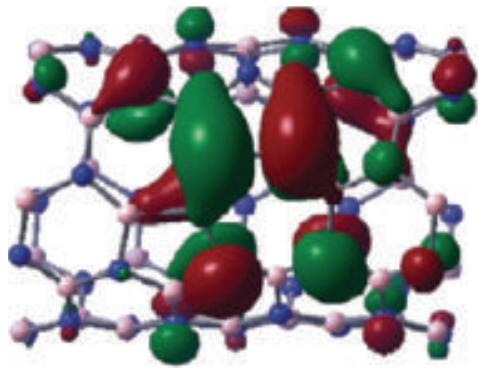

(e) $\operatorname{HOMO}(-6.29 \mathrm{eV})$

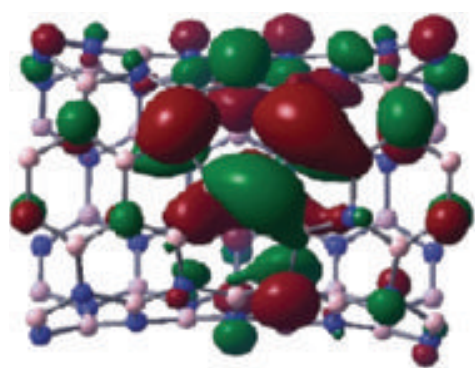

(h) $\operatorname{HOMO}(-6.3 \mathrm{eV})$

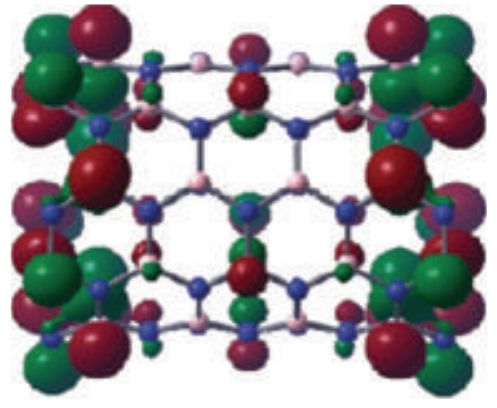

(c) LUMO $(-0.62 \mathrm{eV})$

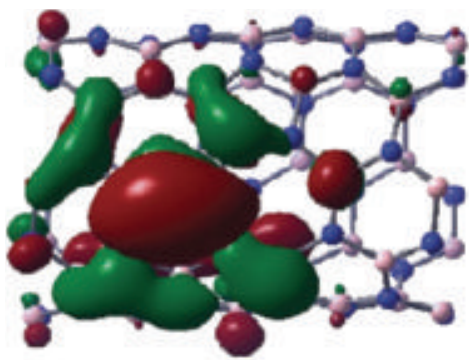

(f) $\operatorname{LUMO}(-1.31 \mathrm{eV})$

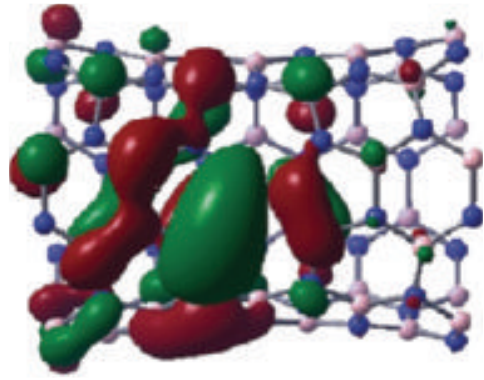

(i) $\operatorname{LUMO}(-1.11 \mathrm{eV})$

FIGURE 17: Optimized geometries of pristine, SW1-defective, and SW2-defective $\mathrm{B}_{45} \mathrm{~N}_{45} \mathrm{H}_{20}$ and their relevant FMOs. Orbital energies are in parentheses [200]. Legend: pink = boron, navy blue = nitrogen.

(28.5 kcal $/ \mathrm{mol}$ per NO molecule). In agreement with the observation for $(\mathbf{C O})_{2}$-adsorbed HSWCNTs, the energy released per molecule decreased presumably because of increased steric effects.

We then turned our attention to adsorbates that have no inherent polarity. If our Pt-doped nanotubes will be applied as nanosensors for gases [148, 150-152, 154], expansion of the scope to simple and unpolarized small molecules is critical. Additionally, activation of unfunctionalized molecules may be important for catalytic applications. $\mathrm{N}_{2}$, in particular, has been the focus of much attention due to its role in the industrial fixation of nitrogen via the Haber-Bosch process [216]. Productive interaction between a transition metal and $\mathrm{N}_{2}$ can take place via two orientations, namely, end-on binding (with the $\mathrm{N}$ atom acting as a $\sigma$-donor to the metal), which typically requires the metal to be low valent [217], and side-on binding [218]. To our surprise, the structures of Pt-doped SWCNTs with either end-on or side-on binding of $\mathrm{N}_{2}$ converged to give a geometry with an end-on-binding motif. The energy released upon this adsorption was much less than the corresponding number for $\mathrm{CO}$ adsorption $(-24.72 \mathrm{kcal} / \mathrm{mol})$. This is not unexpected since the adsorbate is largely nonpolar in character and does not exhibit any natural electrostatic attractive forces to the positively charged $\mathrm{Pt}$ center. The observed $\mathrm{N} \equiv \mathrm{N}$ distance was lengthened only slightly from $1.15 \AA$ in the free gas to $1.16 \AA$ in this complex (Figure 20). Interestingly, the net charge on the $\mathrm{N}_{2}$ molecule was -0.14 , which signifies a net donation of electrons from the Pt atom to the oncoming ligand. We were able to identify a doubly adsorbed complex as in the case of $\mathrm{CO}$ and NO. In this scenario, though, the energy released per molecule of $\mathrm{N}_{2}(-21.96 \mathrm{kcal} / \mathrm{mol})$ was much closer to that of single adsorption $(-24.72 \mathrm{kcal} / \mathrm{mol})$. One possible explanation for this observation is that the weaker interaction between Pt and the adsorbate results in a smaller steric repulsion between the two $\mathrm{N}_{2}$ molecules. The calculated HOMO-LUMO gap for this complex was $0.81 \mathrm{eV}$. 


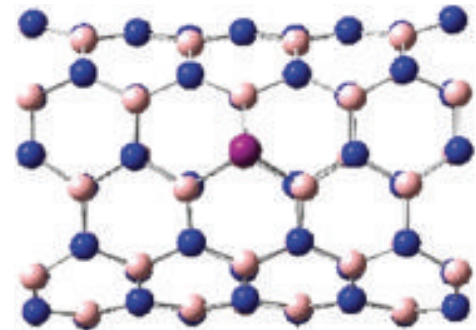

(a) $\mathrm{B}_{45} \mathrm{~N}_{44} \mathrm{H}_{20} \mathrm{Pt}$

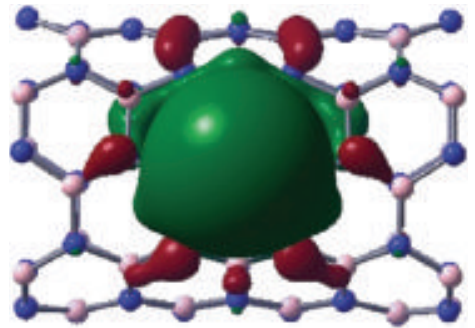

(b) $\alpha$-spin $\operatorname{HOMO}(-3.67 \mathrm{eV})$

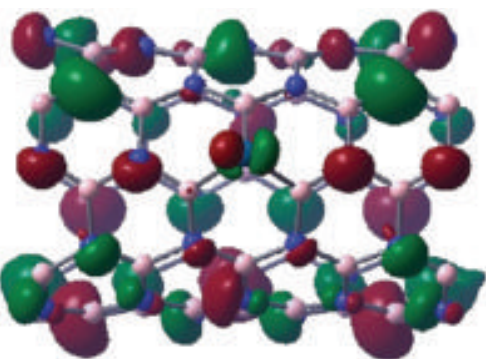

(d) $\beta$-spin $\operatorname{HOMO}(-6.72 \mathrm{eV})$

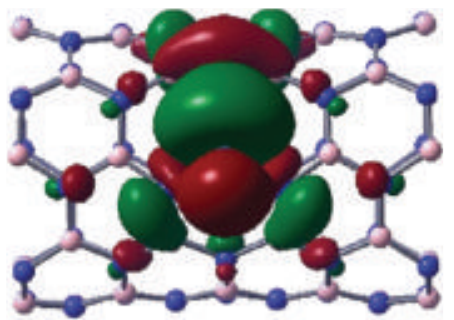

(g) $\alpha$-spin HOMO $(-5.58 \mathrm{eV})$

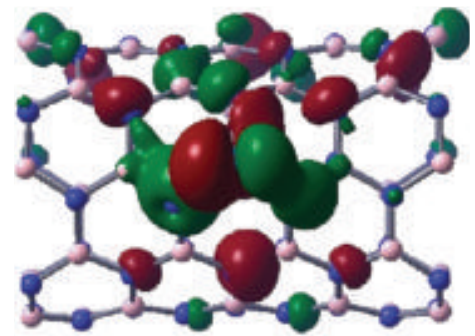

(i) $\beta$-spin HOMO $(-6.49 \mathrm{eV})$

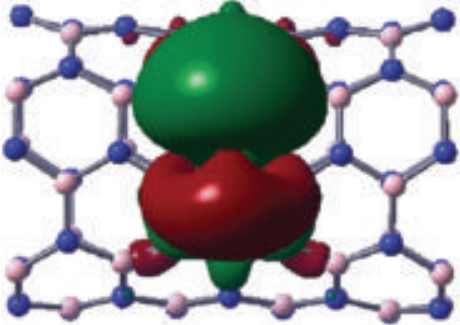

(c) $\alpha$-spin LUMO $(-1.74 \mathrm{eV})$

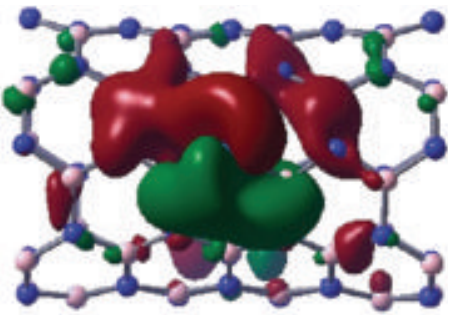

(e) $\beta$-spin LUMO $(-1.94 \mathrm{eV})$

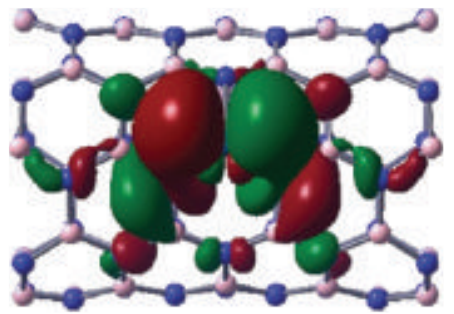

(h) $\alpha$-spin LUMO $(-3.72 \mathrm{eV})$

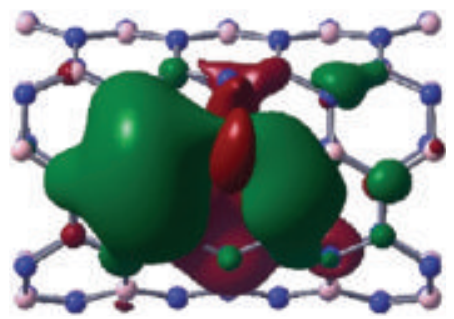

(j) $\beta$-spin LUMO $(-3.43 \mathrm{eV})$

FIgURE 18: Optimized geometries of Pt-doped BNNT resulting from N-substitution (i.e., $\mathrm{B}_{45} \mathrm{~N}_{44} \mathrm{H}_{20} \mathrm{Pt}$ ) and B-substitution (i.e., $\mathrm{B}_{44} \mathrm{~N}_{45} \mathrm{H}_{20} \mathrm{Pt}$ ) and their relevant FMOs. Orbital energies are in parentheses [200]. Legend: pink = boron, navy blue = nitrogen, dark pink = platinum.

3.4. Adsorption of Hydrogen Gas. It is clear that the incorporation of Pt into the sidewall of the SWCNT allows unique interactions with gases that are otherwise not possible. We decided to examine the possibility of side-on adsorption, first examining the interaction of a Pt-doped SWCNT with $\mathrm{H}_{2}$ (Figure 24 and Table 5). Indeed, activation of $\mathrm{H}_{2}$ with $\mathrm{Pt}$ has found tremendous application in organic synthesis with regard to the hydrogenation of alkenes and alkynes. Our Ptdoped SWCNT is unique in the sense that it sits between the two extremes of heterogeneous and homogeneous activation of small molecules.
Using the larger $\mathrm{C}_{169} \mathrm{Pt}$ nanorods capped with fullerenes as our model system, we initially found that the location of the Pt substitution had a drastic effect of the adsorption of $\mathrm{H}_{2}[35,36]$. In the case of both cap-doped HSWCNTs (i.e., $\mathrm{C}_{169} \mathrm{Pt}(\mathrm{ce})$ and $\mathrm{C}_{169} \mathrm{Pt}(\mathrm{c})$ ), the net process appeared to be physisorption, with a relatively weak interaction between the Pt atom and the adsorbate. Only approximately $2.0 \mathrm{kcal} / \mathrm{mol}$ of energy was released. Additionally, the $\mathrm{H}-\mathrm{H}$ bond distance was not significantly altered from that of free $\mathrm{H}_{2}$ in these cases. However, we were surprised to find that $\mathrm{C}_{169} \mathrm{Pt}(\mathrm{w})$ was able to interact strongly with $\mathrm{H}_{2}$ and induce chemisorptions. 

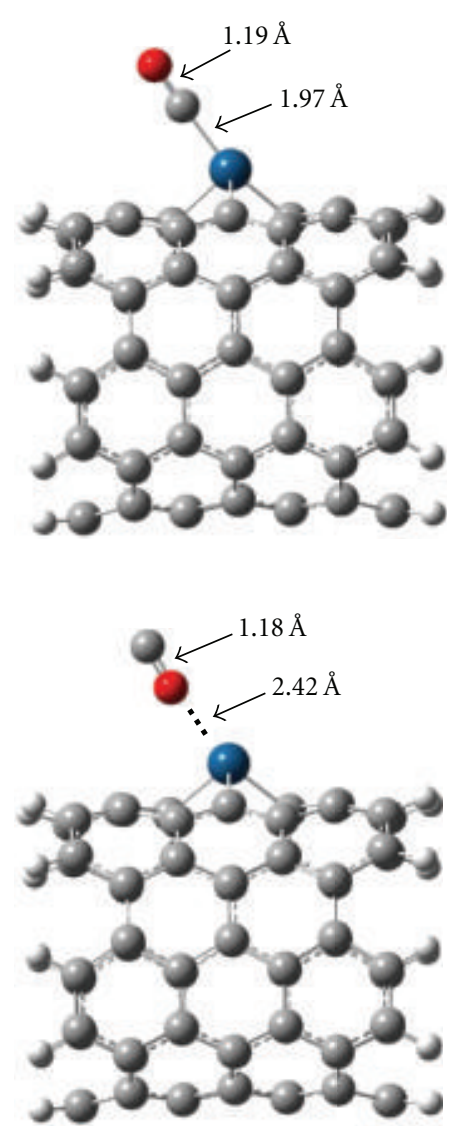

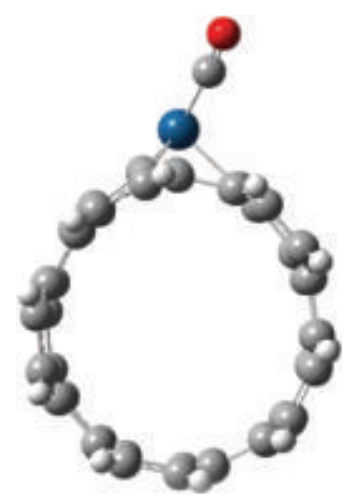

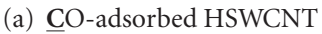

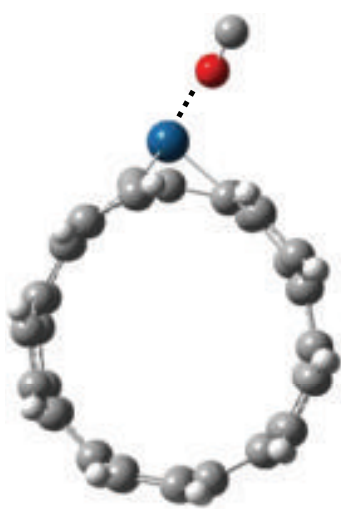

(b) $\underline{\text { OC-adsorbed HSWCNT }}$
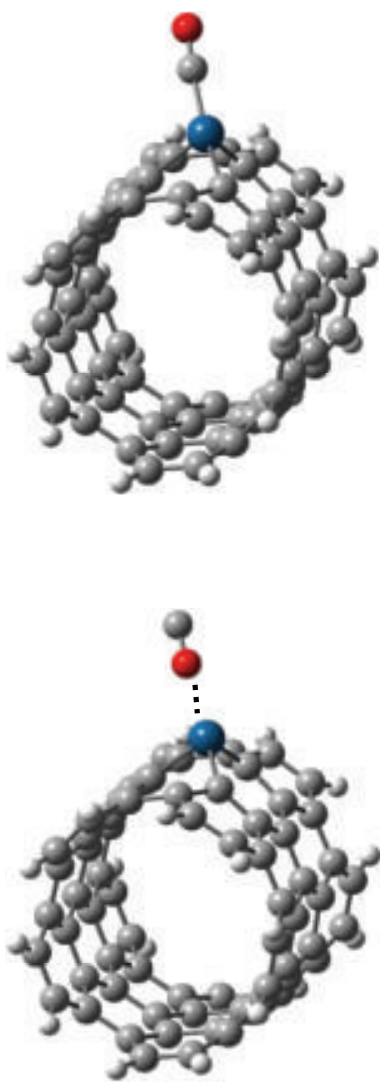

FIGURE 19: Optimized geometries for the adsorption of CO onto a Pt-doped SWCNT. From left to right, these are views perpendicular to the nanotube axis, along the axis, and a 3D perspective [114]. Legend: dark grey = carbon, light grey $=$ hydrogen, red $=$ oxygen, blue $=$ platinum.

In this reaction, a formal oxidative addition of the Pt center is taking place via hemolytic $\mathrm{H}-\mathrm{H}$ cleavage. The energy released for this process was close to $10.0 \mathrm{kcal} / \mathrm{mol}$, almost five times that of physisorption on the cap-doped HSWCNTs. Here, the distance between the $\mathrm{H}$ atoms had increased to $1.70 \AA$.

In comparison, the smaller fragment $(5,5) \mathrm{C}_{69} \mathrm{H}_{20} \mathrm{Pt}$ nanotube segment also yielded a geometry similar to that observed for $\mathrm{C}_{169} \mathrm{Pt}(\mathrm{w})$ [113]. Chemisorption was again the result, and we observed a $2.16 \AA$ separation between the two $\mathrm{H}$ atoms. The energetic preference for this reaction was $-11.32 \mathrm{kcal} / \mathrm{mol}$ for the ground state. The HOMO-LUMO gap was $0.70 \mathrm{eV}$, and single-point calculations revealed a charge of 0.77 on the Pt atom and -0.34 on the adsorbate.

A related study on the isoelectronic Pt-doped BNNTs was also recently reported [208]. Li et al. demonstrate that up to three equivalents of $\mathrm{H}_{2}$ can undergo physisorption to the $\mathrm{Pt}$ center.

3.5. Adsorption of Ethylene. The hydrogenation of alkenes and alkynes using transition metals as an activator also typically requires an interaction of the substrate with the surface. The simplest two-carbon alkene is ethylene $\left(\mathrm{C}_{2} \mathrm{H}_{4}\right)$ and has been studied with regard with to physisorption and chemisorptions [219].
Again, with the larger Pt-doped nanorod models, physisorption was observed to occur with $\mathrm{Pt}-\mathrm{C}$ distances of approximately $2.30 \AA$. The strength of interaction as gauged by the length of the $\mathrm{C}=\mathrm{C}$ double bond suggests a weaker adsorption at the caps $\left(1.40 \AA\right.$ for $\mathrm{C}_{169} \mathrm{Pt}(\mathrm{ce}), 1.41 \AA$ for $\left.\mathrm{C}_{169} \mathrm{Pt}(\mathrm{c})\right)$ than the sidewall (1.42 $\AA$ for $\mathrm{C}_{169} \mathrm{Pt}(\mathrm{w})$ ). Nonetheless, the effect of transition metal coordination is clear, since the double bond is elongated from the $1.35 \AA$ bond distance observed in the free gas. A close analysis of the energy changes associated with the physisorption process reveals that $\mathrm{C}_{169} \mathrm{Pt}(\mathrm{w})$ has the strongest interaction with $\mathrm{C}_{2} \mathrm{H}_{4}[35$, 36]. These distances are in agreement with those reported for the adsorption of ethylene onto an Ir-doped fullerene [97].

We also confirmed that a molecule of $\mathrm{C}_{2} \mathrm{H}_{4}$ can interact with the $\mathrm{Pt}$ center of the $\mathrm{H}$-capped HSWCNT [113]. The amount of energy released, however, was only $-26.43 \mathrm{kcal} / \mathrm{mol}$ for the singlet electronic state, and the HOMO-LUMO gap increased to $0.88 \mathrm{eV}$. The observed $\mathrm{C}=\mathrm{C}$ distance was $1.43 \AA$ (Figure 24 and Table 5). A net negative charge of -0.25 on the adsorbate was found by NBO analysis.

3.6. Adsorption of Acetylene. Having completed the investigation of the adsorption of ethylene, we turned to acetylene $\left(\mathrm{C}_{2} \mathrm{H}_{2}\right)$, a small gas molecule that plays a significant role in 


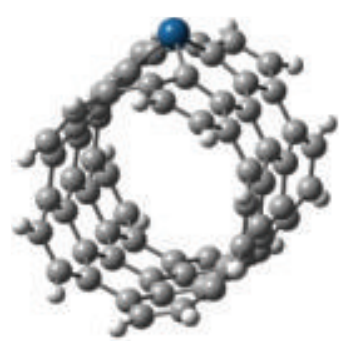

(a) Bare

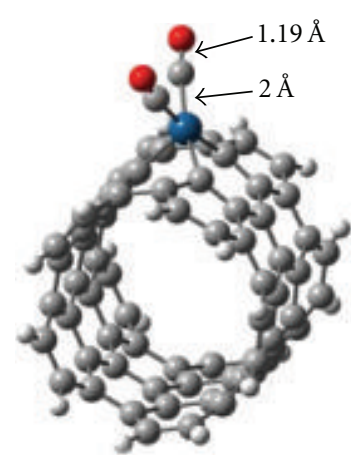

(d) $(\underline{\mathrm{CO}})_{2}$ adsorption

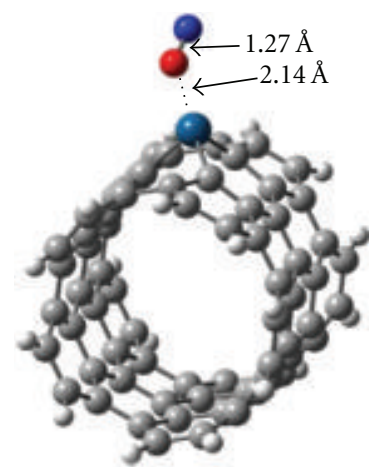

(g) $\underline{\mathrm{ON}}$ adsorption

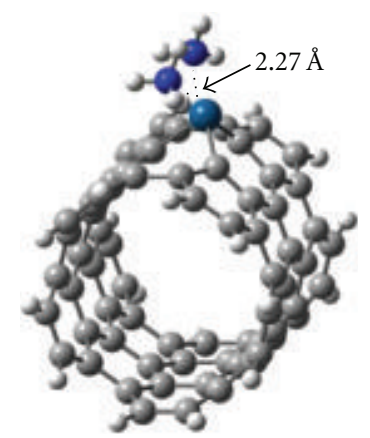

(j) $\left(\mathrm{NH}_{3}\right)_{2}$ adsorption

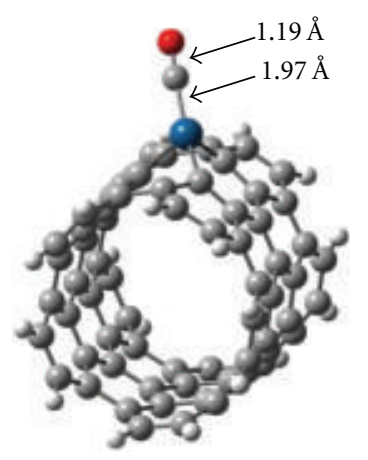

(b) $\underline{\mathrm{CO}}$ adsorption

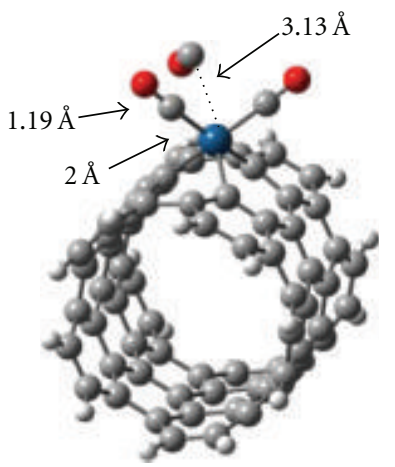

(e) $(\underline{\mathrm{CO}})_{3}$ adsorption

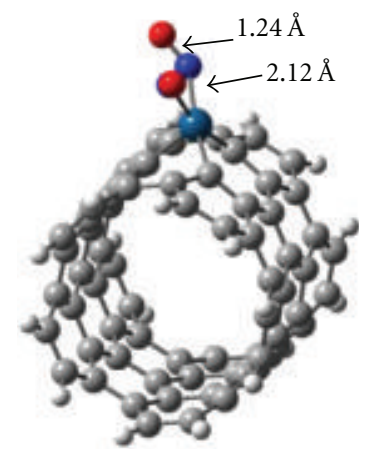

(h) $(\underline{\mathrm{NO}})_{2}$ adsorption

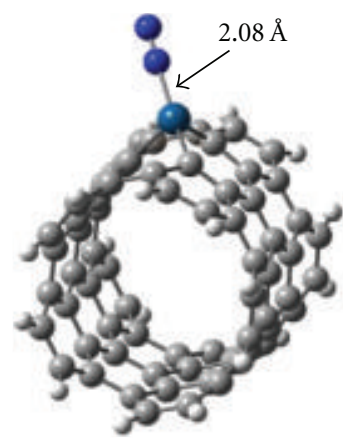

(k) $\mathrm{N}_{2}$ adsorption

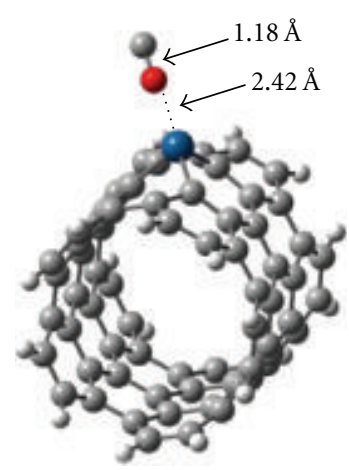

(c) $\underline{\mathbf{O C}}$ adsorption

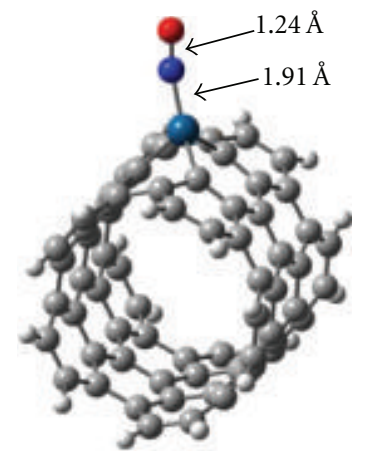

(f) $\underline{\mathrm{NO}}$ adsorption

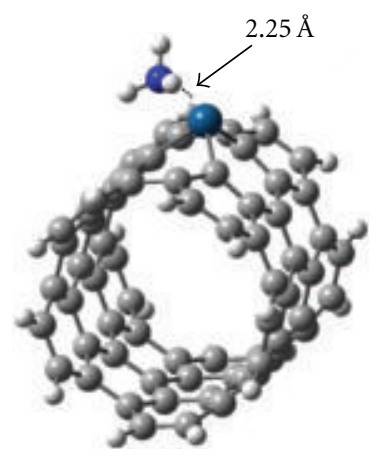

(i) $\mathrm{NH}_{3}$ adsorption

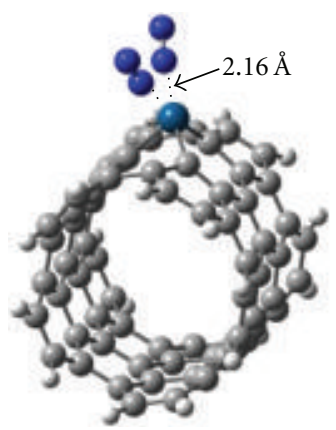

(l) $\left(\mathrm{N}_{2}\right)_{2}$ adsorption

FIGURE 20: Optimized geometries for end-on adsorbed HSWCNTs [114]. Legend: dark grey $=$ carbon, light grey $=$ oxygen, navy blue $=$ nitrogen, red = oxygen, blue = platinum. 
TABLE 3: Binding energy and geometrical data for nanotube-adsorbate complexes $\mathrm{C}_{69} \mathrm{H}_{20} \mathrm{Pt}(\mathrm{XY})$ with end-on binding motif [114] .

\begin{tabular}{|c|c|c|c|c|c|c|c|}
\hline Adsorbate & Spin state & $\Delta E^{\mathrm{a}}$ & $d(\mathrm{PtX})^{\mathrm{b}}$ & $d(\mathrm{XY})^{\mathrm{c}}$ & $q(\mathrm{Pt})^{\mathrm{d}}$ & $q(\mathrm{XY})^{\mathrm{e}}$ & $q(\mathrm{C})^{\mathrm{f}}$ \\
\hline \multirow{2}{*}{ None $^{g}$} & Singlet & 0 & N/A & N/A & 0.82 & N/A & -0.41 \\
\hline & Triplet & 0 & N/A & N/A & 0.84 & N/A & -0.49 \\
\hline \multirow{2}{*}{$\underline{\mathrm{CO}}^{\mathrm{g}, \mathrm{h}}$} & Singlet & -41.23 & 1.97 & 1.19 & 0.85 & -0.12 & -0.43 \\
\hline & Triplet & -33.09 & 1.96 & 1.20 & 0.83 & -0.15 & -0.46 \\
\hline \multirow{2}{*}{$\underline{\mathbf{O}}^{\mathrm{g}, \mathrm{h}}$} & Singlet & -6.98 & 2.42 & 1.18 & 0.87 & -0.02 & -0.41 \\
\hline & Triplet & -6.78 & 2.35 & 1.19 & 0.88 & -0.06 & -0.45 \\
\hline \multirow{2}{*}{$(\underline{\mathrm{CO}})_{2}^{\mathrm{g}, \mathrm{h}}$} & Singlet & -73.67 & $2.00,2.00$ & $1.19,1.19$ & 0.83 & $-0.05,-0.05$ & -0.49 \\
\hline & Triplet & -58.95 & $2.00,2.00$ & $1.19,1.19$ & 0.78 & $-0.02,-0.02$ & -0.49 \\
\hline \multirow{2}{*}{$(\underline{\mathrm{CO}})_{3}{ }^{\mathrm{h}}$} & Singlet & -71.35 & $1.98,2.00,3.13$ & $1.19,1.19,1.19$ & 0.77 & $0.01,-0.01,-0.06$ & -0.37 \\
\hline & Triplet & -73.74 & $2.03,2.03,2.41$ & $1.18,1.18,1.19$ & 0.76 & $0.05,0.05,-0.13$ & -0.46 \\
\hline \multirow{3}{*}{$\underline{N O}^{h}$} & Doublet-s & -46.97 & 1.91 & 1.24 & 0.99 & -0.39 & -0.39 \\
\hline & Doublet- $t$ & -56.49 & 1.91 & 1.24 & 0.99 & -0.39 & -0.39 \\
\hline & Quartet & -46.17 & 2.00 & 1.25 & 0.95 & -0.38 & -0.34 \\
\hline \multirow{3}{*}{$\underline{\mathrm{O}} \mathrm{N}^{\mathrm{h}}$} & Doublet-s & -23.18 & 2.14 & 1.27 & 0.98 & -0.37 & -0.34 \\
\hline & Doublet- $t$ & -32.71 & 2.14 & 1.27 & 0.98 & -0.37 & -0.34 \\
\hline & Quartet & -29.99 & 2.12 & 1.29 & 1.00 & -0.44 & -0.33 \\
\hline \multirow{2}{*}{$(\underline{\mathrm{NO}})_{2}{ }^{\mathrm{h}}$} & Singlet & -69.94 & $2.10,2.12$ & $1.24,1.24$ & 0.99 & $-0.24,-0.28$ & -0.36 \\
\hline & Triplet & -77.75 & $2.12,2.12$ & $1.24,1.24$ & 0.99 & $-0.25,-0.25$ & -0.35 \\
\hline \multirow{2}{*}{$\underline{\mathrm{NH}}_{3}{ }^{\mathrm{i}}$} & Singlet & -31.79 & 2.25 & N/A & 0.88 & 0.18 & -0.44 \\
\hline & Triplet & -31.28 & 2.23 & N/A & 0.87 & 0.18 & -0.50 \\
\hline \multirow{2}{*}{$\left(\underline{\mathbf{N H}}_{3}\right)_{2}{ }^{\mathrm{i}}$} & Singlet & -57.10 & $2.27,2.27$ & N/A & 0.92 & $0.18,0.18$ & -0.48 \\
\hline & Triplet & -55.30 & $2.26,2.26$ & N/A & 0.86 & $0.19,0.19$ & -0.49 \\
\hline \multirow{2}{*}{$\mathrm{N}_{2}$} & Singlet & -24.72 & 2.08 & 1.16 & 0.91 & -0.14 & -0.41 \\
\hline & Triplet & -25.90 & 2.05 & 1.16 & 0.91 & -0.18 & -0.44 \\
\hline \multirow{2}{*}{$\left(\mathrm{N}_{2}\right)_{2}{ }^{\mathrm{i}}$} & Singlet & -43.91 & $2.16,2.16$ & $1.16,1.16$ & 0.93 & $-0.09,-0.09$ & -0.42 \\
\hline & Triplet & -41.68 & $2.16,2.16$ & $1.16,1.16$ & 0.89 & $-0.09,-0.09$ & -0.41 \\
\hline
\end{tabular}

${ }^{\mathrm{a}}$ Total stabilization energy (in $\mathrm{kcal} / \mathrm{mol}$ )

${ }^{b}$ Distance (in $\AA$ ) between Pt and X of XY.

${ }^{\mathrm{c}}$ Distance (in $\AA$ ) between X and Y of XY.

${ }^{\mathrm{d}}$ Partial charge on Pt.

eNet partial charge on XY.

${ }^{\mathrm{f}}$ Net partial charge on the $\mathrm{C}$ atoms of the SWCNT adjacent to Pt.

$\mathrm{g}[20]$.

$\mathrm{h}(\underline{\mathrm{XY}})_{n}$ refers to an $n \mathrm{X}$-end adsorbed HSWCNT fragment.

${ }^{\mathrm{i}}$ End-on adsorption.

the chemical industry $[191,192]$. In fact, the utilization of Pt surfaces for catalytic hydrogenation is known as an efficient strategy for the production of ethane [192, 220, 221]. Alkynes have also been shown to interact with transition metals both through weak donation of $\pi$-electrons of the adsorbate to the metal. In some circumstances, stronger interactions that result in the oxidative addition of the transition metal can liberate a metallocyclopropene organometallic complex.

We only considered the $(5,5) \mathrm{Pt}$-doped SWCNT segment capped with $\mathrm{H}$ atoms for this investigation [113]. We found that the adsorption of $\mathrm{C}_{2} \mathrm{H}_{2}$ resulted in the liberation of $31.36 \mathrm{kcal} / \mathrm{mol}$ of energy for the ground state configuration and lengthened the $\mathrm{C} \equiv \mathrm{C}$ distance from $1.23 \AA$ in the free gas to $1.32 \AA$ (Figure 24 and Table 5). The HOMO-LUMO gap was similar to ethylene adsorption at $0.88 \mathrm{eV}$. A net charge of -0.38 was detected for the alkyne adsorbate, while the $\mathrm{Pt}$ center bore a charge of 0.98 . The separation between the $\mathrm{Pt}$ atom and either $\mathrm{C}$ atoms was approximately $2.15 \AA$. Based on these evidences, we can safely conclude that the chemical reaction of acetylene with a Pt-doped SWCNT results in the generation of a metallocyclopropene via a chemisorptive process. Furthermore, the terminal $\mathrm{C}-\mathrm{H}$ bonds are no longer colinear with the $\mathrm{C} \equiv \mathrm{C}$ bond but instead are bent. The adsorption process hence induces a rehybridization of the $\mathrm{C}$ atoms from $s p$ to almost $s p^{2}$.

\section{Catalytic Applications of Metal-Doped SWCNTs}

4.1. Lewis Acidity of Pt-Doped SWCNTs. Our previous work on Pt-doped SWCNTs revealed that these substitutionally doped nanostructures exhibit certain electronic similarities to alkylplatinum complexes such as $\mathrm{PtMe}_{3}{ }^{+}$[114]. We hence considered the use of HSWCNTs as Lewis acid 
TABle 4: Data for model alkylplatinum and nanotube-adsorbate complexes [114].

\begin{tabular}{|c|c|c|c|c|c|c|}
\hline Species & $\Delta E^{\mathrm{a}}$ & $d(\mathrm{PtC})^{\mathrm{b}}$ & $d(\mathrm{CO})^{\mathrm{c}}$ & $q(\mathrm{Pt})^{\mathrm{d}}$ & $q(\mathrm{CO})^{\mathrm{e}}$ & $q(\mathrm{C})^{\mathrm{f}}$ \\
\hline $\mathrm{PtMe}_{3}{ }^{+}$ & 0 & & & 0.83 & & -2.13 \\
\hline $\mathrm{PtMe}_{3}(\mathrm{CO})^{+}$ & -28.11 & 2.04 & 1.17 & 0.84 & 0.09 & -2.22 \\
\hline $\mathrm{PtMe}_{3}(\mathrm{CO})_{2}^{+}$ & -55.41 & $2.05,2.05$ & $1.17,1.17$ & 0.79 & $0.14,0.14$ & -2.34 \\
\hline $\mathrm{PtMe}_{3}(\mathrm{CO})_{3}^{+}$ & -81.90 & $2.05,2.05,2.05$ & $1.17,1.17,1.17$ & 0.74 & $0.17,0.17,0.17$ & -2.47 \\
\hline $\mathrm{PtMe}_{3}$ & 0 & & & 0.60 & & -2.63 \\
\hline $\mathrm{PtMe}_{3}(\mathrm{CO})$ & -41.19 & 1.93 & 1.19 & 0.68 & -0.05 & -2.71 \\
\hline $\mathrm{PtMe}_{3}(\mathrm{CO})_{2}$ & -63.47 & $1.96,1.96$ & $1.19,1.19$ & 0.75 & $-0.05,-0.05$ & -2.70 \\
\hline $\mathrm{PtMe}_{3}(\mathrm{CO})_{3}$ & -70.64 & $1.98,1.98,2.40$ & $1.19,1.19,1.20$ & 0.75 & $0.00,0.00,-0.17$ & -2.65 \\
\hline $\mathrm{PtMe}_{3}{ }^{-}$ & 0 & & & 0.31 & & -3.01 \\
\hline $\mathrm{PtMe}_{3}(\mathrm{CO})^{-}$ & -64.41 & 1.87 & 1.21 & 0.53 & -0.17 & -3.18 \\
\hline $\mathrm{PtMe}_{3}(\mathrm{CO})_{2}^{-}$ & -67.27 & $1.91,1.92$ & $1.21,1.22$ & 0.77 & $-0.25,-0.35$ & -3.03 \\
\hline $\mathrm{PtMe}_{3}(\mathrm{CO})_{3}^{-}$ & -77.30 & $1.92,1.93,2.97$ & $1.20,1.21,1.21$ & 0.76 & $-0.27,-0.22,-0.22$ & -2.94 \\
\hline $\mathrm{PtMe}_{3}{ }^{2-}$ & 0 & & & -0.48 & & -3.10 \\
\hline $\mathrm{PtMe}_{3}(\mathrm{CO})^{2-}$ & -66.81 & 1.88 & 1.23 & -0.15 & -0.40 & -3.20 \\
\hline $\mathrm{PtMe}_{3}(\mathrm{CO})_{2}^{2-}$ & -86.15 & $1.91,2.03$ & $1.25,1.25$ & 0.65 & $-0.55,-0.56$ & -3.24 \\
\hline $\mathrm{PtMe}_{3}(\mathrm{CO})_{3}{ }^{2-}$ & -107.55 & $1.98,2.00,2.72$ & $1.23,1.24,1.24$ & 0.65 & $-0.43,-0.44,-0.45$ & -3.11 \\
\hline $\mathrm{PtMe}_{3}{ }^{3-}$ & 0 & & & -1.57 & & -3.02 \\
\hline $\mathrm{PtMe}_{3}(\mathrm{CO})^{3-}$ & -71.74 & 1.88 & 1.23 & -1.12 & -0.38 & -3.19 \\
\hline $\mathrm{PtMe}_{3}(\mathrm{CO})_{2}^{3-}$ & -93.82 & $1.91,2.08$ & $1.26,1.26$ & 0.08 & $-0.60,-0.73$ & -3.36 \\
\hline $\mathrm{PtMe}_{3}(\mathrm{CO})_{3}{ }^{3-}$ & -130.61 & $2.14,2.15,2.15$ & $1.25,1.26,1.26$ & 0.21 & $-0.55,-0.55,-0.55$ & -3.25 \\
\hline Pt-doped SWCNT ${ }^{g}$ & 0 & & & 0.82 & & -0.41 \\
\hline$\underline{\text { CO-adsorbed HSWCNTg }}$ & -41.23 & 1.97 & 1.19 & 0.85 & -0.12 & -0.43 \\
\hline$(\underline{\mathrm{CO}})_{2}$-adsorbed HSWCNT ${ }^{\mathrm{g}}$ & -73.67 & $2.00,2.00$ & $1.19,1.19$ & 0.83 & $-0.05,-0.05$ & -0.49 \\
\hline
\end{tabular}

${ }^{\mathrm{a}}$ Total stabilization energy (in $\mathrm{kcal} / \mathrm{mol}$ ).

${ }^{b}$ Distance (in Å) between Pt and C of CO.

${ }^{c}$ Distance (in $\AA$ ) between $\mathrm{C}$ and O of CO.

dPartial charge on Pt.

${ }^{\mathrm{e}} \mathrm{Net}$ partial charge on CO.

${ }^{\mathrm{f}}$ Net partial charge on the $\mathrm{C}$ atoms adjacent to $\mathrm{Pt}$.

gSinglet.

TABLE 5: Binding energy and geometrical data for nanotube-adsorbate complexes $\mathrm{C}_{69} \mathrm{H}_{20} \mathrm{Pt}\left(\mathrm{X}_{2}\right)$ with side-on binding motif [113, 114].

\begin{tabular}{lcccccrrr}
\hline Adsorbate & $\mathrm{X}$ & Spin state & $\Delta E^{\mathrm{a}}$ & $d(\mathrm{PtX})^{\mathrm{b}}$ & $d(\mathrm{XX})^{\mathrm{c}}$ & $q(\mathrm{Pt})^{\mathrm{d}}$ & $q\left(\mathrm{X}_{2}\right)^{\mathrm{e}}$ & $q(\mathrm{C})^{\mathrm{f}}$ \\
\hline \multirow{2}{*}{ None } & $\mathrm{N} / \mathrm{A}$ & Singlet & 0 & N/A & N/A & 0.82 & N/A & -0.41 \\
& $\mathrm{~N} / \mathrm{A}$ & Triplet & 0 & N/A & N/A & 0.84 & N/A & -0.49 \\
\hline \multirow{2}{*}{$\mathrm{H}_{2}$} & $\mathrm{H}$ & Singlet & -11.32 & $1.66,1.68$ & 2.16 & 0.77 & -0.34 & -0.33 \\
& $\mathrm{H}$ & Triplet & -6.02 & $1.66,1.66$ & 2.19 & 0.74 & -0.34 & -0.43 \\
\hline \multirow{2}{*}{$\mathrm{C}_{2} \mathrm{H}_{4}$} & $\mathrm{CH}_{2}$ & Singlet & -26.43 & $2.31,2.20$ & 1.43 & 0.95 & -0.25 & -0.35 \\
& $\mathrm{CH}_{2}$ & Triplet & -24.74 & $2.31,2.30$ & 1.42 & 0.92 & -0.16 & -0.37 \\
\hline $\mathrm{C}_{2} \mathrm{H}_{2}$ & $\mathrm{CH}$ & Singlet & -31.36 & $2.13,2.10$ & 1.32 & 0.98 & -0.38 & -0.34 \\
& $\mathrm{CH}$ & Triplet & -25.29 & $2.17,2.15$ & 1.30 & 0.92 & -0.27 & -0.31 \\
\hline
\end{tabular}

${ }^{\mathrm{a}}$ Total stabilization energy (in $\mathrm{kcal} / \mathrm{mol}$ ).

${ }^{b}$ Distances (in $\AA$ ) between Pt and each X of $\mathrm{X}_{2}$.

${ }^{\mathrm{c}}$ Distance (in $\AA$ ) between $\mathrm{X}$ and $\mathrm{X}$ of $\mathrm{X}_{2}$.

dPartial charge on Pt.

${ }^{\mathrm{e}} \mathrm{Net}$ partial charge on $\mathrm{X}_{2}$.

${ }_{\mathrm{f}}$ Net partial charge on the $\mathrm{C}$ atoms of the SWCNT adjacent to Pt. 


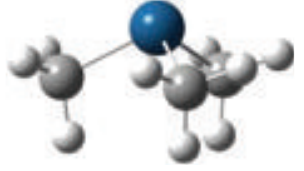

$\mathrm{PtMe}_{3}+$

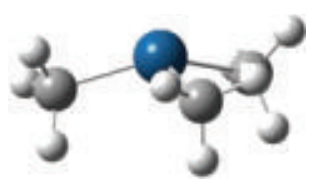

$\mathrm{PtMe}_{3}$

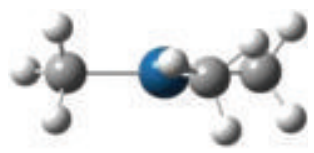

$\mathrm{PtMe}_{3}{ }^{-}$

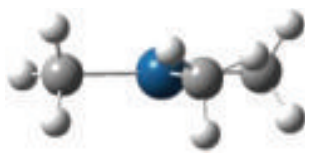

$\mathrm{PtMe}_{3}{ }^{2-}$

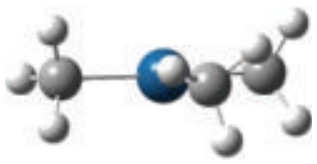

$\mathrm{PtMe}_{3}{ }^{3-}$

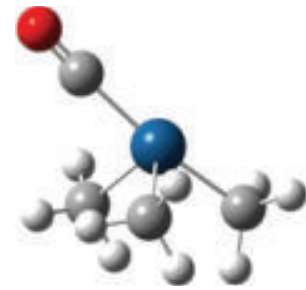

$\mathrm{PtMe}_{3} \mathrm{CO}^{+}$

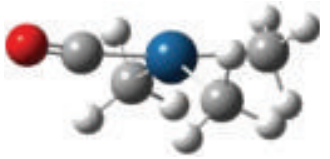

$\mathrm{PtMe}_{3} \mathrm{CO}$

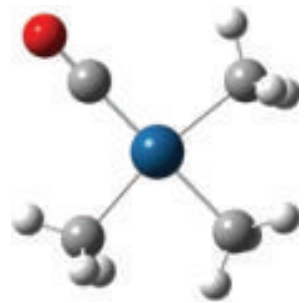

$\mathrm{PtMe}_{3} \mathrm{CO}^{-}$

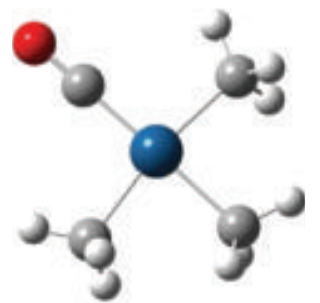

$\mathrm{PtMe}_{3} \mathrm{CO}^{2-}$

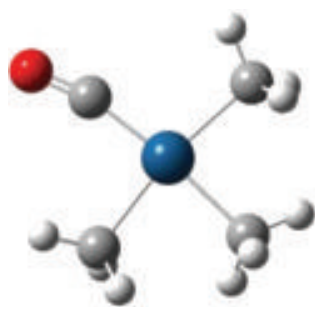

$\mathrm{PtMe}_{3} \mathrm{CO}^{3-}$

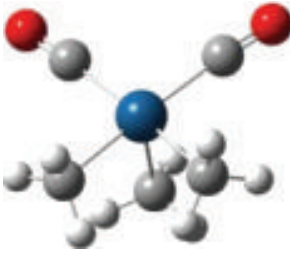

$\mathrm{PtMe}_{3}(\mathrm{CO})_{2}{ }^{+}$

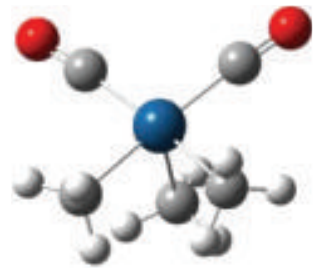

$\mathrm{PtMe}_{3}(\mathrm{CO})_{2}$

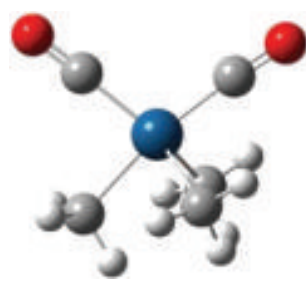

$\mathrm{PtMe}_{3}(\mathrm{CO})_{2}{ }^{-}$

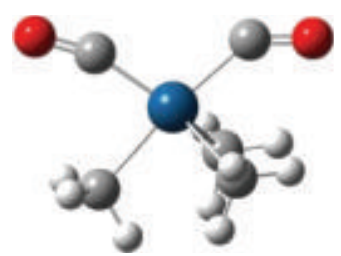

$\mathrm{PtMe}_{3}(\mathrm{CO})_{2}{ }^{2-}$

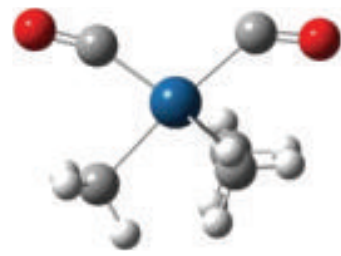

$\mathrm{PtMe}_{3}(\mathrm{CO})_{2}{ }^{3-}$

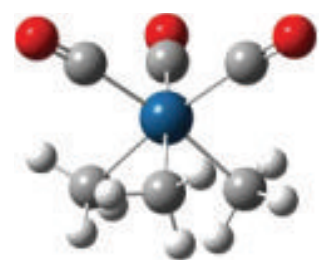

$\mathrm{PtMe}_{3}(\mathrm{CO})_{3}{ }^{+}$

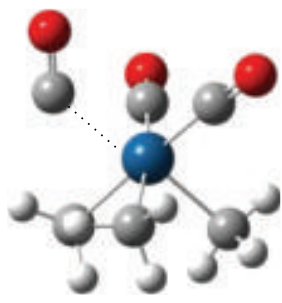

$\mathrm{PtMe}_{3}(\mathrm{CO})_{3}$

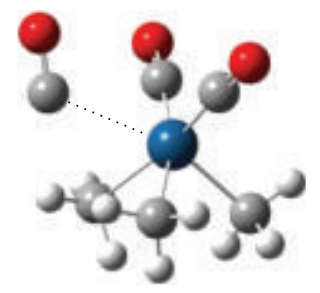

$\mathrm{PtMe}_{3}(\mathrm{CO})_{3}-$

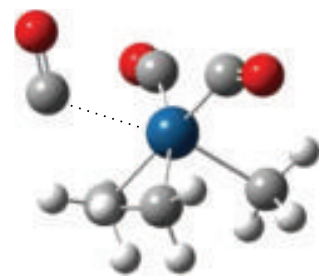

$\mathrm{PtMe}_{3}(\mathrm{CO})_{3}{ }^{2-}$

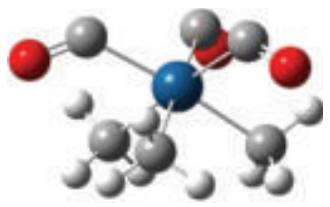

$\mathrm{PtMe}_{3}(\mathrm{CO})_{3}{ }^{3-}$

FIGURE 21: Optimized geometries of alkylplatinum model compounds [114]. Legend: dark grey = carbon, light grey $=$ carbon, red $=$ oxygen, blue $=$ platinum .

catalysts [45]. To evaluate Lewis acidity, we considered three main parameters. First, since $\mathrm{CO}$ is known to coordinate to $\mathrm{Pt}$ atoms, we performed vibrational analyses for the $\mathrm{C} \equiv \mathrm{O}$ stretch as an indicator for the level of backdonation from the metal center to the ligand. Second, the nuclear magnetic resonance (NMR) chemical shift $(\delta)$ of the olefinic $\mathrm{H}$ in the $\beta$ position of an $\alpha, \beta$-unsaturated carbonyl compound, maleic anhydride, was evaluated. This strategy was first pioneered 


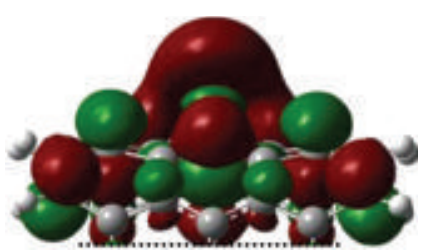

HOMO $(-4.08 \mathrm{eV})$

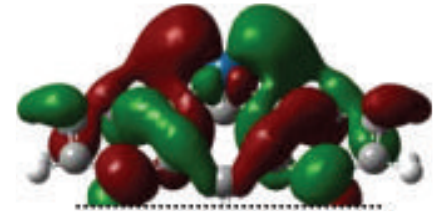

$\operatorname{LUMO}(-3.35 \mathrm{eV})$

(a) Pt-doped SWCNT

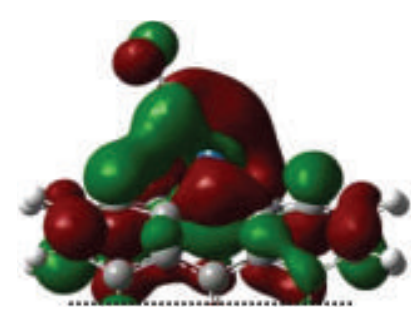

HOMO $(-4.33 \mathrm{eV})$

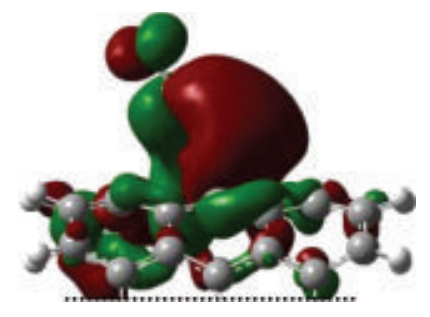

LUMO $(-3.75 \mathrm{eV})$

(c) CO-adsorbed Pt-doped SWCNT

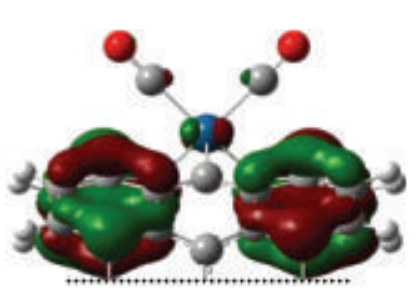

HOMO $(-4.43 \mathrm{eV})$

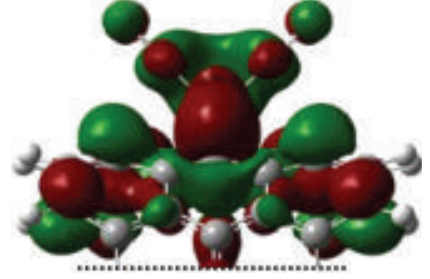

LUMO $(-3.66 \mathrm{eV})$

(e) $(\underline{\mathrm{CO}})_{2}$-adsorbed Pt-doped SWCNT

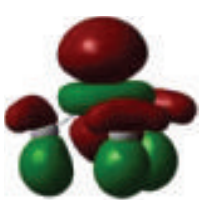

$\operatorname{HOMO}(-12.01 \mathrm{eV})$

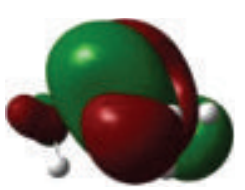

$\operatorname{LUMO}(-8.4 \mathrm{eV})$

(b) $\mathrm{PtMe}_{3}^{+}$

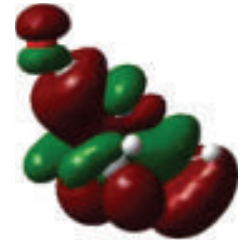

HOMO (-12.23 eV)

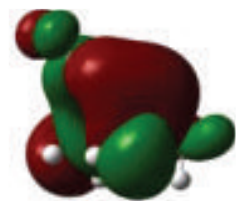

LUMO $(-8.9 \mathrm{eV})$

(d) $\mathrm{PtMe}_{3}(\mathrm{CO})^{+}$

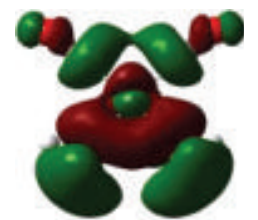

HOMO (-12.17 eV)

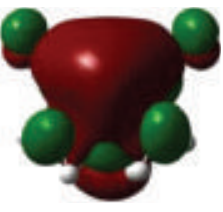

LUMO (-9 eV)

(f) $\mathrm{PtMe}_{3}(\mathrm{CO})_{2}{ }^{+}$

FIgure 22: FMOs for the alkylplatinum complexes and Pt-doped SWCNT. Orbital energies are in parentheses [114].

by Childs and coworkers [222, 223] as an experimental and theoretical method for determining Lewis acidity. Compared to the uncomplexed maleic anhydride (MA), Lewis acid coordination is expected to generate a positive downfield shift of the proton resonance at the $\beta$ position due to a deshielding effect (Figure 25). Hence, chemical shift difference $(\Delta \delta)$ is a direct measure of Lewis acidity. Third, we further envisioned that Pt-doped SWCNTs could also act as catalysts for the Diels-Alder reaction between maleic anhydride and cyclopentadiene (CPD), a [4+2] cycloaddition (Figure 26). This one-step reaction involves a concerted but asynchronous six-membered transition state via either an exo- or endo-pathways, generating two possible products, namely, the exo- and endo-adducts. We evaluated Lewis acidity based on rate enhancement, as well as selectivity between exo- and endo-products. Although subtle solvent effects have been noted in the literature [224-230], we did not consider these factors in our calculations.

To evaluate the Lewis acidity of Pt-doped SWCNTs, a series of model systems were considered, including $\mathrm{PtMe}_{3}{ }^{+}$, $\mathrm{PtPh}_{3}{ }^{+}$, Pt-doped phenaline, Pt-doped sumanene, Pt-doped corannulene, and Pt-doped $\mathrm{C}_{24}$ fullerene. Particularly, Ptdoped $\mathrm{C}_{24}$ fullerene can exist as either one of two isomers, namely, Pt-substitution at a pentagon-pentagon-pentagon junction (PPP isomer) or a hexagon-pentagon-pentagon junction (HPP isomer). As mentioned above, the cationic $\mathrm{PtMe}_{3}{ }^{+}$was observed to bear the most similarity to Pt-doped SWCNT in terms of geometry, localized charge, and ability to bind $\mathrm{CO}$ as a ligand [114]. The other model systems chosen for this investigation include aromatic ligands $\left(\mathrm{PtPh}_{3}{ }^{+}\right)$ and cyclic carbon frameworks. Buckybowl-type architectures $[231,232]$ are derived from smaller pieces of $\mathrm{C}_{60}$ fullerene, sumanene, and corannulene, respectively. The geometrically confined $\mathrm{C}_{24}$ skeleton was also explored as a means of studying the direct effect of curvature and $\pi$-conjugation on the Lewis acidity of Pt-doped SWCNTs.

We chose a segment from a $(5,0)$ Pt-doped SWCNT capped with ten $\mathrm{H}$ atoms with molecular formula $\mathrm{C}_{29} \mathrm{H}_{10} \mathrm{Pt}$. We obtained this structure via substitution of a single $\mathrm{C}$ atom in the middle of the segment with a Pt atom, followed by geometry optimization. Not surprisingly, bare $(5,0)$ Ptdoped SWCNTs exhibited a geometry similar to $(5,5)$ Ptdoped SWCNTs in which the Pt atom protrudes to the exterior of the nanotube sidewall (Figure 27) [45], likely because of the larger atomic radius of $\mathrm{Pt}$ and longer $\mathrm{Pt}-\mathrm{C}$ bonds $[113,114]$. The three neighboring $C$ atoms are arranged in 


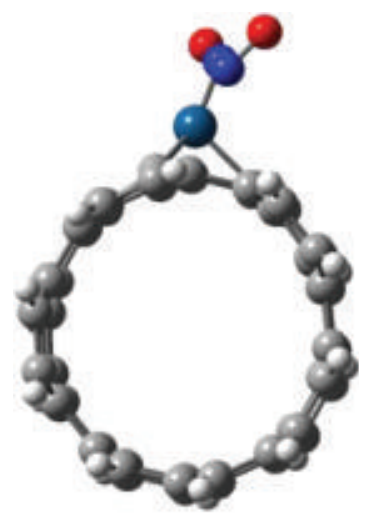

(a) Side view of $(\underline{\mathrm{NO}})_{2}$-adsorbed Pt-doped SWCNT perpendicular to the nanotype axis

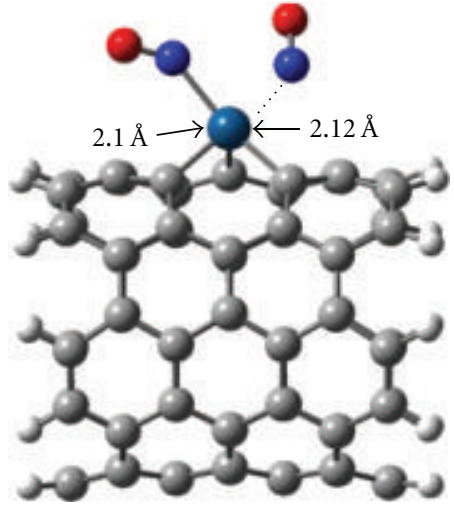

(b) Side view of $(\underline{\mathrm{NO}})_{2}$-adsorbed Ptdoped SWCNT perpendicular to the nanotype axis

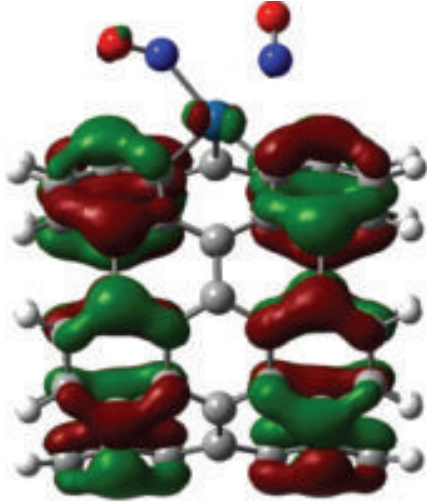

(c) $\operatorname{HOMO}(-4.55 \mathrm{eV})$

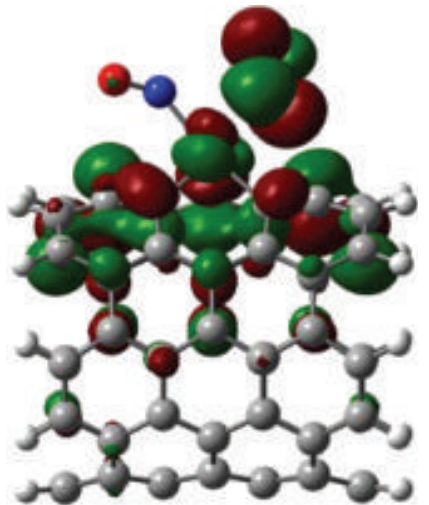

(d) $\operatorname{LUMO}(-3.82 \mathrm{eV})$

FIGURE 23: Optimized geometry of $(\underline{\mathrm{NO}})_{2}$-adsorbed HSWCNT. Orbital energies are in parentheses [113]. Legend: dark grey $=$ carbon, light grey $=$ hydrogen, navy blue $=$ nitrogen, red $=$ oxygen, blue $=$ platinum.

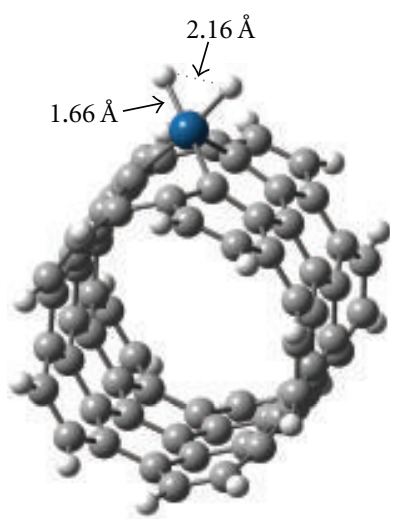

(a) $\mathrm{H}_{2}$ adsorption

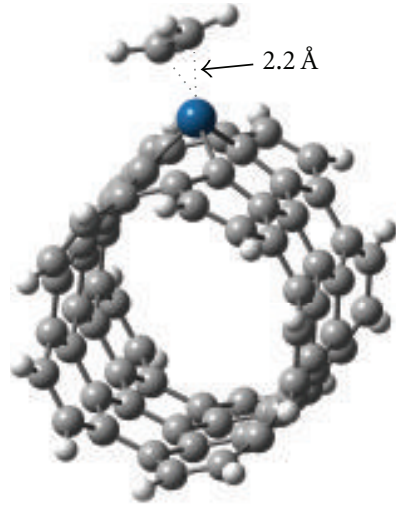

(b) $\mathrm{C}_{2} \mathrm{H}_{4}$ adsorption

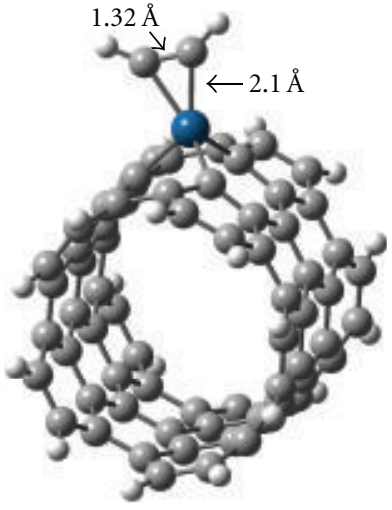

(c) $\mathrm{C}_{2} \mathrm{H}_{2}$ adsorption

FIGURE 24: Optimized geometries for side-on adsorbed HSWCNTs [113]. Legend: dark grey = carbon, light grey = hydrogen, blue = platinum .

a tripodal fashion around the pyramidalized Pt center and exhibit a significant deviation from planarity $\left(\sum=292.2^{\circ}\right.$, cf. $\Sigma=360^{\circ}$ for a planar hybridization scheme) [45]. $\mathrm{PtMe}_{3}{ }^{+}$and $\mathrm{PtPh}_{3}{ }^{+}$both display less pyramidalization, with $\Sigma=297.5^{\circ}$ and $315.4^{\circ}$, respectively. This is because the carbon ligands of these organometallic complexes are not tied back as in the case of the Pt-doped SWCNTs. The Pt-doped analog of phenaline, a segment derived from an idealized graphene sheet, exhibited high levels of buckling $\left(\sum=279.6^{\circ}\right)$. In contrast, the fullerene model systems, Ptdoped sumanene, Pt-doped corannulene, and Pt-doped $\mathrm{C}_{24}$ (PPP and HPP isomers), are all more highly pyramidalized than any of the other systems investigated (i.e., $\sum<270^{\circ}$ ) (Figure 28).

A brief analysis of the FMOs revealed a significant interaction between metal $d$ orbitals and the delocalized $\mathrm{C}$ framework that depended strongly on the $\pi$-curvature (Figure 29). Notably, the amount of electron density present on the Pt center is small in both Pt-doped fullerenes (HPP isomer) and SWCNTs in comparison to the other model complexes studied.
4.2. Evaluation of Lewis Acidity by Adsorption of CO. We decided to examine the coordination of $\mathrm{CO}$ via $\mathrm{C}$-adsorption to alkyl- and arylplatinum complexes as a gauge of Lewis acidity (vide supra). As mentioned previously, the binding of $\mathrm{CO}$ involves donation of the nonbonding $\sigma$ electrons of the $\mathrm{C}$ atom to the appropriate unoccupied metal $d$ orbital. This stimulates the metal center to backdonate electrons to the $\pi^{*}$ orbital of the adsorbate and causes weakening of the $\mathrm{C} \equiv \mathrm{O}$ bond [233-235]. Specifically, a lower $\mathrm{C} \equiv \mathrm{O}$ stretching frequency implies lower Lewis acidity, and vice versa. Our calculations confirm that binding of $\mathrm{CO}$ and the formation of organoplatinum- $\mathrm{CO}$ complexes are energetically favorable. Indeed, simple alkyl- and arylplatinum complexes have a tendency to deplete electron density from the adsorbate (Table 6). Surprisingly, the Pt-doped $(5,0)$ SWCNT model system demonstrated net donation of electron density from the $\mathrm{CO}$ molecule, contrasting our previous work that showed net backdonation in Pt-doped $(5,5)$ SWCNTs $[113,114]$.

By analysis of the vibrational frequencies of $\mathrm{CO}$ molecules bound to alkyl- and arylplatinum complexes, the predicted trend of Lewis acidity is as follows [45]: 
<smiles>CC1(C)C=CC(=O)OC1</smiles>

Maleic anhydride<smiles>CC1=CC(=O)OC1=O</smiles>

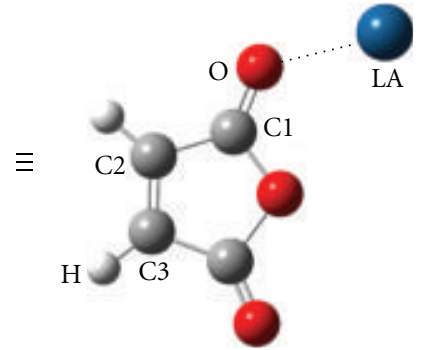

FIGURE 25: Chemical shift perturbation of $\beta$-H in maleic anhydride upon exposure to a Lewis acid (LA) [45].

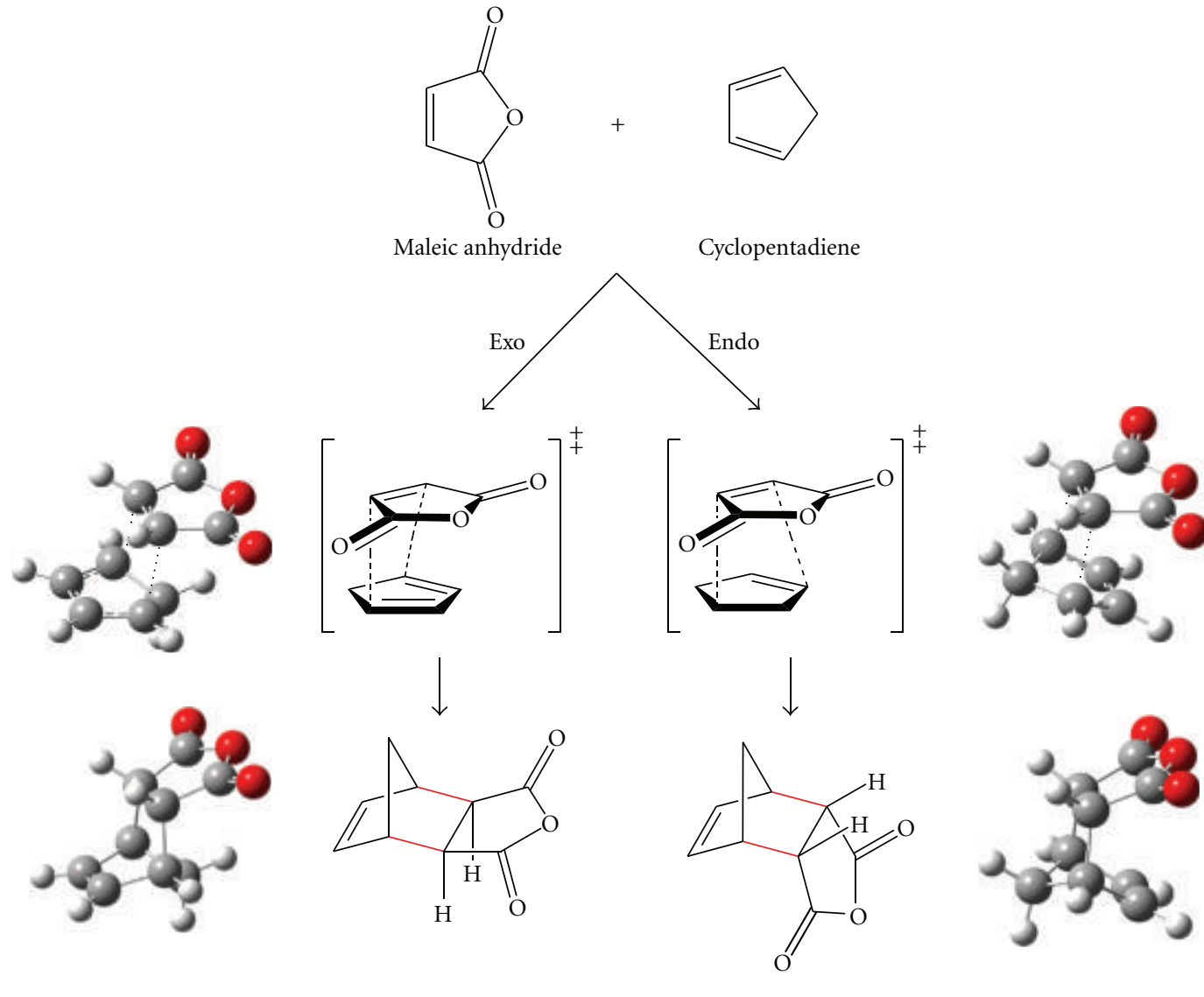

(b) Endo-product

FiguRE 26: Diels-Alder cycloaddition between maleic anhydride and cyclopentadiene by (a) exo- and (b) endo-transition states [45].

$(5,0)$ Pt-doped SWCNT $\sim$ Pt-doped corannulene $<$ Pt-doped $\mathrm{C}_{24}$ PPP isomer $<$ Pt-doped $\mathrm{C}_{24} \mathrm{HPP}$ isomer $<\mathrm{Pt}$-doped sumanene $<\mathrm{Pt}$-doped phenaline $<\mathrm{PtPh}_{3}{ }^{+}<\mathrm{PtMe}_{3}{ }^{+}$.

Overall, it appears that $(5,0)$ Pt-doped SWCNTs are most similar to fullerene models, Pt-doped corannulene, and Pt-doped $\mathrm{C}_{24}$, in their strong affinity for $\mathrm{CO}$. Although these particular organoplatinum models exhibit less positive charge buildup on the Pt atom than the others, the extended carbon frameworks and higher levels of $\pi$-conjugation seem to increase the ability to backbond to incoming ligands.
This leads to very tight Pt-CO interactions ( 2.00 ̊). Ptdoped phenaline appears to be more Lewis acidic $\left(\nu_{\mathrm{C} \equiv \mathrm{O}}\right.$ $=2050.3 \mathrm{~cm}^{-1}$ ) than the other arylplatinum complexes. In comparison to both Pt-doped nanotubes and fullerenes, this arylplatinum complex exhibits lower levels of $\pi$-curvature in the $\mathrm{C}$ backbone and increased levels of planarity. This observation implies that distortion of adjacent $p_{\pi}$ orbitals imposed by curvature decreases the effective Lewis acidity in Pt-doped supramolecular carbon frameworks. $\mathrm{PtMe}_{3}{ }^{+}$and $\mathrm{PtPh}_{3}{ }^{+}$exhibit the weakest interaction with $\mathrm{CO}$ molecules $(d(\mathrm{Pt}-\mathrm{C}) \sim 2.11 \AA)$, in agreement with the observation that decreased $\pi$-curvature and $\pi$-conjugation lead to an increase 


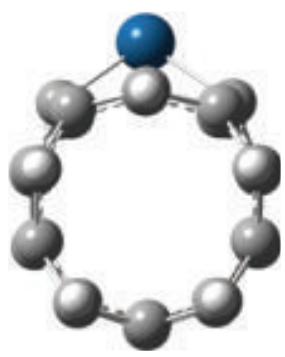

(a) Side view parallel to the nanotube axis

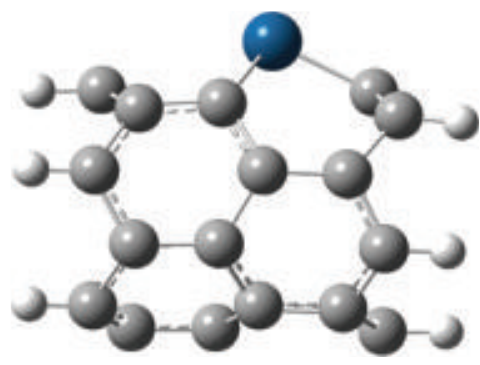

(b) Side view perpendicular to the nanotube axis

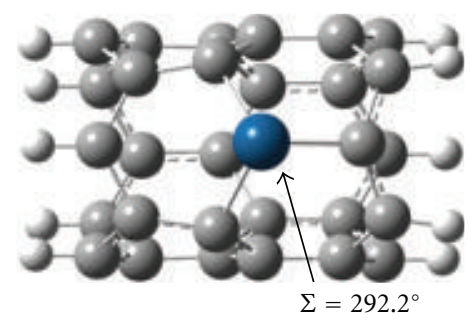

(c) Top view

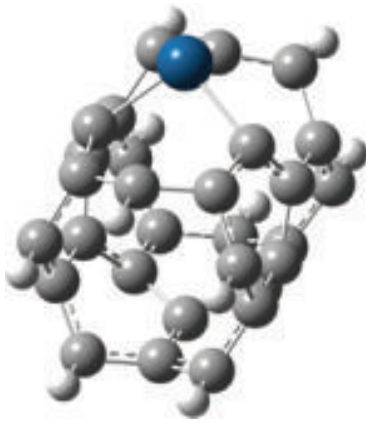

(d) $3 \mathrm{D}$ prerspective

Figure 27: Optimized geometry of model $(5,0)$ Pt-doped SWCNT segment [45]. Legend: dark grey $=$ carbon, light grey $=$ hydrogen, blue $=$ platinum.

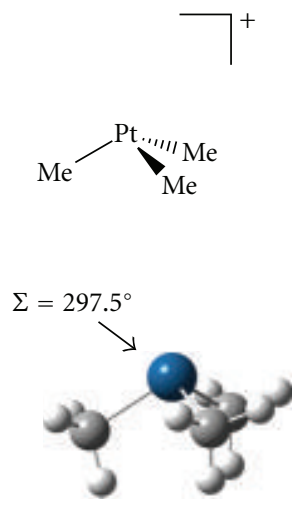

(a) $\mathrm{PtMe}_{3}^{+}$
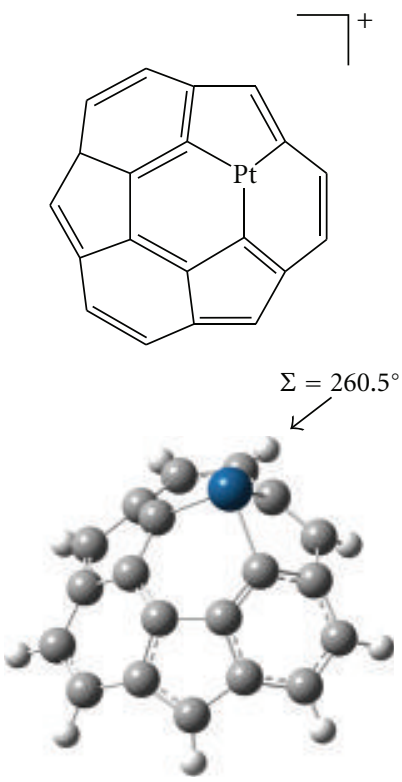

(d) Pt-doped sumanene

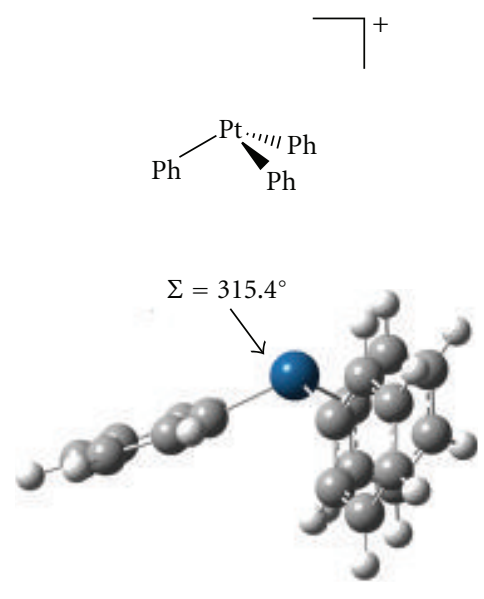

(b) $\mathrm{PtPh}_{3}^{+}$
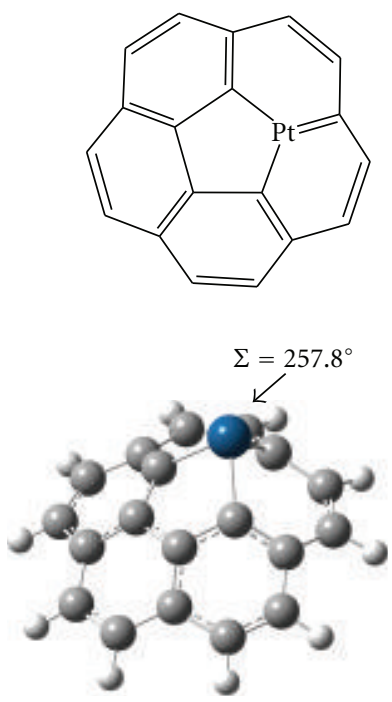

(e) Pt-doped corannulene
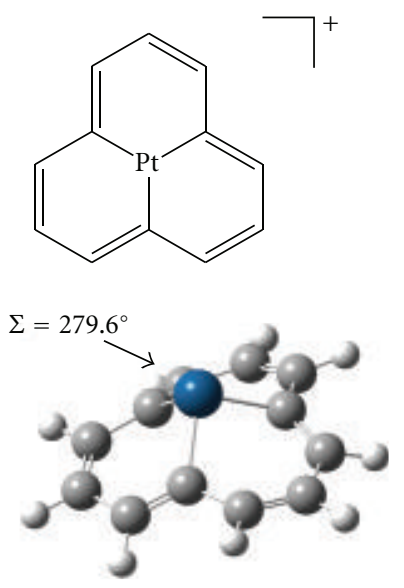

(c) Pt-doped phenaline
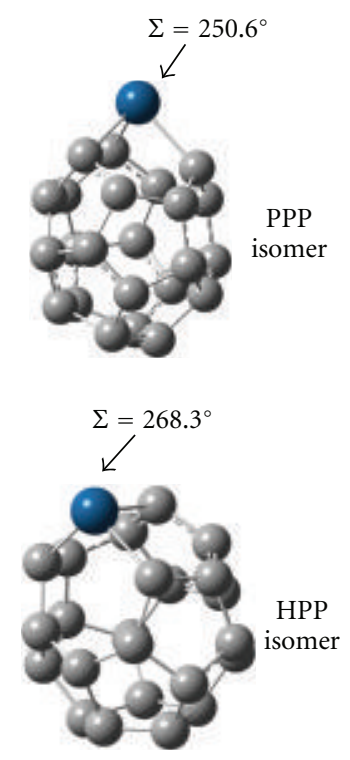

(f) Pt-doped $\mathrm{C}_{24}$ fullerene

FIGURE 28: Optimized geometries of model alkyl- and arylplatinum complexes [45]. 


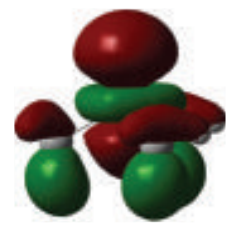

HOMO (-13.28 eV)

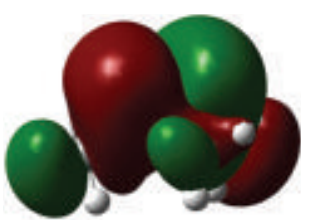

LUMO $(-7.78 \mathrm{eV})$

(a) $\mathrm{PtMe}_{3}{ }^{+}$

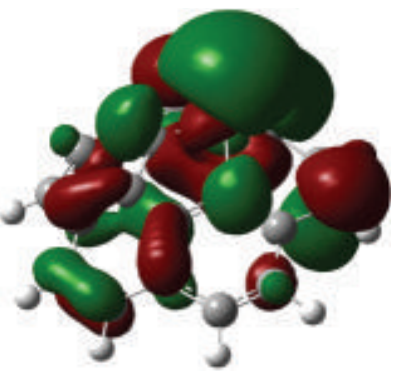

HOMO $(-4.28 \mathrm{eV})$

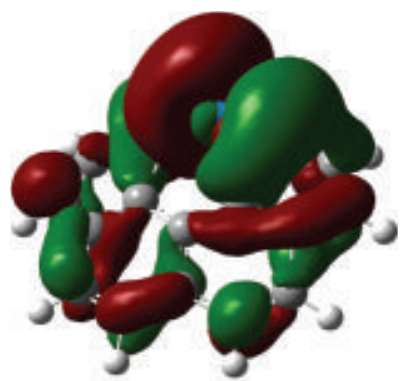

LUMO $(-2.32 \mathrm{eV})$

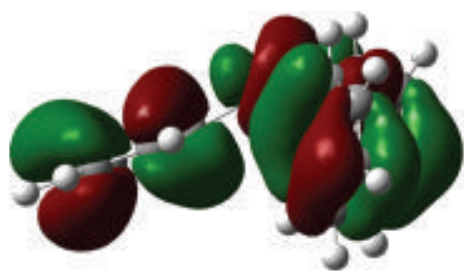

HOMO $(-10.5 \mathrm{eV})$

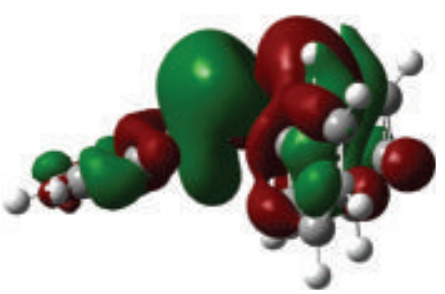

LUMO $(-6.77 \mathrm{eV})$

(b) $\mathrm{PtPh}_{3}{ }^{+}$

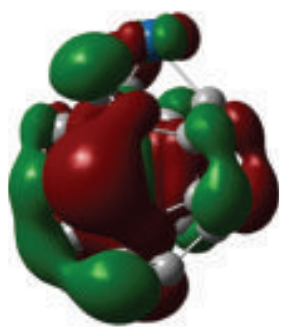

HOMO (-5.91 eV)

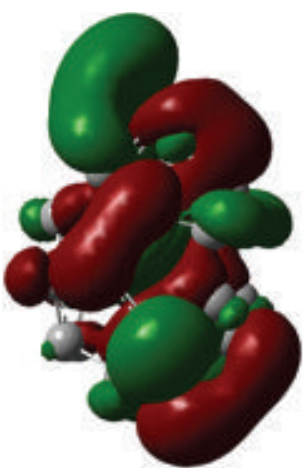

LUMO (-4.25 eV)

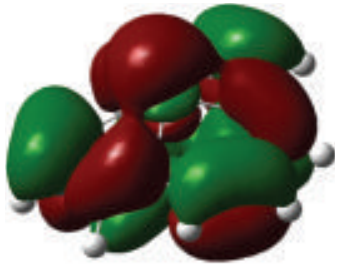

HOMO (-9.51 eV)

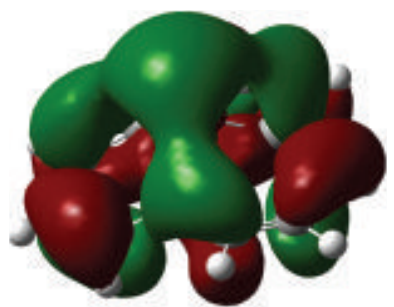

LUMO (-6.99 eV)

(c) Pt-doped phenaline

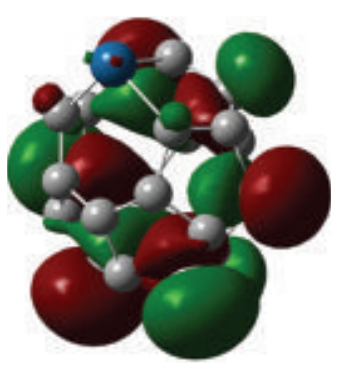

HOMO $(-5.93 \mathrm{eV})$

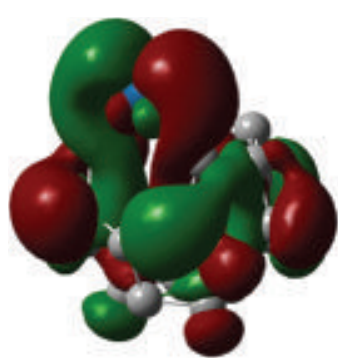

LUMO (-4.61 eV)

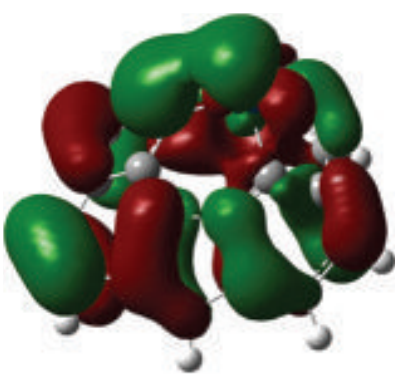

HOMO $(-8.93 \mathrm{eV})$

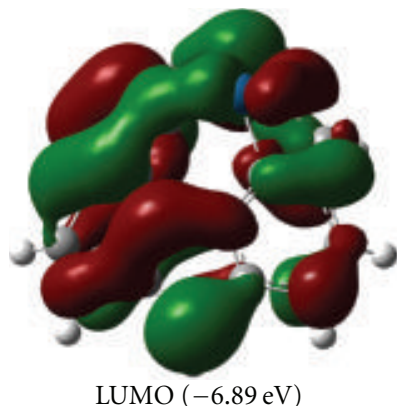

(d) Pt-doped sumanene
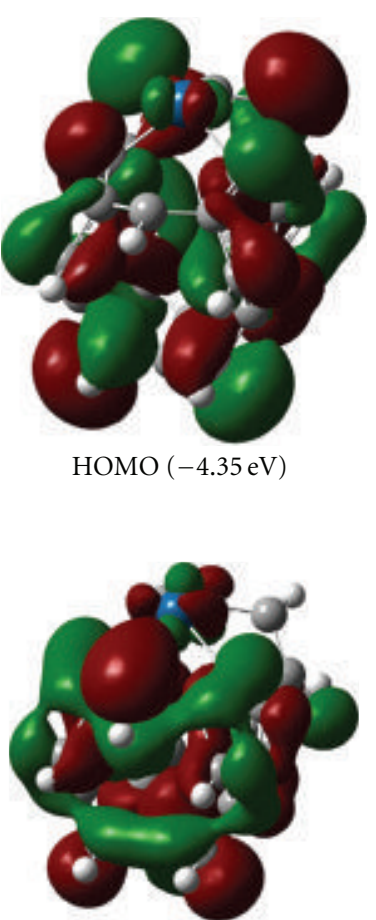

$\operatorname{LUMO}(-3.4 \mathrm{eV})$

(h) $(5,0)$ Pt-doped SWCNT

(e) Pt-doped corannulene

(f) Pt-doped $\mathrm{C}_{24}$ fullerene PPP isomer

(g) Pt-doped $\mathrm{C}_{24}$ fullerene HPP isomer

FIGURE 29: FMOs of model alkyl- and arylplatinum complexes, Pt-doped fullerene and SWCNT. Orbital energies are in parentheses [45].

in Lewis acidity and weaker backbonding. Based on this hypothesis, we expect that Pt-doped phenaline, $\mathrm{PtMe}_{3}{ }^{+}$, and $\mathrm{PtPh}_{3}{ }^{+}$should be superior to organoplatinum complexes with higher $\pi$-curvature in their ability to catalyze chemical reactions (vide infra).
4.3. Evaluation of Lewis Acidity by Complexation with Maleic Anhydride. In 1982, Childs and coworkers suggested a general method for evaluating Lewis acidity by NMR analysis of an $\alpha, \beta$-unsaturated carbonyl compound/Lewis acid complex $[222,223]$. Indeed, the chemical shift $\delta$ of the olefinic 


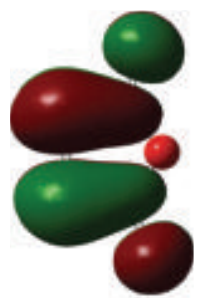

$\operatorname{LUMO}(-3.96 \mathrm{eV})$

(a) Maleic anhydride (MA)

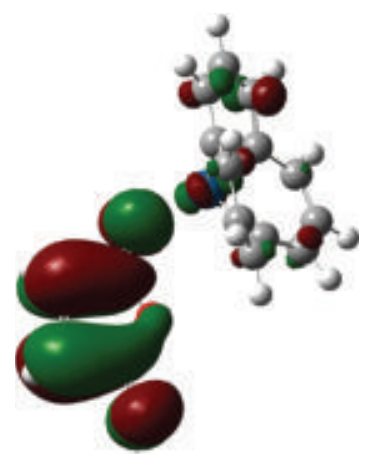

$\operatorname{LUMO}(-7.32 \mathrm{eV})$

(d) Pt-doped phenaline/MA

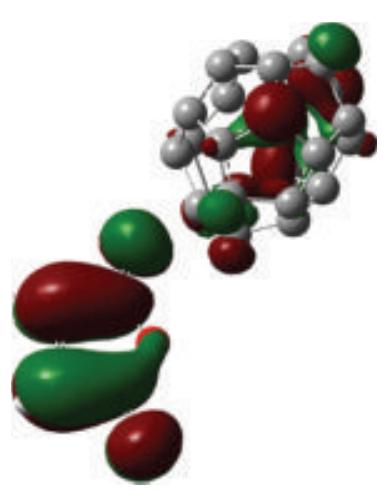

$\operatorname{LUMO}(-4.83 \mathrm{eV})$

(g) Pt-doped $\mathrm{C}_{24}$ fullerene PPP isomer/MA

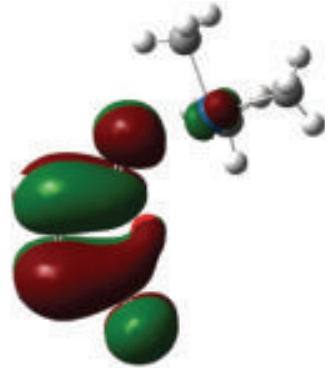

$\operatorname{LUMO}(-7.75 \mathrm{eV})$

(b) $\mathrm{PtMe}_{3}{ }^{+} / \mathrm{MA}$

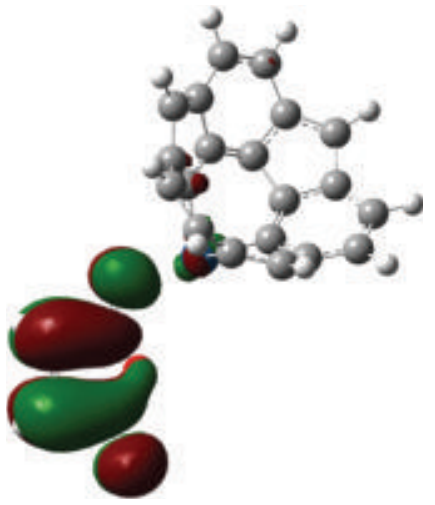

$\operatorname{LUMO}(-7.24 \mathrm{eV})$

(e) Pt-doped sumanene/MA

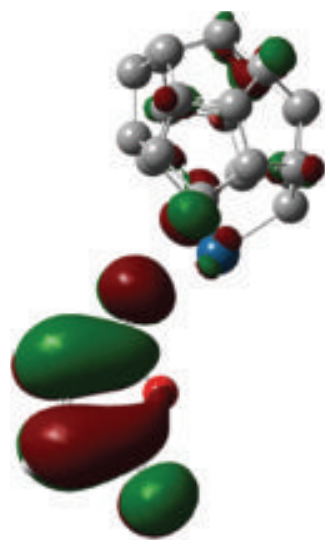

$\operatorname{LUMO}(-5.93 \mathrm{eV})$

(h) Pt-doped $\mathrm{C}_{24}$ fullerene HPP isomer/MA

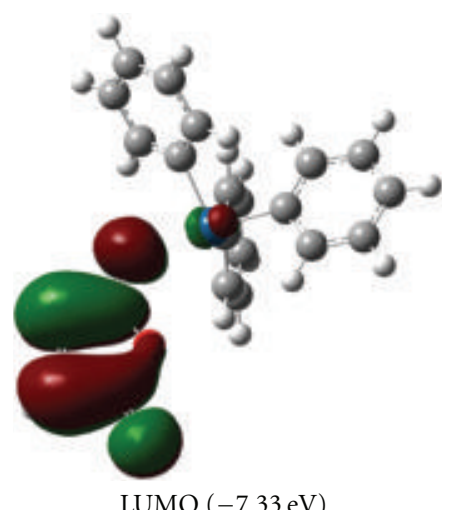

(c) $\mathrm{PtPh}_{3}{ }^{+} / \mathrm{MA}$

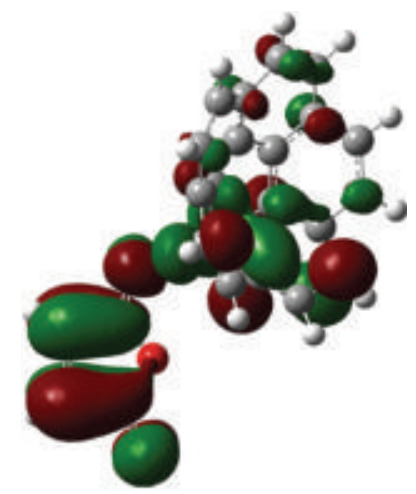

$\operatorname{LUMO}(-3.44 \mathrm{eV})$

(f) Pt-doped corannulene/MA

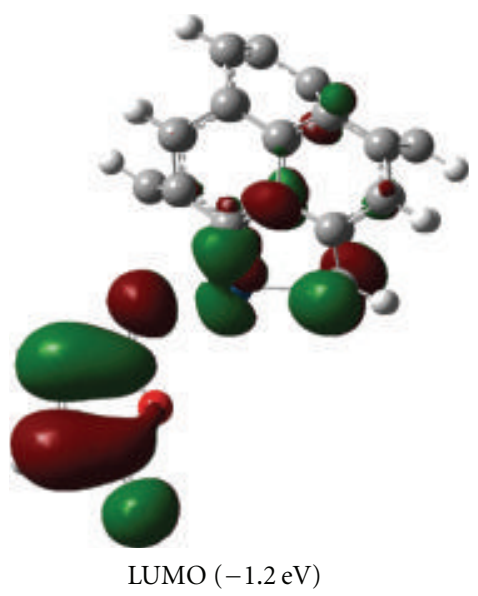

(i) $(5,0)$ Pt-doped SWCNT

Figure 30: LUMO of Lewis acid/maleic anhydride complexes. Orbital energies are in parentheses [45].

$\mathrm{H}$ in the $\beta$ position is expected to shift downfield (i.e., higher ppm). We also analyzed bond lengths as indirect measures of Lewis acidity, since a more Lewis acidic species should cause more significant weakening of the $\mathrm{C} 1=\mathrm{O}$ bond, strengthening of the $\mathrm{C} 1-\mathrm{C} 2$ bond, and weakening of the $\mathrm{C} 2=\mathrm{C} 3$ bond (i.e., the bond between the $\alpha$ and $\beta$ carbon atoms).
Our calculations confirmed that complexation between maleic anhydride and Lewis acids typically causes a downfield shift of the $\beta-\mathrm{H}^{1} \mathrm{H}$ NMR signal (Table 7) [45]. Surprisingly, $(5,0)$ Pt-doped SWCNT and Pt-doped corannulene result in a decreased chemical shift of the $\beta-\mathrm{H}$, implying that the charge-separated resonance structure (Figure 25) is less important than in the free maleic anhydride molecule. 


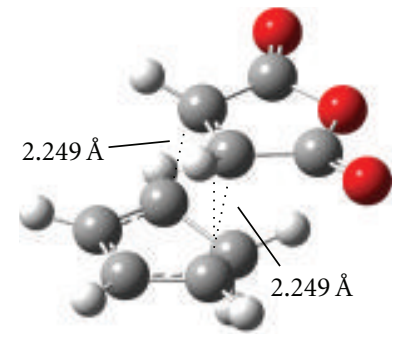

(a) Transition state leading to exo-product

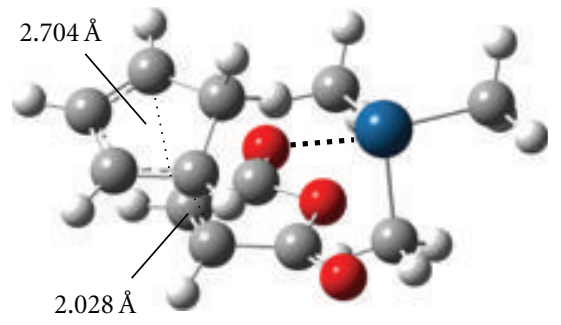

(c) Transition state leading to exo-product (catalyzed by $\mathrm{PtMe}_{3}{ }^{+}$)

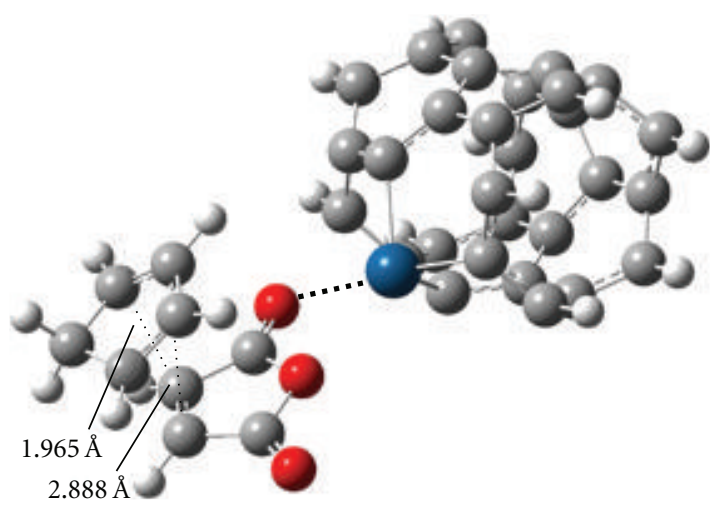

(e) Transition state leading to exo-product (catalyzed by $(5,0) \mathrm{Pt}$-doped SWCNT)

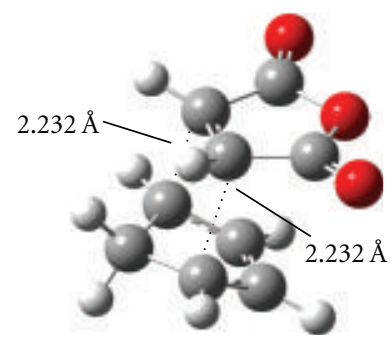

(b) Transition state leading to endo-product

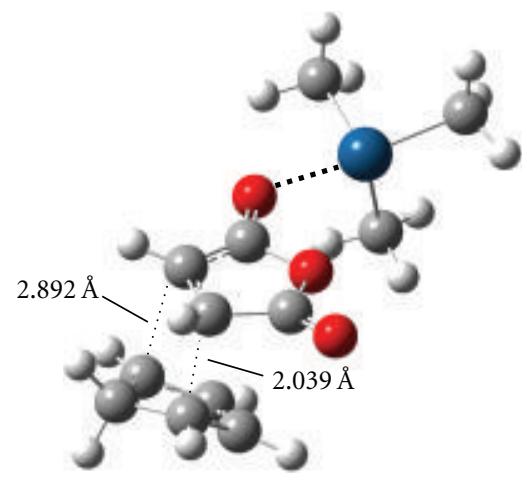

(d) Transition state leading to endo-product (catalyzed by $\mathrm{PtMe}_{3}{ }^{+}$)

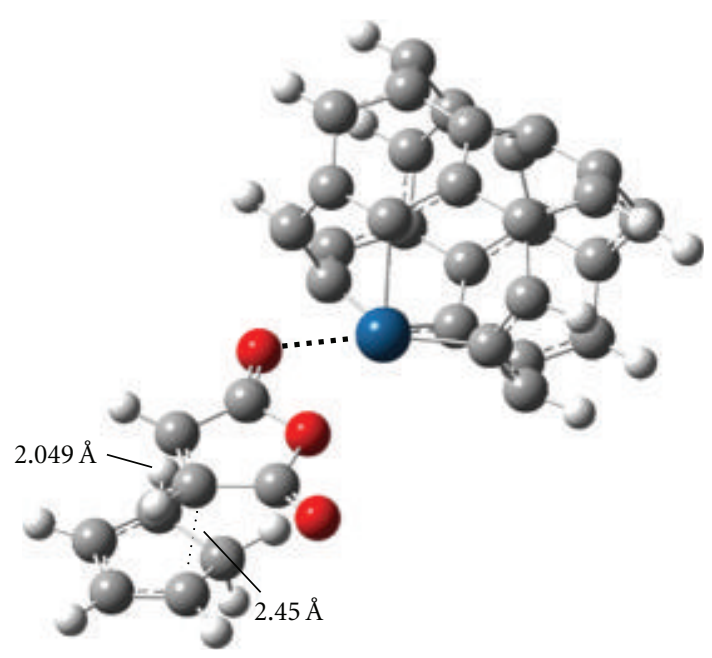

(f) Transition state leading to endo-product (catalyzed by $(5,0)$ Pt-doped SWCNT)

FIgURe 31: Transition states of the Diels-Alder reaction of maleic anhydride and cyclopentadiene as catalyzed by alkyl- and arylplatinum complexes [45]. Legend: dark grey $=$ carbon, light grey $=$ hydrogen, red = oxygen, blue = platinum .

This is likely due to larger steric hindrance toward the productive coordination of maleic anhydride to the $\mathrm{Pt}$ atom. Otherwise, the Lewis acidity of alkyl- and arylplatinum model complexes appear to decrease the chemical shift more than traditional Lewis acids $(\Delta \delta \sim 0.5 \mathrm{ppm})$, except for Pt-doped fullerenes. Hence, our organoplatinum model complexes derived from substitutional doping of a $\mathrm{Pt}$ atom are in fact strong Lewis acids. Also, we demonstrated that Lewis acid/Lewis base pair formation decreases the
$\mathrm{C} 1-\mathrm{C} 2$ bond length and increases $\mathrm{C} 1=\mathrm{O}$ and $\mathrm{C} 2=\mathrm{C} 3$ bond lengths. This is because contribution from the resonance structure involving charge separation gains more weight as a result of the complexation. Accordingly, reactivity at $\mathrm{C} 2$ and C3 towards electrophiles and nucleophiles, respectively, presumably increases as a result of this binding due to charge separation in the maleic anhydride starting material. By bond-length analysis, our alkyl- and arylplatinum complexes appear to be roughly equivalent to traditional Lewis acids in 
their Lewis acidity. It is meaningful to discuss two interesting cases here, namely, the $(5,0)$ Pt-doped SWCNT and Pt-doped corannulene. The coordination of maleic anhydride appears to be more strongly affected by the ligands on the Pt nucleus than the coordination of $\mathrm{CO}$. For instance, complexation of these organoplatinum complexes results in larger geometric deviations than with the corresponding simple alkyl- and arylplatinum complexes, $\mathrm{PtMe}_{3}{ }^{+}$and $\mathrm{PtPh}_{3}{ }^{+}$, respectively. This suggests that higher levels of $\pi$-curvature and increased ability to favor delocalization of the electron density facilitate binding of Lewis bases to Lewis acidic Pt centers. However, a more subtle interplay between steric and electronic factors is obviously present, since the same trends are not observed for the other Pt-doped buckybowls and fullerenes.

The trend of Lewis acidity suggested by chemical shift analysis is as follows [45]:

$(5,0)$ Pt-doped SWCNT $\sim$ Pt-doped corannulene $<$ Pt-doped $\mathrm{C}_{24}$ PPP isomer $<$ Pt-doped $\mathrm{C}_{24} \mathrm{HPP}$ isomer $<$ Pt-doped sumanene $<\mathrm{Pt}$-doped phenaline $<\mathrm{PtPh}_{3}{ }^{+}<\mathrm{PtMe}_{3}{ }^{+}$,

which is virtually identical to the conclusion based on the adsorption of CO.

4.4. Lewis-Acid Catalyzed Diels-Alder Reaction between Maleic Anhydride and Cyclopentadiene. While CO coordination and maleic anhydride complexation provide ideas of Lewis acid strength of our organoplatinum complexes, perhaps the true test is their application as catalysts in a chemical reaction. The Diels-Alder reaction between maleic anhydride and cyclopentadiene is ideal for this purpose. This reaction is a $[4+2]$ cycloaddition of a diene (i.e., cyclopentadiene) and an alkene (i.e., maleic anhydride) and generates a cyclohexene product. The key driving force is the formation of two new $\sigma$ bonds at the expense of two $\pi$ bonds. Lewis acids can promote this transformation by lowering the LUMO energy of the dienophile by binding to a Lewis basic site, leading to a more energetically favorable overlap between the dienophile LUMO and the diene HOMO (see Figure 26). This particular cycloaddition that we chose to study is also an example of what is termed a normal electrondemand Diels-Alder reaction. An inverse electron-demand Diels-Alder reaction involves molecular orbital interactions between the dienophile HOMO and the diene LUMO. In our studies, distortion of the electron density on the LUMO of the maleic anhydride was found to be typically quite small (Figure 30). In fact, significant interaction between the LUMO with the lobes on the model alkyl- and arylplatinum complexes could only be observed for Pt-doped corannulene. Decreased LUMO energies varied significantly for each of the model complexes investigated.

The cyclohexene product formed in the Diels-Alder reaction can exist as one of two diastereomeric compounds (Figure 26). The so-called endo-product is kinetically favored and involves secondary orbital interactions between the two unreactive $\mathrm{C}$ atoms on the diene and the $\pi$ orbitals of the neighboring $\mathrm{C}=\mathrm{O}$ groups on the alkene [236]. In comparison, the exo-product is accessible through thermodynamic control. The distribution of isomeric products resulting from the Diels-Alder reaction depends on many parameters, including choice of the catalyst/ligand, solvent, and reaction temperature, among others.

Although $\mathrm{PtMe}_{3}{ }^{+}$can be a catalyst for Diels-Alder reactions $[237,238]$, the use of Pt-doped supramolecules including buckybowls, fullerenes, and nanotubes has not yet been realized. Our investigations provide a preliminary insight into this possibility [45]. We considered exo- and endoreaction pathways for our proposed catalysis and found similarity with previous studies of the Diels-Alder reaction, suggesting a concerted but asynchronous transition state [224$230,239,240]$. In general, we can conclude that alkyl- and arylplatinum catalysts for the Diels-Alder reaction of maleic anhydride and cyclopentadiene results in an enhancement of reaction rate (Table 8). Interestingly, Pt-doped fullerene demonstrates only an approximate 3 -fold rate increase, while systems displaying less ability to delocalize the electron density yield greater enhancements (up to $10^{7}$-fold). Pt-doped SWCNT actually decreases the predicted reaction rate (i.e., it inhibits the reaction). Careful examination of the geometric structures revealed that ligands on Pt centers with extended $\mathrm{C}$ frameworks typically give transition states that are more synchronous in character in comparison to the highly reactive and less sterically encumbered $\mathrm{PtMe}_{3}{ }^{+}$and $\mathrm{PtPh}_{3}{ }^{+}$ (Figure 31). Thus, it seems that the polarization of the alkene and formation of the charged-separated species (see Figure 25) has the largest influence on catalyzing the [4+2] cycloaddition. The reason behind the enhanced reactivity, however, is not clear because the reaction we are studying involves two nonpolar starting materials (i.e., maleic anhydride and cyclopentadiene). Pyramidalization of the carbon framework, on the other hand, appears to have relatively little impact on the effectiveness of the proposed catalysis.

If we assume kinetic control of the Diels-Alder reaction, systems with higher levels of delocalization of the electron density in the catalyst tend to give lower preference for the endo-product. In fact, the catalyst that demonstrates the highest rate enhancements (i.e., $\mathrm{PtMe}_{3}{ }^{+}$) also exhibits the highest selectivity for the endo-product. Furthermore, in no cases is the exo-product favored over the endo-product. Based on these observations, it appears that decreased steric hindrance is ideal for promoting diastereoselectivity in the Diels-Alder reaction. The generality of this statement, however, requires further investigation since we have chosen a finite model of a SWCNT with $\mathrm{H}$ capping atoms to examine the feasibility of catalysis. Moreover, the interaction between two metal centers in close proximity of each other as substitutional dopant atoms in an extended carbon framework may play important roles in both the efficiency and selectivity in catalysis.

\section{Proposed Applications of Substitutionally Doped SWCNTs}

5.1. Substitutionally Doped SWCNTs in Nanosensors and Nanoelectronics. With the model SWCNTs and a brief examination of the interaction with gas molecules, we herein propose several applications of these macromolecules. 


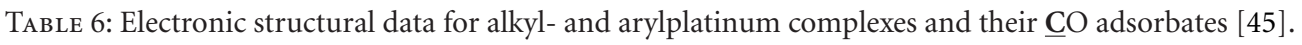

\begin{tabular}{|c|c|c|c|c|c|c|c|c|c|}
\hline Pt complex & $\Sigma^{\mathrm{a}}$ & $q(\mathrm{Pt})^{\mathrm{b}}$ & $\mathrm{E}_{\text {elec }}{ }^{\mathrm{c}}$ & $\Delta \mathrm{G}^{\mathrm{d}}$ & $d(\mathrm{Pt}-\mathrm{C})^{\mathrm{e}}$ & $d(\mathrm{C} \equiv \mathrm{O})^{\mathrm{e}}$ & $\nu_{C \equiv O}{ }^{f}$ & $q(\mathrm{Pt} / \mathrm{CO})^{\mathrm{g}}$ & $q(\mathrm{CO})^{\mathrm{h}}$ \\
\hline $\mathrm{PtMe}_{3}^{+}$ & $297.5^{\circ}$ & 0.77 & -24.02 & -8.25 & 2.116 & 1.156 & 2089.3 & 0.54 & 0.25 \\
\hline $\mathrm{PtPh}_{3}{ }^{+}$ & $315.4^{\circ}$ & 0.77 & -16.83 & -0.46 & 2.113 & 1.160 & 2055.1 & 0.54 & 0.22 \\
\hline Pt-doped phenaline & $279.6^{\circ}$ & 0.74 & -28.58 & -13.07 & 2.057 & 1.161 & 2050.3 & 0.40 & 0.23 \\
\hline Pt-doped sumanene & $260.5^{\circ}$ & 0.77 & -35.16 & -19.67 & 2.025 & 1.163 & 2043.4 & 0.39 & 0.21 \\
\hline Pt-doped corannulene & $257.8^{\circ}$ & 0.59 & -34.30 & -18.22 & 1.983 & 1.179 & 1949.4 & 0.26 & 0.08 \\
\hline Pt-doped $\mathrm{C}_{24}$ fullerene PPP isomer & $250.6^{\circ}$ & 0.69 & -31.58 & -16.74 & 2.027 & 1.167 & 2017.3 & 0.32 & 0.17 \\
\hline Pt-doped $\mathrm{C}_{24}$ fullerene HPP isomer & $268.3^{\circ}$ & 0.66 & -32.71 & -17.59 & 1.995 & 1.166 & 2026.4 & 0.30 & 0.22 \\
\hline$(5,0)$ Pt-doped SWCNT & $292.2^{\circ}$ & 0.53 & -36.02 & -20.31 & 1.971 & 1.179 & 1949.8 & 0.12 & 0.12 \\
\hline
\end{tabular}

${ }^{a}$ Sum of angles around Pt center (without adsorbate).

b Partial charge on Pt atom (without adsorbate).

${ }^{\mathrm{c}}$ Electronic energy of stabilization (in $\mathrm{kcal} / \mathrm{mol}$ ) upon $\underline{\mathrm{CO}}$ adsorption.

${ }^{\mathrm{d}}$ Free energy of stabilization (in $\mathrm{kcal} / \mathrm{mol}$ ) upon $\underline{\mathrm{CO}}$ adsorption at $298 \mathrm{~K}$.

${ }^{\mathrm{e}}$ Bond length (in $\AA$ ) between atoms $\mathrm{X}$ and $\mathrm{Y}$.

${ }^{\mathrm{f}}$ Vibration frequency (in $\mathrm{cm}^{-1}$ ) of bound $\mathrm{C} \equiv \mathrm{O}$ molecule ( $\mathrm{cf} .2028 .8 \mathrm{~cm}^{-1}$ for unbound free CO).

gartial charge of Pt atom in $\underline{\mathrm{CO}}$-adsorbed Pt complex.

hPartial charge on bound CO molecule.

TABLE 7: Electronic structural data for Lewis acid/maleic anhydride complexes [45].

\begin{tabular}{|c|c|c|c|c|c|c|c|}
\hline LA/MA complex & $d(\mathrm{C} 1=\mathrm{O})^{\mathrm{a}}$ & $d(\mathrm{C} 1-\mathrm{C} 2)^{\mathrm{a}}$ & $d(\mathrm{C} 2=\mathrm{C} 3)^{\mathrm{a}}$ & $q(\mathrm{O})^{\mathrm{b}}$ & $q(\mathrm{C} 3)^{\mathrm{c}}$ & $\delta(\mathrm{H})^{\mathrm{d}}$ & $\Delta \delta(\mathrm{H})^{\mathrm{e}}$ \\
\hline Uncoordinated maleic anhydride & 1.223 & 1.499 & 1.351 & -0.496 & -0.250 & 6.25 & 0.00 \\
\hline $\mathrm{PtMe}_{3}{ }^{+} / \mathrm{MA}$ & 1.248 & 1.488 & 1.354 & -0.583 & -0.215 & 7.02 & 0.77 \\
\hline $\mathrm{PtPh}_{3}{ }^{+} / \mathrm{MA}$ & 1.243 & 1.488 & 1.354 & -0.557 & -0.221 & 6.94 & 0.69 \\
\hline Pt-doped phenaline/MA & 1.249 & 1.486 & 1.356 & -0.584 & -0.229 & 6.80 & 0.55 \\
\hline Pt-doped sumanene/MA & 1.249 & 1.484 & 1.356 & -0.577 & -0.221 & 6.71 & 0.46 \\
\hline Pt-doped corannulene/MA & 1.278 & 1.440 & 1.384 & -0.643 & -0.311 & 5.53 & -0.72 \\
\hline Pt-doped $\mathrm{C}_{24}$ fullerene PPP isomer/MA & 1.254 & 1.472 & 1.363 & -0.595 & -0.266 & 6.30 & 0.05 \\
\hline Pt-doped $\mathrm{C}_{24}$ fullerene HPP isomer/MA & 1.245 & 1.479 & 1.359 & -0.552 & -0.250 & 6.39 & 0.14 \\
\hline$(5,0)$ Pt-doped SWCNT/MA & 1.265 & 1.451 & 1.376 & -0.604 & -0.297 & 5.63 & -0.62 \\
\hline $\mathrm{AlMe}_{3} / \mathrm{MA}$ & 1.238 & 1.487 & 1.355 & -0.597 & -0.245 & 6.36 & 0.11 \\
\hline $\mathrm{AlCl}_{3} / \mathrm{MA}$ & 1.245 & 1.490 & 1.353 & -0.675 & -0.225 & 6.60 & 0.35 \\
\hline $\mathrm{BBr}_{3} / \mathrm{MA}$ & 1.256 & 1.486 & 1.354 & -0.569 & -0.234 & 6.38 & 0.12 \\
\hline $\mathrm{BCl}_{3} / \mathrm{MA}$ & 1.254 & 1.489 & 1.353 & -0.555 & -0.233 & 6.40 & 0.15 \\
\hline $\mathrm{BF}_{3} / \mathrm{MA}$ & 1.244 & 1.492 & 1.352 & -0.561 & -0.234 & 6.48 & 0.23 \\
\hline $\mathrm{SnCl}_{4} / \mathrm{MA}$ & 1.241 & 1.492 & 1.352 & -0.622 & -0.233 & 6.46 & 0.20 \\
\hline $\mathrm{TiCl}_{4} / \mathrm{MA}$ & 1.237 & 1.492 & 1.352 & -0.508 & -0.236 & 6.41 & 0.16 \\
\hline
\end{tabular}

${ }^{\mathrm{a}}$ Bond length (in $\AA$ ) between atoms $\mathrm{X}$ and $\mathrm{Y}$.

${ }^{b}$ Partial charge on $\mathrm{O}$ atom.

'Partial charge on $\mathrm{C} 3$ atom.

${ }^{\mathrm{d}}$ Chemical shift (in ppm) on $\mathrm{H}$ atom (referenced to tetramethylsilane).

${ }^{e}$ Difference in chemical shift (in ppm) on $\mathrm{H}$ atom relative to uncoordinated maleic anhydride (referenced to tetramethylsilane).

Since defected SWCNTs can react with dissolved NO to form N-doped SWCNTs [81], it is possible that injecting such nanostructures into biological systems may provide promise for use as an artificial antioxidant. However, because of the huge thermodynamic preference for chemical reactions between $5-1 \mathrm{DB}$ defects and NO, reversibility of this process comes into question. Nonetheless, we know that introduction of $\mathrm{N}$ atoms results in increased clearance rates [123] and, hence, may provide a strategy for removing these macromolecules after they have undergone irreversible NO capture. We can imagine a scenario in which vacancy defects are formed via high-energy processes $[83,84]$, such as the harmful UV-A and UV-B rays from the sun. If pristine SWCNTs can be implanted into the human body, environmental stresses may trigger the formation of 5-1DB defects and provide a queue to decrease the amount of free biological NO in the body and thereby maintain homeostasis.

Another possible use of defected SWCNTs would be as a sensor for biological NO [241]. Perhaps a more intriguing starting point for the development of a nanosensor, however, would be our proposed transition metal-doped SWCNTs [113]. We feel that Pt-doped SWCNTs are of specific interest due to their ability to adsorb a wide array of small gaseous molecules. The key strategy for analyzing and detecting 
adsorption would be in monitoring the electronic structure of HSWCNTs. Thus, our proposal below also pertains to the possibility of using Pt-doped SWCNTs in nanoelectronics.

In theory, minor fluctuations in electronic structure can be evaluated by considering the amount of charge transfer that takes place between the nanotube superstructure and the small molecule adsorbate. Additionally, analysis of the HOMO-LUMO gap may provide some insight. Peng and coworkers have previously suggested that charge transfer between the nanotube and adsorbate can result in a change in the conductance along the axis as described by the following relationship [71]:

$$
\Delta Q=C_{g} \cdot \Delta V_{g}=\delta \theta \frac{\pi d l}{\sigma},
$$

where $\Delta Q$ is the charge transfer, which is directly proportional to the capacitance, $C_{g}$, and the observed voltage change, $\Delta V_{g}$. The nanotube length and diameter are $l$ and $d$, respectively, while $\sigma$ and $\theta$ are the molecular cross-section area and coverage, respectively [71]. From Table 9, the trend between the adsorbate species and net charge transfer is clear.

In our investigations [113], although the magnitude of charge transfer is small, it has been demonstrated that a value of 0.28 is sufficient for observing macromolecular changes in measurable quantities such as conductivity (in the case of B- and N-doped SWCNTs), hence ratifying their application as nanosensors. It is also possible that extension of these terminated fragments in either direction ad infinitum with multiple doping sites per nm of nanotube should enhance the sensitivity enough such that a practically useful device can be prepared based on these macromolecules. Additionally, other strategies, including the use of a polymer matrix to encapsulate these structures, may also help. For instance, carbon nanotubes have demonstrated that their inclusion in insulating polymer matrices can cause the resulting material to become conductive above a certain filler concentration known as the percolation threshold [34]. Bryning et al. have demonstrated that this value can be as low as $0.005 \mathrm{vol} \%$ in SWCNT/epoxy composites [242].

Furthermore, one can also envision the utilization of these macromolecules as nanowires [33]. In nanoelectronics, carbon nanotubes have been proposed as field effect transistors (FETs) [11, 12, 15, 243], optoelectronic devices, and nanoelectromechanical systems (NEMSs) [244, 245]. In fact, carbon nanotubes have been used to build an FET with a back gate (e.g., Infineon Technologies). In this design, the carbon nanotube is situated at the top of electrodes, which themselves are separated by a dielectric spacer to the backgate. The conductive nanochannel hence provides a connection between the drain and source electrodes. Applications of devices of this type, such as in nonvolatile molecular memory elements, have been considered $[14,246]$. As such, the ability of manipulating conductance across a wire with simple exposure to gases would be an attractive one since this would provide a relatively straightforward method for controlling a nanocircuit. In theory, should the conductance of the carbon nanotube be too high, introduction of a gaseous atmosphere of $\mathrm{CO}$, for instance, should increase resistivity. This effect would be compounded if a single SWCNT was doped at multiple sites. The key advantage to electronic manipulation of this type is the ability to reversibly control conductivity by removal of the resistive gas by purging the atmosphere with inert gases such as argon. Because of the high diffusion rates of gaseous molecules, extremely fast circuit breaks are possible. In the future, more complicated electronic devices may contain differentially doped SWCNT that may be selectively modified in terms of its electronic structure depending on the nature of the adsorbate. Obviously, selective modification of one SWCNT in the presence of thousands of others remains a significant challenge and may require new engineering solutions.

\subsection{Substitutionally Doped SWCNTs in Nanocatalysis. Based} on our studies, the additional $\pi$-delocalization of electrons in Pt-doped supramolecular frameworks (e.g., buckybowls, fullerenes, and nanotubes) appears to offer less useful rate enhancements and selectivities in comparison with the readily available simple $\mathrm{PtMe}_{3}{ }^{+}$system [45]. Again, we believe that using Pt-doped SWCNTs and other transition metal-doped congeners as catalysts warrant further investigation. Since these nanomaterials sit at the boundary between homogeneous and heterogeneous catalysis, their independent synthesis and characterization may provide an opportunity to establish the connection between reaction mechanisms of these two types of catalysis. Additionally, we may also view substitutional doping with $\mathrm{Pt}$ atoms as a strategy for developing heterogeneous Lewis acid catalysis, in which immobilization of reactive Lewis acids may allow for recovery and reuse of precious metals.

We also envision that more complex systems may be possible in the case of substitutional doping. In fact, because nanotubes are channels, we may one day be able to achieve a nanoscale version of microfluidics. For instance, we can imagine a SWCNT with a smaller diameter with substitutional transition metal doping that can act as catalysts that are themselves encased in a SWCNT with a much larger diameter. These nanochannels may provide enhanced chemical reactivity due to higher local concentrations of the reactive partners. We can even dream of synthesizing nanotubes containing multiple substitutional dopants of either the same or different transition metal in which their proximity provide unique types of catalysis that are not possible in the homogeneous bulk solution. Nanocatalysis remains an emerging field that will continue to develop in the years to come.

\section{Concluding Remarks}

Within DFT, the rich chemistry of substitutionally doped SWCNTs has been investigated. We summarize our findings as follows:

(1) A vacancy defect formed by removal of a single C atom from the sidewall of a SWCNT can undergo structural rearrangement to give a structure containing a five-membered carbocycle and a single $\mathrm{C}$ atom with one dangling bond (i.e., the 5-1DB defect). 
TABLE 8: Free energies and rates of the Diels-Alder reaction of maleic anhydride and cyclopentadiene as catalyzed by alkyl- and arylplatinum complexes [45].

\begin{tabular}{|c|c|c|c|c|c|c|c|}
\hline Catalyst & $\Delta \mathrm{G}_{\mathrm{exo}} \neq \mathrm{a}$ & $\Delta \mathrm{G}_{\text {exo }}{ }^{\mathrm{b}}$ & $\Delta \mathrm{G}_{\mathrm{exo}} \neq \mathrm{c}$ & $\Delta \mathrm{G}_{\text {exo }}{ }^{\mathrm{d}}$ & $\Delta \Delta \mathrm{G}^{\ddagger \mathrm{e}}$ & $k_{\text {endo }} / k_{\text {exo }}{ }^{\mathrm{f}}$ & $k_{\text {cat }} / k_{\text {uncat }}{ }^{\mathrm{g}}$ \\
\hline None & 27.28 & -3.83 & 26.67 & -3.03 & 0.60 & 2.78 & 1.00 \\
\hline $\mathrm{PtMe}_{3}{ }^{+}$ & 15.85 & -8.06 & 14.41 & -9.54 & 1.44 & 11.43 & $1.27 \times 10^{3}$ \\
\hline $\mathrm{PtPh}_{3}{ }^{+}$ & 17.43 & -8.19 & 16.82 & -8.48 & 0.61 & 2.79 & $1.58 \times 10^{3}$ \\
\hline Pt-doped phenaline & 17.69 & -8.15 & 16.67 & -7.70 & 1.02 & 5.60 & $1.47 \times 10^{3}$ \\
\hline Pt-doped sumanene & 16.76 & -8.57 & 16.19 & -8.40 & 0.57 & 2.63 & $3.01 \times 10^{3}$ \\
\hline Pt-doped corannulene & 16.03 & -13.26 & 15.30 & -13.28 & 0.73 & 3.43 & $8.22 \times 10^{6}$ \\
\hline Pt-doped $\mathrm{C}_{24}$ PPP isomer & 23.54 & -4.04 & 22.68 & -3.45 & 0.86 & 4.26 & 1.42 \\
\hline Pt-doped $\mathrm{C}_{24} \mathrm{HPP}$ isomer & 23.49 & -4.47 & 22.49 & -4.17 & 1.00 & 5.44 & 2.99 \\
\hline$(5,0)$ Pt-doped SWCNT & 30.23 & 2.47 & 30.11 & -3.47 & 0.12 & 1.23 & 0.55 \\
\hline
\end{tabular}

${ }^{\mathrm{a}}$ Free energy (in $\mathrm{kcal} / \mathrm{mol}$ ) required to reach transition state leading to exo-product at $298 \mathrm{~K}$.

${ }^{b}$ Free energy (in $\mathrm{kcal} / \mathrm{mol}$ ) change to exo-product in at $298 \mathrm{~K}$.

${ }^{\mathrm{c}}$ Free energy (in $\mathrm{kcal} / \mathrm{mol}$ ) required to reach transition state leading to endo-product at $298 \mathrm{~K}$.

${ }^{\mathrm{d}}$ Free energy (in kcal $/ \mathrm{mol}$ ) change to endo-product at $298 \mathrm{~K}$.

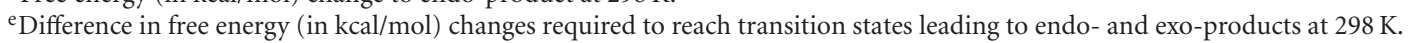

${ }^{\mathrm{f}}$ Relative rate leading to endo-product versus exo-product.

gRelative rate of catalyzed Diels-Alder reaction versus uncatalyzed Diels-Alder reaction.

TABLE 9: Charge transfer and HOMO-LUMO gap data for nanotube-adsorbate complexes with side-on binding motif [113, 114].

\begin{tabular}{lccc}
\hline Analyte & Average charge transfer ${ }^{\mathrm{a}}$ & HOMO-LUMO gap $(\mathrm{eV})$ & Change in HOMO-LUMO gap (eV) \\
\hline None & N/A & 0.74 & 0 \\
\hline $\mathrm{CO}^{\mathrm{b}}$ & 0.05 & 0.78 & 0.04 \\
\hline $\mathrm{NO}^{\mathrm{c}}$ & 0.28 & 0.74 & 0.00 \\
\hline $\mathrm{NH}_{3}{ }^{\mathrm{d}}$ & -0.18 & 0.75 & 0.01 \\
\hline $\mathrm{N}_{2}{ }^{\mathrm{e}}$ & 0.09 & 0.81 & 0.07 \\
\hline $\mathrm{H}_{2}$ & 0.34 & 0.70 & -0.04 \\
\hline $\mathrm{C}_{2} \mathrm{H}_{4}$ & 0.25 & 0.88 & 0.14 \\
\hline $\mathrm{C}_{2} \mathrm{H}_{2}$ & 0.38 & 0.88 & 0.14 \\
\hline
\end{tabular}

${ }^{a}$ Represents charge donated from the Pt-doped SWCNT to the adsorbate.

${ }^{b}$ Represents $(\underline{\mathbf{C O}})_{2}$-adsorbed HSWCNT.

${ }^{c}$ Represents $(\underline{\mathbf{N}} \mathrm{O})_{2}$-adsorbed HSWCNT.

${ }^{\mathrm{d}}$ Represents $\left(\mathrm{N}_{3}\right)_{2}$-adsorbed HSWCNT.

${ }^{\mathrm{e}}$ Represents $\left(\mathrm{N}_{2}\right)_{2}$-adsorbed HSWCNT.

This active vacancy reacts with $\mathrm{NO}$ liberating $\mathrm{NO}_{2}$ and $\mathrm{N}$-doped SWCNTs in a selective fashion.

(2) 5-1DB defects can react with $\mathrm{O}_{3}$ to generate $\mathrm{O}_{2}$ and O-doped SWCNTs in a selective fashion. Substitutional O-doping yields a structure containing a $\mathrm{C}-\mathrm{O}$ bond exhibiting strong similarities to $\mathrm{C}=\mathrm{O}$ double bonds.

(3) Substitutional doping with transition metals, such as $\mathrm{Pt}$, results in slight buckling of the nanotube sidewall to give a structure in which the transition metal dopant is situated in a position protruding to the exterior of the sidewall and the Pt atom and three adjacent $\mathrm{C}$ atoms are situated in a tripodal fashion.

(4) Substitutional doping with transition metals depends strongly on the doping location. Nanotubes capped with fullerene hemispheres can be doped either at the cap or the sidewall. Cap doping gives chemical reactivities more similar to the corresponding transition metal-doped fullerenes. Sidewall doping offers different opportunities for chemical reactions.

(5) Adsorption of small molecules onto Pt-doped SWCNTs is analogous to coordination chemistry of alkylplatinum complexes with one caveat. Namely, because the nanotube provides much larger steric bulk, multiple adsorption may become thermodynamically unfavorable. However, weak interaction with the extended delocalized $\pi$-electrons may play a role.

(6) Adsorption provides a facile method for manipulating electronic structure of Pt-doped SWCNTs. This is because coordination of adsorbates to the $\mathrm{Pt}$ atom embedded in the sidewall of SWCNTs can result in either ligand-to-metal or metal-to-ligand charge transfer, depending on the nature of the adsorbate. This results in manipulation of the HOMO-LUMO gap. 
(7) Pt-doped SWCNTs exhibit Lewis acidity similar to that of simple alkyl- and arylplatinum complexes. Evaluation of Lewis acid strength can be done by measuring the stretching frequency of a bound molecule of $\mathrm{CO}$ or by ${ }^{1} \mathrm{H}$ NMR studies of the $\beta-\mathrm{H}$ of Lewis acid/Lewis base complexes formed with $\alpha, \beta$-unsaturated carbonyl compounds. However, because the nanotube provides larger steric bulk than simple alkyl- and arylplatinum complexes, the ability to activate a substrate for catalysis may be impeded.

Without doubt, since transition metal-doped SWCNTs have yet to be prepared experimentally, much of the work presented here remains a theoretical prediction. Nonetheless, we have provided a comprehensive overview of the potential of these materials. Their behavior in polymer composites, in particular, may provide a handle by which some of these properties can be amplified to useful levels. Further research involving computational studies using periodic boundary conditions as well as experimental efforts will provide a closer look at potential of these nanomaterials as nanosensors, nanocatalysts, and nanodevices. Our initial investigations here will provide inspiration and guidance to experimentalists in their endeavors.

\section{Acknowledgments}

The authors thank the Natural Sciences and Engineering Research Council (NSERC) of Canada for financial support. WestGrid and C-HORSE have provided the necessary computational resources. C. S. Yeung gratefully acknowledges NSERC for an Undergraduate Student Research Award.

\section{References}

[1] S. Iijima, "Helical microtubules of graphitic carbon," Nature, vol. 354 , no. 6348 , pp. 56-58, 1991.

[2] S. Iijima and T. Ichihashi, "Single-shell carbon nanotubes of 1-nm diameter," Nature, vol. 363, no. 6430, pp. 603-605, 1993.

[3] N. Karousis, N. Tagmatarchis, and D. Tasis, "Current progress on the chemical modification of carbon nanotubes," Chemical Reviews, vol. 110, no. 9, pp. 5366-5397, 2010.

[4] D. Tasis, N. Tagmatarchis, A. Bianco, and M. Prato, "Chemistry of carbon nanotubes," Chemical Reviews, vol. 106, no. 3, pp. 1105-1136, 2006.

[5] P. M. Ajayan, "Nanotubes from carbon," Chemical Reviews, vol. 99, no. 7, pp. 1787-1799, 1999.

[6] H. R. Byon and H. C. Choi, "Network single-walled carbon nanotube-field effect transistors (SWNT-FETs) with increased schottky contact area for highly sensitive biosensor applications," Journal of the American Chemical Society, vol. 128, no. 7, pp. 2188-2189, 2006.

[7] N. Ferrer-Anglada, V. Gomis, Z. El-Hachemi, U. D. Weglikovska, M. Kaempgen, and S. Roth, "Carbon nanotube based composites for electronic applications: CNTconducting polymers, CNT-Cu," Physica Status Solidi, vol. 203, no. 6, pp. 1082-1087, 2006.

[8] Z. Chen, J. Appenzeller, Y. M. Lin et al., "An integrated logic circuit assembled on a single carbon nanotube," Science, vol. 311 , no. 5768 , p. $1735,2006$.
[9] K. V. Singh, R. R. Pandey, X. Wang et al., "Covalent functionalization of single walled carbon nanotubes with peptide nucleic acid: nanocomponents for molecular level electronics," Carbon, vol. 44, no. 9, pp. 1730-1739, 2006.

[10] N. Robertson and C. A. McGowan, "A comparison of potential molecular wires as components for molecular electronics," Chemical Society Reviews, vol. 32, no. 2, pp. 96103, 2003.

[11] A. Javey, J. Guo, Q. Wang, M. Lundstrom, and H. Dai, "Ballistic carbon nanotube field-effect transistors," Nature, vol. 424, no. 6949, pp. 654-657, 2003.

[12] A. Javey, H. Kim, M. Brink et al., "High- $\kappa$ dielectrics for advanced carbon-nanotube transistors and logic gates," Nature Materials, vol. 1, no. 4, pp. 241-246, 2002.

[13] P. Avouris, "Molecular electronics with carbon nanotubes," Accounts of Chemical Research, vol. 35, no. 12, pp. 1026-1034, 2002.

[14] M. Radosavljević, M. Freitag, K. V. Thadani, and A. T. Johnson, "Nonvolatile molecular memory elements based on ambipolar nanotube field effect transistors," Nano Letters, vol. 2, no. 7, pp. 761-764, 2002.

[15] S. J. Tans, A. R. M. Verschueren, and C. Dekker, "Roomtemperature transistor based on a single carbon nanotube," Nature, vol. 393, no. 6680, pp. 49-52, 1998.

[16] D. A. Britz and A. N. Khlobystov, "Noncovalent interactions of molecules with single walled carbon nanotubes," Chemical Society Reviews, vol. 35, no. 7, pp. 637-659, 2006.

[17] C. Li and T.-W. Chou, "Atomistic modeling of carbon nanotube-based mechanical sensors," Journal of Intelligent Material Systems and Structures, vol. 17, no. 3, pp. 247-254, 2006.

[18] Y. Yeo-Heung, A. Miskin, P. Kang et al., "Carbon nanofiber hybrid actuators: part I-liquid electrolyte-based," Journal of Intelligent Material Systems and Structures, vol. 17, no. 2, pp. 107-116, 2006.

[19] Y. H. Yun, V. Shanov, M. J. Schulz et al., "Development of novel single-wall carbon nanotube-epoxy composite ply actuators," Smart Materials and Structures, vol. 14, no. 6, pp. 1526-1532, 2005.

[20] B. J. Landi, R. P. Raffaelle, M. J. Heben, J. L. Alleman, W. VanDerveer, and T. Gennett, "Development and characterization of single wall carbon nanotube-Nafion composite actuators," Materials Science and Engineering B, vol. 116, no. 3, pp. 359362, 2005.

[21] M. Nakazawa, S. Nakahara, T. Hirooka, M. Yoshida, T. Kaino, and K. Komatsu, "Polymer saturable absorber materials in the $1.5 \mu \mathrm{m}$ band using poly-methyl-methacrylate and polystyrene with single-wall carbon nanotubes and their application to a femtosecond laser," Optics Letters, vol. 31, no. 7, pp. 915-917, 2006.

[22] J. Seo, S. Ma, Q. Yang et al., "Third-order optical nonlinearities of singlewall carbon nanotubes for nonlinear transmission limiting application," Journal of Physics: Conference Series, vol. 38, no. 1, pp. 37-40, 2006.

[23] Y. Sakakibara, A. G. Rozhin, H. Kataura, Y. Achiba, and M. Tokumoto, "Carbon nanotube-poly(vinylalcohol) nanocomposite film devices: applications for femtosecond fiber laser mode lockers and optical amplifier noise suppressors," Japanese Journal of Applied Physics, vol. 44, no. 4 A, pp. 16211625, 2005.

[24] S. Y. Set, H. Yaguchi, Y. Tanaka, and M. Jablonski, "Laser mode locking using a saturable absorber incorporating carbon nanotubes," Journal of Lightwave Technology, vol. 22, no. 1, pp. 51-56, 2004. 
[25] E. S. Jeng, A. E. Moll, A. C. Roy, J. B. Gastala, and M. S. Strano, "Detection of DNA hybridization using the near-infrared band-gap fluorescence of single-walled carbon nanotubes," Nano Letters, vol. 6, no. 3, pp. 371-375, 2006.

[26] D. H. Wu, W. T. Chien, C. S. Chen, and H. H. Chen, "Resonant frequency analysis of fixed-free single-walled carbon nanotube-based mass sensor," Sensors and Actuators A, vol. 126, no. 1, pp. 117-121, 2006.

[27] J. Kim, J. Baek, H. Kim, K. Lee, and S. Lee, "Integration of enzyme immobilized single-walled carbon nanotubes mass into the microfluidic platform and its application for the glucose-detection," Sensors and Actuators A, vol. 128, no. 1, pp. 7-13, 2006.

[28] M. E. Kose, B. A. Harruff, Y. Lin, L. M. Veca, F. Lu, and Y. P. Sun, "Efficient quenching of photoluminescence from functionalized single-walled carbon nanotubes by nitroaromatic molecules," Journal of Physical Chemistry B, vol. 110, no. 29, pp. 14032-14034, 2006.

[29] W. Wongwiriyapan, S. I. Honda, H. Konishi et al., "Singlewalled carbon nanotube thin-film sensor for ultrasensitive gas detection," Japanese Journal of Applied Physics, vol. 44, no. 16-19, pp. L482-L484, 2005.

[30] J. Liu, S. Tian, and W. Knoll, "Properties of polyaniline/carbon nanotube multilayer films in neutral solution and their application for stable low-potential detection of reduced $\beta$-nicotinamide adenine dinucleotide," Langmuir, vol. 21, no. 12, pp. 5596-5599, 2005.

[31] H. Zhang, "Fabrication of a single-walled carbon nanotubemodified glassy carbon electrode and its application in the electrochemical determination of epirubicin," Journal of Nanoparticle Research, vol. 6, no. 6, pp. 665-669, 2004.

[32] P. Serp, M. Corrias, and P. Kalck, "Carbon nanotubes and nanofibers in catalysis," Applied Catalysis A, vol. 253, no. 2, pp. 337-358, 2003.

[33] M. Glerup, V. Krstić, C. Ewels, M. Holzinger, and G. V. Lier, Doping of Carbon Nanotubes in Doped Nanomaterials and Nanodevices, vol. 3, American Scientific, Valencia, Calif, USA, 2010.

[34] M. Moniruzzaman and K. I. Winey, "Polymer nanocomposites containing carbon nanotubes," Macromolecules, vol. 39, no. 16, pp. 5194-5205, 2006.

[35] W. Q. Tian, L. V. Liu, and Y. A. Wang, "Electronic properties and reactivity of Pt-doped carbon nanotubes," Physical Chemistry Chemical Physics, vol. 8, no. 30, pp. 3528-3539, 2006.

[36] W. Q. Tian, L. V. Liu, and Y. A. Wang, "Electronic properties and reactivity of the doped and defected single-walled carbon nanotubes," in Handbook of Theoretical andComputational Nanotechnology, M. Rieth and W. Schommers, Eds., chapter 10, pp. 499-524, American Scientific, Valencia, Calif, USA, 2006.

[37] C. A. Dyke and J. M. Tour, "Covalent functionalization of single-walled carbon nanotubes for materials applications," Journal of Physical Chemistry A, vol. 108, no. 51, pp. 1115111159, 2004.

[38] E. T. Thostenson, Z. Ren, and T. W. Chou, "Advances in the science and technology of carbon nanotubes and their composites: a review," Composites Science and Technology, vol. 61, no. 13, pp. 1899-1912, 2001.

[39] M. S. Dresselhaus, G. Dresselhaus, and P. C. Eklund, Science of Fullerenes and Carbon Nanotubes, chapter 19, Academic Press, San Diego, Calif, USA, 1995.
[40] N. Hamada, S. I. Sawada, and A. Oshiyama, "New onedimensional conductors: graphitic microtubules," Physical Review Letters, vol. 68, no. 10, pp. 1579-1581, 1992.

[41] X. Lu and Z. Chen, "Curved Pi-conjugation, aromaticity, and the related chemistry of small fullerenes $(<\mathrm{C} 60)$ and singlewalled carbon nanotubes," Chemical Reviews, vol. 105, no. 10, pp. 3643-3696, 2005.

[42] R. C. Haddon, "Chemistry of the fullerenes: the manifestation of strain in a class of continuous aromatic molecules," Science, vol. 261, no. 5128, pp. 1545-1550, 1993.

[43] R. C. Haddon, L. T. Scott, G. J. Bujtor, and A. K. Scott, “ $\pi$ Orbital conjugation and rehybridization in bridged annulenes and deformed molecules in general: $\pi$-orbital axis vector analysis," Pure and Applied Chemistry, vol. 58, pp. 137142, 1986.

[44] Z. Chen, W. Thiel, and A. Hirsch, "Reactivity of the convex and concave surfaces of single-walled carbon nanotubes (SWCNTs) towards addition reactions: dependence on the carbon-atom pyramidalization," ChemPhysChem, vol. 4, no. 1, pp. 93-97, 2003.

[45] C. S. Yeung and Y. A. Wang, "Lewis acidity of Pt-doped buckybowls,fullerenes, and single-walled nanotubes," submitted to The Journal of Physical Chemistry $C$.

[46] J. Li, G. Jia, and Y. Zhang, "Chemical anisotropies of carbon nanotubes and fullerenes caused by the curvature directivity," Chemistry - A European Journal, vol. 13, no. 22, pp. 64306436, 2007.

[47] J. Li, G. Jia, Y. Zhang, and Y. Chen, "Bond-curvature effect of sidewall $[2+1]$ cycloadditions of single-walled carbon nanotubes: a new criterion to the adduct structures," Chemistry of Materials, vol. 18, no. 15, pp. 3579-3584, 2006.

[48] M. J. O’Connell, P. Boul, L. M. Ericson et al., "Reversible water-solubilization of single-walled carbon nanotubes by polymer wrapping," Chemical Physics Letters, vol. 342, no. 34, pp. 265-271, 2001.

[49] L. A. Girifalco, M. Hodak, and R. S. Lee, "Carbon nanotubes, buckyballs, ropes, and a universal graphitic potential," Physical Review B, vol. 62, no. 19, pp. 13104-13110, 2000.

[50] P. L. McEuen, M. Bockrath, D. H. Cobden, Y. G. Yoon, and S. G. Louie, "Disorder, pseudospins, and backscattering in carbon nanotubes," Physical Review Letters, vol. 83, no. 24, pp. 5098-5101, 1999.

[51] J. Kong, E. Yenilmez, T. W. Tombler et al., "Quantum interference and ballistic transmission in nanotube electron waveguides," Physical Review Letters, vol. 87, no. 10, Article ID 106801, 2001.

[52] C. T. White and T. N. Todorov, "Carbon nanotubes as long ballistic conductors," Nature, vol. 393, no. 6682, pp. 240-242, 1998.

[53] T. Hertel and G. Moos, "Electron-phonon interaction in single-wall carbon nanotubes: a time-domain study," Physical Review Letters, vol. 84, no. 21, pp. 5002-5005, 2000.

[54] J. L. Stevens, A. Y. Huang, H. Peng, I. W. Chiang, V. N. Khabashesku, and J. L. Margrave, "Sidewall aminofunctionalization of single-walled carbon nanotubes through fluorination and subsequent reactions with terminal diamines," Nano Letters, vol. 3, no. 3, pp. 331-336, 2003.

[55] R. K. Saini, I. W. Chiang, H. Peng et al., "Covalent sidewall functionalization of single wall carbon nanotubes," Journal of the American Chemical Society, vol. 125, no. 12, pp. 36173621, 2003. 
[56] E. T. Mickelson, C. B. Huffman, A. G. Rinzler, R. E. Smalley, R. H. Hauge, and J. L. Margrave, "Fluorination of single-wall carbon nanotubes," Chemical Physics Letters, vol. 296, no. 12, pp. 188-194, 1998.

[57] S. Banerjee and S. S. Wong, "Rational sidewall functionalization and purification of single-walled carbon nanotubes by solution-phase ozonolysis," Journal of Physical Chemistry B, vol. 106, no. 47, pp. 12144-12151, 2002.

[58] X. Lu, L. Zhang, X. Xu, N. Wang, and Q. Zhang, "Can the sidewalls of single-wall carbon nanotubes be ozonized?" Journal of Physical Chemistry B, vol. 106, no. 9, pp. 21362139, 2002.

[59] J. L. Delgado, P. De La Cruz, F. Langa, A. Urbina, J. Casado, and J. T. López Navarrete, "Microwave-assisted sidewall functionalization of single-wall carbon nanotubes by DielsAlder cycloaddition," Chemical Communications, vol. 10, no. 15, pp. 1734-1735, 2004.

[60] X. Lu, F. Tian, N. Wang, and Q. Zhang, "Organic functionalization of the sidewalls of carbon nanotubes by Diels-Alder reactions: a theoretical prediction," Organic Letters, vol. 4, no. 24, pp. 4313-4315, 2002.

[61] X. Lu, F. Tian, Y. Feng, X. Xu, N. Wang, and Q. Zhang, "Sidewall oxidation and complexation of carbon nanotubes by base-catalyzed cycloaddition of transition metal oxide: a theoretical prediction," Nano Letters, vol. 2, no. 11, pp. 13251327, 2002.

[62] L. Long, X. Lu, F. Tian, and Q. Zhang, "Hydroboration of $\mathrm{C}(100)$ surface, fullerene, and the sidewalls of singlewall carbon nanotubes with borane," Journal of Organic Chemistry, vol. 68, no. 11, pp. 4495-4498, 2003.

[63] F. Liang, A. K. Sadana, A. Peera et al., "A convenient route to functionalized carbon nanotubes," Nano Letters, vol. 4, no. 7, pp. 1257-1260, 2004.

[64] M. Holzinger, O. Vostrowsky, A. Hirsch et al., "Sidewall functionalization of carbon nanotubes," Angewandte Chemie International Edition, vol. 40, no. 21, pp. 4002-4005, 2001.

[65] M. Holzinger, J. Abraham, P. Whelan et al., "Functionalization of single-walled carbon nanotubes with (R-)oxycarbonyl nitrenes," Journal of the American Chemical Society, vol. 125, no. 28, pp. 8566-8580, 2003.

[66] V. Georgakilas, K. Kordatos, M. Prato, D. M. Guldi, M. Holzinger, and A. Hirsch, "Organic functionalization of carbon nanotubes," Journal of the American Chemical Society, vol. 124, no. 5, pp. 760-761, 2002.

[67] W. Zhang, J. K. Sprafke, M. Ma et al., "Modular functionalization of carbon nanotubes and fullerenes," Journal of the American Chemical Society, vol. 131, no. 24, pp. 8446-8454, 2009.

[68] W. Zhang and T. M. Swager, "Functionalization of singlewalled carbon nanotubes and fullerenes via a dimethyl acetylenedicarboxylate-4-dimethylaminopyridine zwitterion approach," Journal of the American Chemical Society, vol. 129, no. 25, pp. 7714-7715, 2007.

[69] N. Tagmatarchis, V. Georgakilas, M. Prato, and H. Shinohara, "Sidewall functionalization of single-walled carbon nanotubes through electrophilic addition," Chemical Communications, no. 18, pp. 2010-2011, 2002.

[70] H. Peng, L. B. Alemany, J. L. Margrave, and V. N. Khabashesku, "Sidewall carboxylic acid functionalization of singlewalled carbon nanotubes," Journal of the American Chemical Society, vol. 125, no. 49, pp. 15174-15182, 2003.

[71] H. Sawada, K. Shindo, K. Ueno, and K. Hamazaki, "Reactions of fluoroalkanoyl peroxides with single-walled carbon nanotubes: application to sidewall modification of singlewalled carbon nanotubes with the introduction of fluoroalkyl groups," Polymers for Advanced Technologies, vol. 16, no. 1112, pp. 764-769, 2005.

[72] T. Nakamura, M. Ishihara, T. Ohana, A. Tanaka, and Y. Koga, "Sidewall modification of single-walled carbon nanotubes using photolysis of perfluoroazooctane," Chemical Communications, vol. 10, no. 11, pp. 1336-1337, 2004.

[73] J. L. Bahr, J. Yang, D. V. Kosynkin, M. J. Bronikowski, R. E. Smalley, and J. M. Tour, "Functionalization of carbon nanotubes by electrochemical reduction of aryl diazonium salts: a bucky paper electrode," Journal of the American Chemical Society, vol. 123, no. 27, pp. 6536-6542, 2001.

[74] M. Terrones, A. Jorio, M. Endo et al., "New direction in nanotube science," Materials Today, vol. 7, no. 9, pp. 30-45, 2004.

[75] C. Ewels, M. Glerup, and V. Krstić, "Nitrogen and boron doping in carbon nanotubes," in Doped Nanomaterials and Nanodevices, vol. 3, American Scientific, Valencia, Calif, USA, 2010.

[76] D. Golberg, Y. Bando, W. Han, K. Kurashima, and T. Sato, "Single-walled B-doped carbon, B/N-doped carbon and BN nanotubes synthesized from single-walled carbon nanotubes through a substitution reaction," Chemical Physics Letters, vol. 308, no. 3-4, pp. 337-342, 1999.

[77] S. L. Sung, S. H. Tsai, C. H. Tseng, F. K. Chiang, X. W. Liu, and H. C. Shih, "Well-aligned carbon nitride nanotubes synthesized in anodic alumina by electron cyclotron resonance chemical vapor deposition," Applied Physics Letters, vol. 74, no. 2, pp. 197-199, 1999.

[78] P. L. Gai, O. Stephan, K. McGuire et al., "Structural systematics in boron-doped single wall carbon nanotubes," Journal of Materials Chemistry, vol. 14, no. 4, pp. 669-675, 2004.

[79] M. Glerup, J. Steinmetz, D. Samaille et al., "Synthesis of Ndoped SWNT using the arc-discharge procedure," Chemical Physics Letters, vol. 387, no. 1-3, pp. 193-197, 2004.

[80] D. Srivastava, M. Menon, C. Daraio, S. Jin, B. Sadanadan, and A. M. Rao, "Vacancy-mediated mechanism of nitrogen substitution in carbon nanotubes," Physical Review B, vol. 69, no. 15, Article ID 153414, 2004.

[81] L. V. Liu, W. Q. Tian, and Y. A. Wang, "Chemical reaction of nitric oxides with the 5-1DB defect of the single-walled carbon nanotube," Journal of Physical Chemistry B, vol. 110, no. 5, pp. 1999-2005, 2006.

[82] A. V. Krasheninnikov, K. Nordlund, M. Sirviö, E. Salonen, and J. Keinonen, "Formation of ion-irradiation-induced atomic-scale defects on walls of carbon nanotubes," Physical Review B, vol. 63, no. 24, Article ID 245405, 2001.

[83] P. M. Ajayan, V. Ravikumar, and J. C. Charlier, "Surface reconstructions and dimensional changes in single-walled carbon nanotubes," Physical Review Letters, vol. 81, no. 7, pp. 1437-1440, 1998.

[84] A. V. Krasheninnikov and K. Nordlund, "Stability of irradiation-induced point defects on walls of carbon nanotubes," Journal of Vacuum Science and Technology B, vol. 20, no. 2, pp. 728-733, 2002.

[85] A. H. Nevidomskyy, G. Csányi, and M. C. Payne, "Chemically active substitutional nitrogen impurity in carbon nanotubes," Physical Review Letters, vol. 91, no. 10, Article ID 105502, 2003.

[86] H. J. Choi, J. Ihm, S. G. Louie, and M. L. Cohen, "Defects, quasibound states, and quantum conductance in metallic 
carbon nanotubes," Physical Review Letters, vol. 84, no. 13, pp. 2917-2920, 2000.

[87] S. Latil, S. Roche, D. Mayou, and J. C. Charlier, "Mesoscopic transport in chemically doped carbon nanotubes," Physical Review Letters, vol. 92, no. 25, Article ID 256805, 2004.

[88] K. Liu, P. Avouris, R. Martel, and W. K. Hsu, "Electrical transport in doped multiwalled carbon nanotubes," Physical Review B, vol. 63, no. 16, Article ID 161404, 2001.

[89] H. S. Kang and S. Jeong, "Nitrogen doping and chirality of carbon nanotubes," Physical Review B, vol. 70, Article ID 233411, 2004.

[90] C. C. Kaun, B. Larade, H. Mehrez, J. Taylor, and H. Guo, "Current-voltage characteristics of carbon nanotubes with substitutional nitrogen," Physical Review B, vol. 65, no. 20, Article ID 205416, 2002.

[91] S. H. Yang, W. H. Shin, J. W. Lee, S. Y. Kim, S. I. Woo, and J. K. Kang, "Interaction of a transition metal atom with intrinsic defects in single-walled carbon nanotubes," Journal of Physical Chemistry B, vol. 110, no. 28, pp. 13941-13946, 2006.

[92] G. Mpourmpakis, G. E. Froudakis, A. N. Andriotis, and M. Menon, "Carbon-nanotube tips with edge made of a transition metal," Applied Physics Letters, vol. 87, no. 19, Article ID 193105, 2005.

[93] S. Dag, Y. Ozturk, S. Ciraci, and T. Yildirim, "Adsorption and dissociation of hydrogen molecules on bare and functionalized carbon nanotubes," Physical Review B, vol. 72, no. 15, Article ID 155404, 2005.

[94] W. Q. Deng, X. Xu, and W. A. Goddard, "A two-stage mechanism of bimetallic catalyzed growth of single-walled carbon nanotubes," Nano Letters, vol. 4, no. 12, pp. 23312335, 2004.

[95] A. Thess, R. Lee, P. Nikolaev et al., "Crystalline ropes of metallic carbon nanotubes," Science, vol. 273, no. 5274, pp. 483-487, 1996.

[96] A. Hayashi, Y. Xie, J. M. Poblet, J. M. Campanera, C. B. Lebrilla, and A. L. Balch, "Mass spectrometric and computational studies of heterofullerenes $\left(\left[\mathrm{C}_{58} \mathrm{Pt}\right]^{-},\left[\mathrm{C}_{59} \mathrm{Pt}\right]^{+}\right)$ obtained by laser ablation of electrochemically depositedfilms," Journal of Physical Chemistry A, vol. 108, no. 12, pp. 2192-2198, 2004.

[97] Q. Kong, J. Zhuang, J. Xu et al., "Contrasting behaviors of metal fullerides CRh and CM $(\mathrm{M}=\mathrm{La}, \mathrm{Y})$ in the metallofullerene formation by laser ablation," Journal of Physical Chemistry A, vol. 107, no. 19, pp. 3670-3677, 2003.

[98] Q. Kong, J. Zhuang, X. Li et al., "Formation of metallofullerenes by laser ablation of externally doped fullerenes $\mathrm{C}_{60} \mathrm{M}_{\mathrm{x}}(\mathrm{M}=\mathrm{Sm}, \mathrm{Pt}$ and Ni)," Applied Physics A, vol. 75, no. 3, pp. 367-374, 2002.

[99] J. M. Poblet, J. Muñoz, K. Winkler et al., "Geometric and electronic structure of metal-cage fullerenes, $\mathrm{C}_{59} \mathrm{M}(\mathrm{M}$ : Pt, Ir) obtained by laser ablation of electrochemically deposited films," Chemical Communications, no. 6, pp. 493-494, 1999.

[100] T. Kimura, T. Sugai, and H. Shinohara, "Production and mass spectroscopic characterization of metallocarbon clusters incorporating Sc, Y, and Ca atoms," International Journal of Mass Spectrometry, vol. 188, no. 3, pp. 225-232, 1999.

[101] W. Branz, I. M. L. Billas, N. Malinowski, F. Tast, M. Heinebrodt, and T. P. Martin, "Cage substitution in metalfullerene clusters," Journal of Chemical Physics, vol. 109, no. 9, pp. 3425-3430, 1998.

[102] K. B. Shelimov, D. E. Clemmer, and M. F. Jarrold, "Structures and isomerization of $\mathrm{LaC}$ clusters," Journal of Physical Chemistry, vol. 99, no. 29, pp. 11376-11386, 1995.
[103] K. B. Shelimov, D. E. Clemmer, and M. F. Jarrold, "Structures and formation of small LaC metallofullerenes," Journal of Physical Chemistry, vol. 98, no. 49, pp. 12819-12821, 1994.

[104] D. Changgeng, Y. Jinlong, H. Rongsheng, and W. Kelin, "Formation mechanism and structural and electronic properties of metal-substituted fullerenes CM (M = Co, Rh, and Ir)," Physical Review A, vol. 64, no. 4, Article ID 043201, 2001.

[105] M. Sparta, K. J. Børve, and V. R. Jensen, "Structure and stability of networked metallofullerenes of the transition metals," Journal of Physical Chemistry A, vol. 110, no. 41, pp. 11711-11716, 2006.

[106] G. Lu, K. Deng, H. Wu, J. Yang, and X. Wang, "Geometric and electronic structures of metal-substitutional fullerene $\mathrm{C}_{59} \mathrm{Sm}$ and metal-exohedral fullerenes $\mathrm{C}_{60} \mathrm{Sm}$," Journal of Chemical Physics, vol. 124, no. 5, Article ID 054305, 2006.

[107] J. M. Campanera, C. Bo, A. L. Balch, J. Ferré, and J. M. Poblet, "Prediction of heterofullerene stabilities: a combined DFT and chemometric study of CPt, CPt and C Pt," Chemistry-A European Journal, vol. 11, no. 9, pp. 2730-2742, 2005.

[108] I. M. L. Billas, C. Massobrio, M. Boero et al., "First principles calculations of iron-doped heterofullerenes," Computational Materials Science, vol. 17, no. 2-4, pp. 191-195, 2000.

[109] D. Changgeng, Y. Jinlong, C. Xiangyuan, and C. T. Chan, "Geometric and electronic structures of metal-substituted fullerenes CM (M=Fe, Co, Ni, and Rh)," Journal of Chemical Physics, vol. 111, no. 18, pp. 8481-8485, 1999.

[110] W. Q. Tian, L. V. Liu, Y.-K. Chen, and Y. A. Wang, "Electronic structure and reactivities of perfect, defected, and doped single-walled carbon nanotubes," in Trends in Computational Nanomechanics: Transcending Length and Time Scales, T. Dumitrica, Ed., chapter 16, Springer, Dordrecht, The Netherlands, 2010.

[111] L. V. Liu, W. Q. Tian, and Y. A. Wang, "Ozonization at the vacancy defect site of the single-walled carbon nanotube," Journal of Physical Chemistry B, vol. 110, no. 26, pp. 1303713044, 2006.

[112] L. V. Liu, W. Q. Tian, and Y. A. Wang, "Ab initio studies of vacancy-defected fullerenes and single-walled carbon nanotubes," International Journal of Quantum Chemistry, vol. 109, no. 14, pp. 3441-3456, 2009.

[113] C. S. Yeung, L. V. Liu, and Y. A. Wang, "Adsorption of small gas molecules onto Pt-doped single-walled carbon nanotubes," Journal of Physical Chemistry C, vol. 112, no. 19, pp. 7401-7411, 2008.

[114] C. S. Yeung, L. V. Liu, and Y. A. Wang, "Novel nanotubecoordinated platinum complexes," Journal of Computational and Theoretical Nanoscience, vol. 4, no. 6, pp. 1108-1119, 2007.

[115] C. W. Lam, J. T. James, R. McCluskey, S. Arepalli, and R. L. Hunter, "A review of carbon nanotube toxicity and assessment of potential occupational and environmental health risks," Critical Reviews in Toxicology, vol. 36, no. 3, pp. 189-217, 2006.

[116] A. Nel, T. Xia, L. Mädler, and N. Li, "Toxic potential of materials at the nanolevel," Science, vol. 311, no. 5761, pp. 622-627, 2006.

[117] A. S. Karakoti, L. L. Hench, and S. Seal, "The potential toxicity of nanomaterials - the role of surfaces," Journal of the Minerals, Metals, and Materials Society, vol. 58, no. 7, pp. 7782, 2006.

[118] H. M. Kipen and D. L. Laskin, "Smaller is not always better: nanotechnology yields nanotoxicology," American Journal of Physiology: Lung Cellular and Molecular Physiology, vol. 289, no. 5, pp. L696-L697, 2005. 
[119] R. F. Service, “Nanotechnology grows up,” Science, vol. 304, no. 5678, pp. 1732-1734, 2004.

[120] K. L. Dreher, "Health and environmental impact of nanotechnology: toxicological assessment of manufactured nanoparticles," Toxicological Sciences, vol. 77, no. 1, pp. 3-5, 2004.

[121] J. Muller, F. Huaux, N. Moreau et al., "Respiratory toxicity of multi-wall carbon nanotubes," Toxicology and Applied Pharmacology, vol. 207, no. 3, pp. 221-231, 2005.

[122] M. Chiaretti, G. Mazzanti, S. Bosco et al., "Carbon nanotubes toxicology and effects on metabolism and immunological modification in vitro and in vivo," Journal of Physics Condensed Matter, vol. 20, no. 47, Article ID 474203, 2008.

[123] R. Singh, D. Pantarotto, L. Lacerda et al., "Tissue biodistribution and blood clearance rates of intravenously administered carbon nanotube radiotracers," Proceedings of the National Academy of Sciences of the United States of America, vol. 103, no. 9, pp. 3357-3362, 2006.

[124] A. Nel, "Air pollution-related illness: effects of particles," Science, vol. 308, no. 5723, pp. 804-806, 2005.

[125] A. T. Bell, "The impact of nanoscience on heterogeneous catalysis," Science, vol. 299, no. 5613, pp. 1688-1691, 2003.

[126] K. Donaldson and C. L. Tran, "Inflammation caused by particles and fibers," Inhalation Toxicology, vol. 14, no. 1, pp. 5-27, 2002.

[127] B. Halliwell and J. M. C. Gutteridge, Free Radicals in Biology and Medicine, Oxford University Press, Oxford, UK, 1999.

[128] L. Ding, J. Stilwell, T. Zhang et al., "Molecular characterization of the cytotoxic mechanism of multiwall carbon nanotubes and nano-onions on human skin fibroblast," Nano Letters, vol. 5, no. 12, pp. 2448-2464, 2005.

[129] V. E. Kagan, Y. Y. Tyurina, V. A. Tyurin et al., "Direct and indirect effects of single walled carbon nanotubes on RAW 264.7 macrophages: role of iron," Toxicology Letters, vol. 165, no. 1, pp. 88-100, 2006.

[130] G. Jia, H. Wang, L. Yan et al., "Cytotoxicity of carbon nanomaterials: single-wall nanotube, multi-wall nanotube, and fullerene," Environmental Science and Technology, vol. 39, no. 5, pp. 1378-1383, 2005.

[131] J. Cheng, E. Flahaut, and H. C. Shuk, "Effect of carbon nanotubes on developing zebrafish (Danio rerio) embryos," Environmental Toxicology and Chemistry, vol. 26, no. 4, pp. 708-716, 2007.

[132] J. B. Mangum, E. A. Turpin, A. Antao-Menezes, M. F. Cesta, E. Bermudez, and J. C. Bonner, "Single-walled carbon nanotube (SWCNT)-induced interstitial fibrosis in the lungs of rats is associated with increased levels of PDGF mRNA and the formation of unique intercellular carbon structures that bridge alveolar macrophages In Situ," Particle and Fibre Toxicology, vol. 3, article 15, 2006.

[133] C. W. Lam, J. T. James, R. McCluskey, and R. L. Hunter, "Pulmonary toxicity of single-wall carbon nanotubes in mice 7 and 90 days after intractracheal instillation," Toxicological Sciences, vol. 77, no. 1, pp. 126-134, 2004.

[134] M. L. Schipper, N. Nakayama-Ratchford, C. R. Davis et al., "A pilot toxicology study of single-walled carbon nanotubes in a small sample of mice," Nature Nanotechnology, vol. 3, no. 4, pp. 216-221, 2008.

[135] O. W. Griffith and D. J. Stuehr, "Nitric oxide synthases: properties and catalytic mechanism," Annual Review of Physiology, vol. 57, pp. 707-736, 1995.

[136] M. R. Miller and I. L. Megson, "Recent developments in nitric oxide donor drugs," British Journal of Pharmacology, vol. 151, no. 3, pp. 305-321, 2007.
[137] E. Culotta and D. E. Koshland, "No news is good news," Science, vol. 258, no. 5090, pp. 1862-1865, 1992.

[138] J. M. Fukuto and L. J. Ignarro, "In vivo aspects of nitric oxide (NO) chemistry: does peroxynitrite (-OONO) play a major role in cytotoxicity," Accounts of Chemical Research, vol. 30, pp. 149-152, 1997.

[139] B. I. Jugdutt, "Nitric oxide in heart failure: friend or foe," Heart Failure Reviews, vol. 7, no. 4, pp. 385-389, 2002.

[140] D. Bruch-Gerharz, T. Ruzicka, and V. Kolb-Bachofen, "Nitric oxide in human skin: current status and future prospects," Journal of Investigative Dermatology, vol. 110, no. 1, pp. 1-7, 1998.

[141] R. P. Hunter, "Nitric oxide, inducible nitric oxide synthase and inflammation in veterinary medicine," Animal Health Research Reviews, vol. 3, no. 2, pp. 119-133, 2002.

[142] R. L. Scher, "Role of nitric oxide in the development of distant metastasis from squamous cell carcinoma," Laryngoscope, vol. 117, no. 2, pp. 199-209, 2007.

[143] P. Vallance and J. Leiper, "Blocking no synthesis: how, where and why?" Nature Reviews Drug Discovery, vol. 1, no. 12, pp. 939-950, 2002.

[144] P. S. Wheatley, A. R. Butler, M. S. Crane et al., "NO-releasing zeolites and their antithrombotic properties," Journal of the American Chemical Society, vol. 128, no. 2, pp. 502-509, 2006.

[145] M. C. Frost, M. M. Reynolds, and M. E. Meyerhoff, "Polymers incorporating nitric oxide releasing/generating substances for improved biocompatibility of blood-contacting medical devices," Biomaterials, vol. 26, no. 14, pp. 1685-1693, 2005.

[146] E. B. Caruso, S. Petralia, S. Conoci, S. Giuffrida, and S. Sortino, "Photodelivery of nitric oxide from water-soluble platinum nanoparticles," Journal of the American Chemical Society, vol. 129, no. 3, pp. 480-481, 2007.

[147] M. Lucci, A. Reale, A. Di Carlo et al., "Optimization of a NO gas sensor based on single walled carbon nanotubes," Sensors and Actuators B, vol. 118, no. 1-2, pp. 226-231, 2006.

[148] S. Peng and K. Cho, "Ab initio study of doped carbon nanotube sensors," Nano Letters, vol. 3, no. 4, pp. 513-517, 2003.

[149] L. B. Da Silva, S. B. Fagan, and R. Mota, "Ab initio study of deformed carbon nanotube sensors for carbon monoxide molecules," Nano Letters, vol. 4, no. 1, pp. 65-67, 2004.

[150] E. Bekyarova, M. Davis, T. Burch et al., "Chemically functionalized single-walled carbon nanotubes as ammonia sensors," Journal of Physical Chemistry B, vol. 108, no. 51, pp. 1971719720, 2004.

[151] M. Lucci, A. Reale, A. Di Carlo et al., "Optimization of a NO gas sensor based on single walled carbon nanotubes," Sensors and Actuators B, vol. 118, no. 1-2, pp. 226-231, 2006.

[152] P. G. Collins, K. Bradley, M. Ishigami, and A. Zettl, "Extreme oxygen sensitivity of electronic properties of carbon nanotubes," Science, vol. 287, no. 5459, pp. 1801-1804, 2000.

[153] J. Kong, M. G. Chapline, and H. Dai, "Capillary force lithography," Advanced Materials, vol. 13, no. 18, pp. 13861389, 2001.

[154] J. Kong, N. R. Franklin, C. Zhou et al., "Nanotube molecular wires as chemical sensors," Science, vol. 287, no. 5453, pp. 622-625, 2000.

[155] E. D. Glendening, A. E. Carpenter, and F. Weinhold, "NBO," Version 3.1, 1995.

[156] A. E. Reed, L. A. Curtiss, and F. Weinhold, "Intermolecular interactions from a natural bond orbital, donor-acceptor viewpoint," Chemical Reviews, vol. 88, no. 6, pp. 899-926, 1988. 
[157] K. Fukui, T. Yonezawa, and H. Shingu, "A molecular orbital theory of reactivity in aromatic hydrocarbons," The Journal of Chemical Physics, vol. 20, no. 4, pp. 722-725, 1952.

[158] K. Fukui, T. Yonezawa, C. Nagata, and H. Shingu, "Molecular orbital theory of orientation in aromatic, heteroaromatic, and other conjugated molecules," The Journal of Chemical Physics, pp. 1433-1442, 1954.

[159] K. Fukui, "Role of frontier orbitals in chemical reactions," Science, vol. 218, pp. 747-754, 1987.

[160] K. Fukui, "Role of frontier orbitals in chemical reactions," Theory of Orientation and Stereoselection, Springer, Berlin, Germany, 1975.

[161] R. G. Parr and W. Yang, Density-Functional Theory of Atoms and Molecules, Oxford University Press, New York, NY, USA, 1989.

[162] A. Tenderholt, "PyMOlyze," Version 1.1, 2005.

[163] M. J. Frisch, G. W. Trucks, and H. B. Schlegel, “Gaussian 03," Revision B.05. Gaussian, Inc., Wallingford, Conn, USA, 2004.

[164] J. J. P. Stewart, "Optimization of parameters for semiempirical methods. I. Method," Journal of Computational Chemistry, vol. 10, pp. 209-220, 1989.

[165] C. Lee, W. Yang, and R. G. Parr, "Development of the ColleSalvetti correlation-energy formula into a functional of the electron density," Physical Review B, vol. 37, pp. 785-789, 1988.

[166] A. D. Becke, "Density-functional thermochemistry. III. The role of exact exchange," Journal of Chemical Physics, vol. 98, pp. 5648-5652, 1993.

[167] B. Miehlich, A. Savin, H. Stoll, and H. Preuss, "Results obtained with the correlation energy density functionals of becke and Lee, Yang and Parr," Chemical Physics Letters, vol. 157, no. 3, pp. 200-206, 1989.

[168] P. C. Hariharan and J. A. Pople, "Accuracy of AHn equilibrium geometries by single determinant molecular orbital theory," Molecular Physics, vol. 27, pp. 209-214, 1974.

[169] W. J. Hehre, K. Ditchfield, and J. A. Pople, "Self-consistent molecular orbital methods. XII. Further extensions of gaussian-type basis sets for use in molecular orbital studies of organic molecules," The Journal of Chemical Physics, vol. 56, no. 5, pp. 2257-2261, 1972.

[170] R. Ditchfield, W. J. Hehre, and J. A. Pople, "Self-consistent molecular-orbital methods. IX. An extended gaussian-type basis for molecular-orbital studies of organic molecules," The Journal of Chemical Physics, vol. 54, no. 2, pp. 724-728, 1971.

[171] M. S. Gordon, "The isomers of silacyclopropane," Chemical Physics Letters, vol. 76, pp. 163-168, 1980.

[172] F. Maseras and K. J. Morokuma, "IMOMM-a new integrated ab-initio plus molecular mechanics geometry optimization scheme of equilibrium structures and transition states," Journal of Computational Chemistry, vol. 16, pp. 1170-1179, 1995.

[173] A. K. Rappé, C. J. Casewit, K. S. Colwell, W. A. Goddard, and W. M. Skiff, "UFF, a full periodic table force field for molecular mechanics and molecular dynamics simulations," Journal of the American Chemical Society, vol. 114, no. 25, pp. 10024-10035, 1992.

[174] M. J. S. Dewar, E. G. Zoebisch, E. F. Healy, and J. J. P. Stewart, "AM1: a new general purpose quantum mechanical molecular model," Journal of the American Chemical Society, vol. 107, no. 13, pp. 3902-3909, 1985.

[175] M. J. S. Dewar, M. L. McKee, and H. S. Rzepa, "MNDO parameters for third period elements," Journal of the American Chemical Society, vol. 100, no. 11, p. 3607, 1978.
[176] M. J. S. Dewar and W. Thiel, "Ground states of molecules. 38. The MNDO method. Approximations and parameters," Journal of the American Chemical Society, vol. 99, no. 15, pp. 4899-4907, 1977.

[177] X. Lu, Z. Chen, and P. V. R. Schleyer, "Are stone-wales defect sites always more reactive than perfect sites in the sidewalls of single-wall carbon nanotubes?" Journal of the American Chemical Society, vol. 127, no. 1, pp. 20-21, 2005.

[178] W. L. Yim and Z. F. Liu, "A reexamination of the chemisorption and desorption of ozone on the exterior of a $(5,5)$ singlewalled carbon nanotube," Chemical Physics Letters, vol. 398, no. 4-6, pp. 297-303, 2004

[179] H. B. Schlegel, S. S. Iyengar, X. Li et al., "Ab initio molecular dynamics: propagating the density matrix with Gaussian orbitals. III. Comparison with Born-Oppenheimer dynamics," Journal of Chemical Physics, vol. 117, no. 19, pp. 8694-8704, 2002.

[180] H. B. Schlegel, J. M. Millam, S. S. Iyengar et al., "Ab initio molecular dynamics: propagating the density matrix with Gaussian orbitals," Journal of Chemical Physics, vol. 114, no. 22, pp. 9758-9763, 2001.

[181] S. S. Iyengar, H. B. Schlegel, J. M. Millam, G. A. Voth, G. E. Scuseria, and M. J. Frisch, "Ab initio molecular dynamics: propagating the density matrix with Gaussian orbitals. II. Generalizations based on mass-weighting, idempotency, energy conservation and choice of initial conditions," Journal of Chemical Physics, vol. 115, no. 22, pp. 10291-10302, 2001.

[182] P. J. Hay, W. R. Wadt, A. Y. Kumar, and R. S. Srivastava, "Ab initio effective core potentials for molecular calculations. Potentials for potassium to gold including the outermost core orbitals," Journal of Chemical Physics, vol. 82, pp. 299-316, 1985.

[183] T. H. Dunning and P. J. Hay, Modern Theoretical Chemistry, vol. 3, Plenum, New York, NY, USA, 1976.

[184] P. Mastrorilli, C. F. Nobile, G. P. Suranna et al., "Synthesis and carbonylation of platinum(II) organometallic complexes with bis(phosphanyl) monosulfides-Crystal structures of $\left[\kappa^{2} P, S-\mathrm{Ph}_{2} \mathrm{CH}_{2} \mathrm{P}(\mathrm{S}) \mathrm{Ph}_{2} \mathrm{Pt}\left(\mathrm{CH}_{3}\right)(\mathrm{Cl})\right]$ and $[\kappa P, \mu-\kappa S$ $\left.\mathrm{Ph}_{2} \mathrm{CH}_{2} \mathrm{CH}_{2} \mathrm{P}(\mathrm{S}) \mathrm{Ph}{ }_{2} \mathrm{Pt}\left(\mathrm{CH}_{3}\right)\right]_{2}\left[\mathrm{BF}_{4}\right]_{2}$," European Journal of Inorganic Chemistry, no. 6, pp. 1234-1242, 2004.

[185] A. W. Ehlers, S. Dapprich, S. F. Vyboishchikov, and G. Frenking, "Structure and bonding of the transition-metal carbonyl complexes $\mathrm{M}(\mathrm{CO}) \mathrm{L}(\mathrm{M}=\mathrm{Cr}, \mathrm{Mo}, \mathrm{W})$ and $\mathrm{M}(\mathrm{CO}) \mathrm{L}$ $(\mathrm{M}=\mathrm{Ni}, \mathrm{Pd}, \mathrm{Pt} ; \mathrm{L}=\mathrm{CO}, \mathrm{SiO}, \mathrm{CS}, \mathrm{N}, \mathrm{NO}, \mathrm{CN}, \mathrm{NC}, \mathrm{HCCH}$, $\mathrm{CCH}, \mathrm{CH}, \mathrm{CF}, \mathrm{H})$," Organometallics, vol. 15, no. 1, pp. 105117, 1996.

[186] J. Puga, R. Patrini, K. M. Sanchez, and B. C. Gates, "Surfacemediated organometallic synthesis: preparation of platinum carbonyl $[\mathrm{Pt} 3(\mathrm{CO}) 6] \mathrm{n} 2-(\mathrm{n}=3,4)$ by the carbonylation of platinum complexes on magnesium oxide under carbon monoxide and carbon monoxide + dihydrogen," Inorganic Chemistry, vol. 30, no. 11, pp. 2479-2483, 1991.

[187] G. W. Smith and E. A. Carter, "Interactions of NO and CO with Pd and Pt atoms," Journal of Physical Chemistry, vol. 95, no. 6, pp. 2327-2339, 1991.

[188] H. Orita, I. Nakamura, and T. Fujitani, "Studies of NO adsorption on $\mathrm{Pt}(110)-(1 \times 2)$ and $(1 \times 1)$ surfaces using density functional theory," Journal of Physical Chemistry B, vol. 109, no. 20, pp. 10312-10318, 2005.

[189] H. Orita, N. Itoh, and Y. Inada, "All electron scalar relativistic calculations on adsorption of $\mathrm{CO}$ on $\operatorname{Pt}\left(\begin{array}{lll}1 & 1 & 1\end{array}\right)$ with fullgeometry optimization: a correct estimation for $\mathrm{CO}$ sitepreference," Chemical Physics Letters, vol. 384, no. 4-6, pp. 271-276, 2004. 
[190] L. Wang, W. Li, M. Zhang, and K. Tao, "The interactions between the $\mathrm{NiB}$ amorphous alloy and $\mathrm{TiO}$ support in the $\mathrm{NiB} / \mathrm{TiO}$ amorphous catalysts," Applied Catalysis A, vol. 259, no. 2, pp. 185-190, 2004.

[191] J. W. Medlin and M. D. Allendorf, "Theoretical study of the adsorption of acetylene on the (111) surfaces of Pd, Pt, Ni, and Rh," Journal of Physical Chemistry B, vol. 107, no. 1, pp. 217-223, 2003.

[192] F. J. Williams, A. Palermo, S. Tracey, M. S. Tikhov, and R. M. Lambert, "Electrochemical promotion by potassium of the selective hydrogenation of acetylene on platinum: reaction studies and XP spectroscopy," Journal of Physical Chemistry $B$, vol. 106, no. 22, pp. 5668-5672, 2002.

[193] A. D. Becke, "Density-functional exchange-energy approximation with correct asymptotic behavior," Physical Review A, vol. 38, pp. 3098-3100, 1988.

[194] J. P. Perdew, K. Burke, and Y. Wang, "Generalized gradient approximation for the exchange-correlation hole of a manyelectron system," Physical Review B, vol. 54, no. 23, pp. 16533-16539, 1996.

[195] J. P. Perdew, J. A. Chevary, S. H. Vosko et al., "Atoms, molecules, solids, and surfaces: applications of the generalized gradient approximation for exchange and correlation," Physical Review B, vol. 46, no. 11, pp. 6671-6687, 1992.

[196] J. P. Perdew, K. Burke, and M. Ernzerhof, "Generalized gradient approximation made simple," Physical Review Letters, vol. 77, no. 18 , pp. 3865-3868, 1996.

[197] J. R. Cheeseman, G. W. Trucks, T. A. Keith, and M. J. J. Frisch, "A Comparison of models for calculating nuclear magnetic resonance shielding tensors," Journal of Chemical Physics, vol. 104, pp. 5497-5509, 1996.

[198] K. Wolinski, J. F. Hinton, and P. Pulay, "Efficient implementation of the gauge-independent atomic orbital method for NMR chemical shift calculations," Journal of the American Chemical Society, vol. 112, no. 23, pp. 8251-8260, 1990.

[199] R. Ditchfield, "Self-consistent perturbation theory of diamagnetism: I. A gauge-invariant LCAO method for NMR chemical shifts," Molecular Physics, vol. 27, pp. 789-807, 1974.

[200] Y. K. Chen, L. V. Liu, and Y. A. Wang, "Density functional study of interaction of atomic Pt with Pristine and stonewales-defective single-walled boron nitride nanotubes," Journal of Physical Chemistry C, vol. 114, no. 29, pp. 1238212388,2010

[201] R. L. Kuczkowski, "The structure and mechanism of formation of ozonides," Chemical Society Reviews, vol. 21, no. 1, pp. 79-83, 1992.

[202] R. Criegee, "Mechanism of ozonolysis," Angewandte Chemie International Edition in English, vol. 14, pp. 745-752, 1975.

[203] F. A. Carey and R. J. Sundberg, Advanced Organic Chemistry, Part A: Structures and Mechanisms, Springer, New York, NY, USA, 5th edition, 2007.

[204] T. Dumitrică and B. Yakobsen, "Rate theory of yield in boron nitride nanotubes," Physical Review B, vol. 72, Article ID 035418, 2005.

[205] T. Dumitricǎ, H. F. Bettinger, G. E. Scuseria, and B. I. Yakobson, "Thermodynamics of yield in boron nitride nanotubes," Physical Review B, vol. 68, no. 8, Article ID 085412, 2003.

[206] H. F. Bettinger, T. Dumitricǎ, G. E. Scuseria, and B. I. Yakobson, "Mechanically induced defects and strength of BN nanotubes," Physical Review B, vol. 65, no. 4, Article ID 041406, 2002.
[207] Y. Li, Z. Zhou, D. Golberg, Y. Bando, P. R. Von Schleyer, and Z. Chen, "Stone-Wales defects in single-walled boron nitride nanotubes: formation energies, electronic structures, and reactivity," Journal of Physical Chemistry C, vol. 112, no. 5, pp. 1365-1370, 2008.

[208] X. M. Li, W. Q. Tian, X. R. Huang, C. C. Sun, and L. Jiang, "Adsorption of hydrogen on novel Pt-doped BN nanotube: a density functional theory study," Journal of Molecular Structure: THEOCHEM, vol. 901, no. 1-3, pp. 103-109, 2009.

[209] M. Gajdoš, J. Hafner, and A. Eichler, "Ab initio densityfunctional study of $\mathrm{NO}$ on close-packed transition and noble metal surfaces: I. Molecular adsorption," Journal of Physics Condensed Matter, vol. 18, no. 1, pp. 13-40, 2006.

[210] V. Rosca, G. L. Beltramo, and M. T. M. Koper, "Reduction of $\mathrm{NO}$ adlayers on $\mathrm{Pt}(110)$ and $\mathrm{Pt}(111)$ in acidic media: evidence for adsorption site-specific reduction," Langmuir, vol. 21, no. 4, pp. 1448-1456, 2005.

[211] E. H. G. Backus, A. Eichler, M. L. Grecea, A. W. Kleyn, and M. Bonn, "Adsorption and dissociation of NO on stepped Pt (533)," Journal of Chemical Physics, vol. 121, no. 16, pp. 79467954, 2004.

[212] G. Natile, F. P. Intini, R. Bertani et al., "Synthesis and characterisation of the amidine complexes trans- $[\mathrm{PtCl}(\mathrm{NH}$ ) $\mathrm{HNC}(\mathrm{NH}) \mathrm{R}] \mathrm{Cl}(\mathrm{R}=\mathrm{Me}, \mathrm{Ph}, \mathrm{CH} \mathrm{Ph})$ derived from addition of NH to the coordinated nitriles in trans-[PtCl(NCR)]," Journal of Organometallic Chemistry, vol. 690, no. 8, pp. 2121-2127, 2005.

[213] G. Bernhardt, H. Brunner, N. Gruber et al., "Carboplatin derivatives with superior antitumor activity compared to the parent compound," Inorganica Chimica Acta, vol. 357, no. 15, pp. 4452-4466, 2004.

[214] M. U. H. Baik, R. A. Friesner, and S. J. Lippard, "cis$\left\{\mathrm{Pt}\left(\mathrm{NH}_{3}\right)_{2}(\mathrm{~L})\right\}^{2+/+}\left(\mathrm{L}=\mathrm{Cl}, \mathrm{H}_{2} \mathrm{O}, \mathrm{NH}_{3}\right)$ binding to purines and $\mathrm{CO}$ : does $\pi$-back-donation play a role?" Inorganic Chemistry, vol. 42, no. 26, pp. 8615-8617, 2003.

[215] G. Novell-Leruth, A. Valcárcel, A. Clotet, J. M. Ricart, and J. Pérez-Ramírez, "DFT characterization of adsorbed NH species on $\mathrm{Pt}(100)$ and $\mathrm{Pt}(111)$ surfaces," Journal of Physical Chemistry B, vol. 109, no. 38, pp. 18061-18069, 2005.

[216] M. D. Fryzuk, “Ammonia transformed," Nature, vol. 427, no. 6974, pp. 498-499, 2004.

[217] U. J. Kilgore, X. Yang, J. Tomaszewski, J. C. Huffman, and D. J. Mindiola, "Activation of atmospheric nitrogen and azobenzene $\mathrm{N}=\mathrm{N}$ bond cleavage by a transient $\mathrm{Nb}$ (III) complex," Inorganic Chemistry, vol. 45, no. 26, pp. 1071210721, 2006.

[218] E. A. MacLachlan and M. D. Fryzuk, "Synthesis and reactivity of side-on-bound dinitrogen metal complexes," Organometallics, vol. 25, no. 7, pp. 1530-1543, 2006.

[219] E. M. Stuve and R. J. Madix, "Use of the $\pi \sigma$ parameter for characterization of rehybridization upon adsorption on metal surfaces," Journal of Physical Chemistry, vol. 89, no. 15, pp. 3183-3185, 1985.

[220] N. R. Avery, "Thermal evolution of acetylene adsorbed on Pt(111)," Langmuir, vol. 4, no. 2, pp. 445-448, 1988.

[221] P. C. Stair and G. A. Somorjai, "The adsorption of hydrocarbons on platinum studied by low-energy electron diffraction intensities. The ordered $(2 \times 2)$ overlayers of acetylene and ethylene on the (111) crystal face of platinum," Journal of Chemical Physics, vol. 66, no. 5, pp. 2036-2044, 1977.

[222] R. F. Childs, D. L. Mulholland, and A. Nixon, "The Lewis acid complexes of $\alpha, \beta$-unsaturated carbonyl and nitrile compounds. A nuclear magnetic resonance study," Canadian Journal of Chemistry, vol. 60, pp. 801-808, 1982. 
[223] P. Laszlo and M. Teston, "Determination of the acidity of Lewis acids," Journal of the American Chemical Society, vol. 112, no. 24, pp. 8750-8754, 1990.

[224] J. DeChancie, O. Acevedo, and J. D. Evanseck, "Density functional theory determination of an axial gateway to explain the rate and endo selectivity enhancement of DielsAlder reactions by bis(oxazoline)-Cu(II)," Journal of the American Chemical Society, vol. 126, no. 19, pp. 6043-6047, 2004.

[225] O. Acevedo and J. D. Evanseck, "The effect of solvent on a Lewis acid catalyzed Diels-Alder reaction, using computed and experimental kinetic isotope effects," Organic Letters, vol. 5, no. 5, pp. 649-652, 2003.

[226] Y.-S. Fu, S.-C. Tsai, C.-H. Huang, S.-Y. Yen, W.-P. Hu, and S. J. Yu, "Kinetics study and theoretical modeling of the dielsalder reactions of cyclopentadiene and cyclohexadiene with methyl vinyl ketone. The effects of a novel organotungsten catalyst," Journal of Organic Chemistry, vol. 68, no. 8, pp. 3068-3077, 2003.

[227] J. L. G. Ruano, F. R. Clemente, L. G. Gutiérrez, R. Gordillo, A. M. M. Castro, and J. H. R. Ramos, "Cyclic vinyl p-tolyl sulfilimines as chiral dienophiles: theoretical study on the stereoselectivity, Lewis acid catalysis, and solvent effects in their Diels-Alder reactions," Journal of Organic Chemistry, vol. 67, no. 9, pp. 2926-2933, 2002.

[228] N. M. Brunkan and M. R. Gagné, "(dppe)Pt(OTf) and (RBINAP)Pt(OTf) Lewis acids catalyze the Diels-Alder reaction by different mechanisms," Organometallics, vol. 21, no. 8, pp. 1576-1582, 2002.

[229] K. Pignat and G. Strukul, "Cationic complexes of palladium(II) and platinum(II) as Lewis acid catalysts for the Diels-Alder reaction," Organometallics, vol. 19, no. 24, pp. 5160-5167, 2000.

[230] D. M. Birney and K. N. Houk, "Transition structures of the lewis acid catalyzed Diels-Alder reaction of butadiene with acrolein. The origins of selectivity," Journal of the American Chemical Society, vol. 112, no. 11, pp. 4127-4133, 1990.

[231] Y. T. Wu and J. S. Siegel, "Aromatic molecular-bowl hydrocarbons: synthetic derivatives, their structures, and physical properties," Chemical Reviews, vol. 106, no. 12, pp. 4843 4867, 2006.

[232] V. M. Tsefrikas and L. T. Scott, "Geodesic polyarenes by flash vacuum pyrolysis," Chemical Reviews, vol. 106, no. 12, pp. 4868-4884, 2006.

[233] C. E. Housecroft, and A. G. Sharpe, Inorganic Chemistry, Pearson Educational Limited, Essex, UK, 2001.

[234] G. O. Spessard and G. L. Miessler, Organometallic Chemistry, chapter 4, Prentice Hall, Upper Saddle River, NJ, USA, 1996.

[235] G. Blyholder, "Molecular orbital view of chemisorbed carbon monoxide," Journal of Physical Chemistry, vol. 68, no. 10, pp. 2772-2778, 1964.

[236] J. I. Garcia, J. A. Mayoral, and L. Salvatella, "Do secondary orbital interactions really exists?" Accounts of Chemical Research, vol. 33, no. 10, pp. 658-664, 2000.

[237] V. Hsieh, A. G. De Crisci, A. J. Lough, and U. Fekl, "Lewisacidity of trimethylplatinum(IV) with labile oxygen-donor ligands," Organometallics, vol. 26, no. 4, pp. 938-944, 2007.

[238] J. Procelewska, A. Zahl, G. Liehr et al., "Mechanistic information on the reductive elimination from cationic trimethylplatinum(IV) complexes to form carbon-carbon bonds," Inorganic Chemistry, vol. 44, no. 22, pp. 7732-7742, 2005.
[239] H. Sun, D. Zhang, C. Ma, and C. Liu, "Theoretical study on the diels-alder reaction of cyclopentadiene with methacrolein catalyzed by diethylimidazolium cation," International Journal of Quantum Chemistry, vol. 107, no. 9, pp. 1875-1885, 2007.

[240] M. J. S. Dewar, S. Olivella, and J. J. P. Stewart, "Mechanism of the Diels-Alder reaction: reactions of butadiene with ethylene and cyanoethylenes," Journal of the American Chemical Society, vol. 108, no. 19, pp. 5771-5779, 1986.

[241] L. Menzel, A. A. Kosterev, R. F. Curl et al., "Spectroscopic detection of biological NO with a quantum cascade laser," Applied Physics B, vol. 72, no. 7, pp. 859-863, 2001.

[242] M. B. Bryning, M. F. Islam, J. M. Kikkawa, and A. G. Yodh, "Very low conductivity threshold in bulk isotropic single-walled carbon nanotube-epoxy composites," Advanced Materials, vol. 17, no. 9, pp. 1186-1191, 2005.

[243] W. B. Choi, J. U. Chu, K. S. Jeong et al., "Ultrahigh-density nanotransistors by using selectively grown vertical carbon nanotubes," Applied Physics Letters, vol. 79, no. 22, pp. 36963698, 2001.

[244] A. M. Fennimore, T. D. Yuzvinsky, W. Q. Han, M. S. Fuhrer, J. Cumings, and A. Zetti, "Rotational actuators based on carbon nanotubes," Nature, vol. 424, no. 6947, pp. 408-410, 2003.

[245] C. H. Ke, N. Pugno, B. Peng, and H. D. Espinosa, "Experiments and modeling of carbon nanotube-based NEMS devices," Journal of the Mechanics and Physics of Solids, vol. 53, no. 6, pp. 1314-1333, 2005.

[246] W. B. Choi, S. Chae, E. Bae et al., "Carbon-nanotubebased nonvolatile memory with oxide-nitride-oxide film and nanoscale channel," Applied Physics Letters, vol. 82, no. 2, pp. 275-277, 2003. 

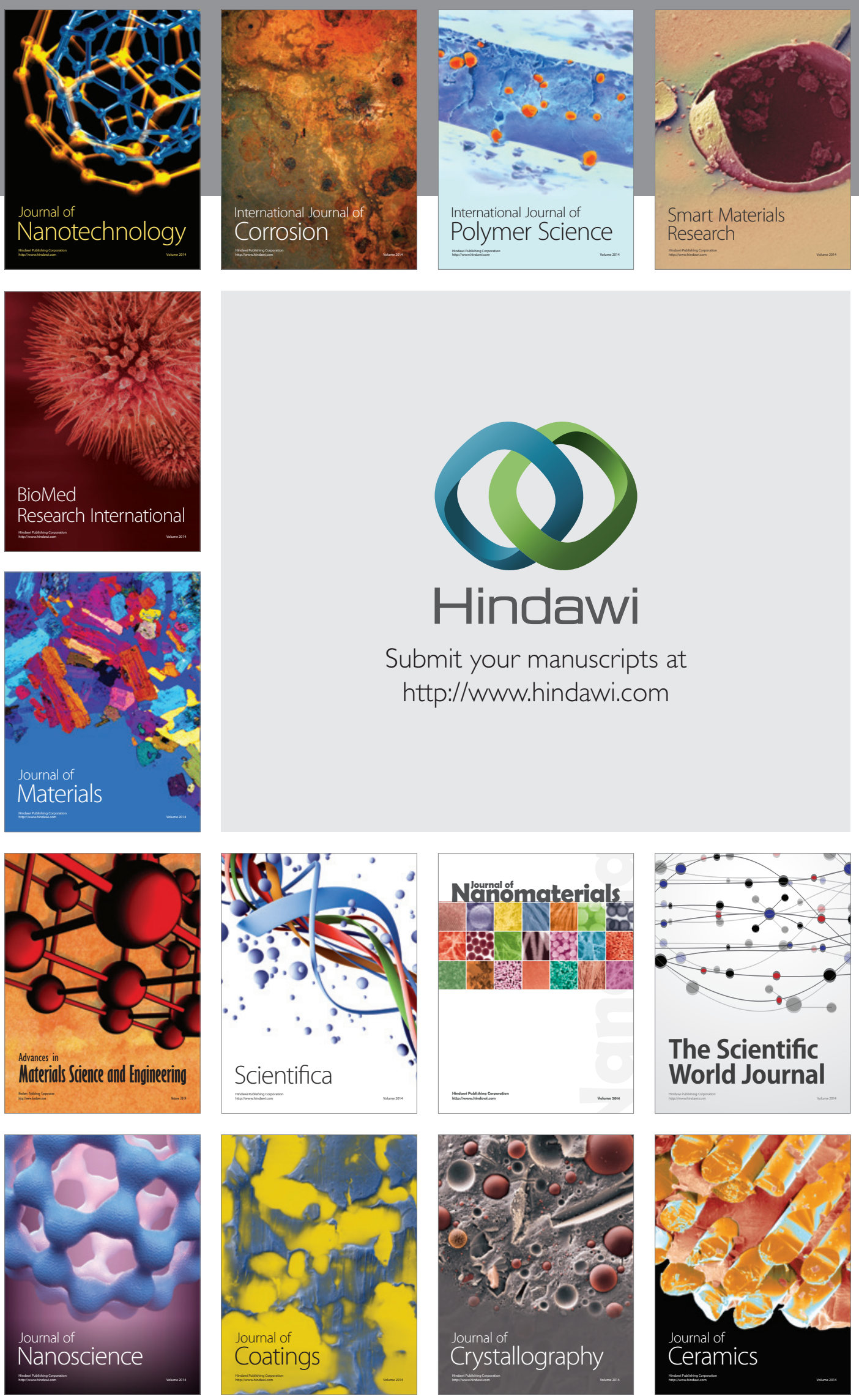

The Scientific World Journal

Submit your manuscripts at

http://www.hindawi.com

\section{World Journal}

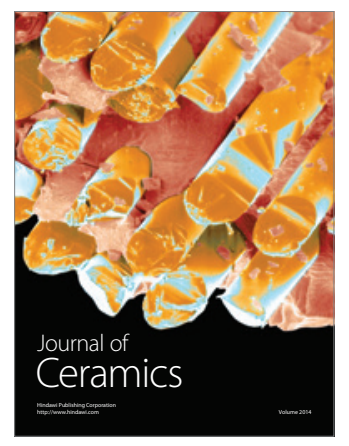

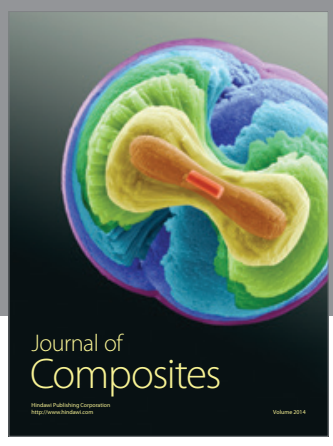
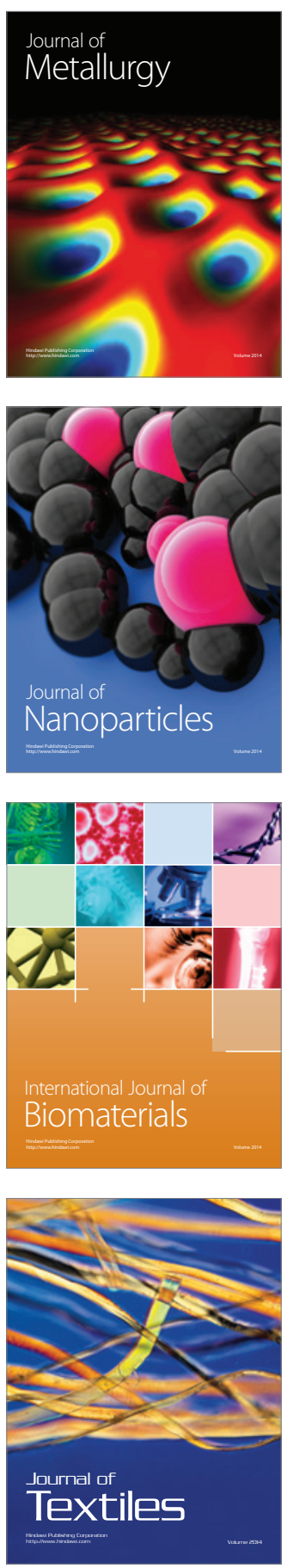